UCRL-ID-131493

\title{
Results of a Coupled Fracture-Flow Test at the $0.5-\mathrm{m}$ Scale
}

\author{
M. S. Costantino \\ Steven R. Carlson \\ Stephen C. Blair
}

August 14, 1998

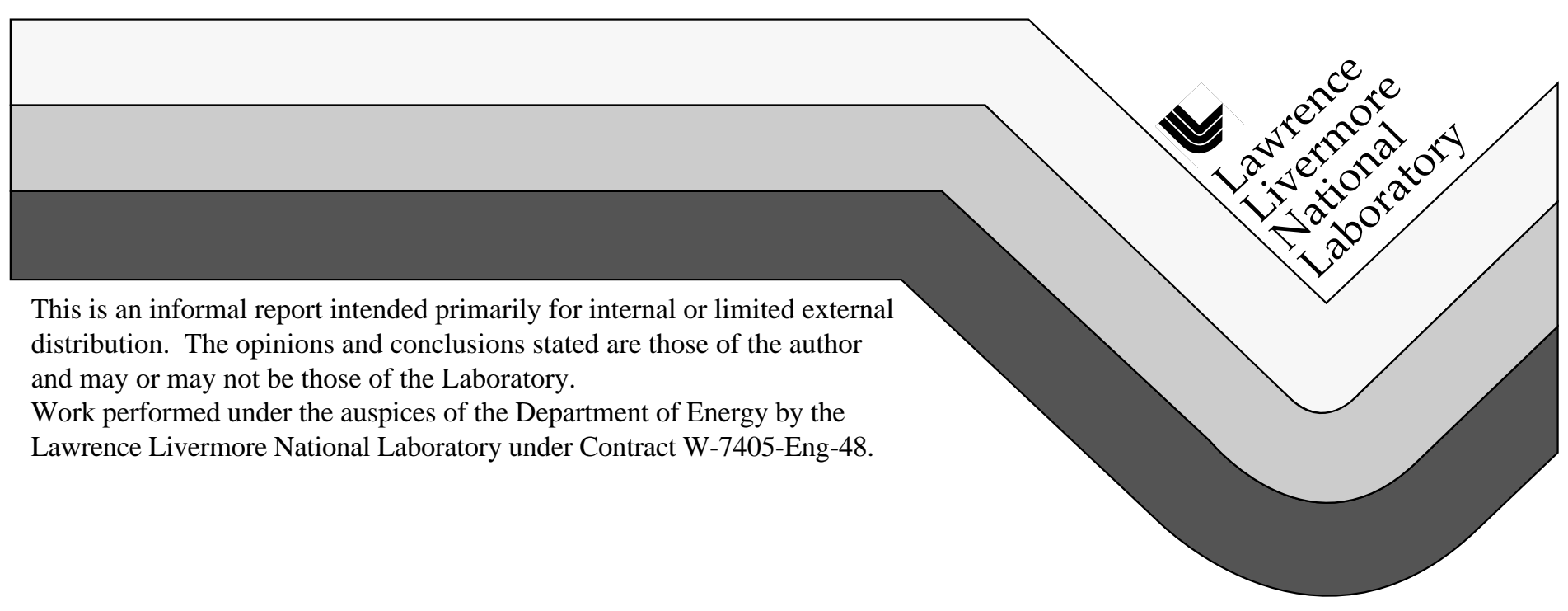




\section{DISCLAIMER}

This document was prepared as an account of work sponsored by an agency of the United States Government. Neither the United States Government nor the University of California nor any of their employees, makes any warranty, express or implied, or assumes any legal liability or responsibility for the accuracy, completeness, or usefulness of any information, apparatus, product, or process disclosed, or represents that its use would not infringe privately owned rights. Reference herein to any specific commercial product, process, or service by trade name, trademark, manufacturer, or otherwise, does not necessarily constitute or imply its endorsement, recommendation, or favoring by the United States Government or the University of California. The views and opinions of authors expressed herein do not necessarily state or reflect those of the United States Government or the University of California, and shall not be used for advertising or product endorsement purposes.

This report has been reproduced directly from the best available copy.

Available to DOE and DOE contractors from the Office of Scientific and Technical Information P.O. Box 62, Oak Ridge, TN 37831

Prices available from (615) 576-8401, FTS 626-8401

Available to the public from the National Technical Information Service U.S. Department of Commerce 5285 Port Royal Rd., Springfield, VA 22161 


\title{
Results of a Coupled Fracture-Flow Test at the $0.5-\mathrm{m}$ Scale
}

\author{
by \\ M. S. Costantino \\ Steven R. Carlson \\ Stephen C. Blair \\ SPLL37M4 \\ WBS 1.2.3.12.3 \\ BAB000000-01717-5700-00006
}

August 14, 1998

Lawrence Livermore National Laboratory

Livermore, California 



\section{Contents}

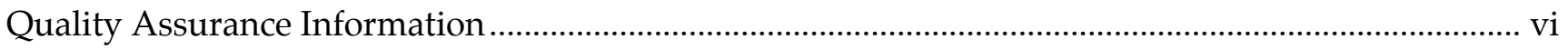

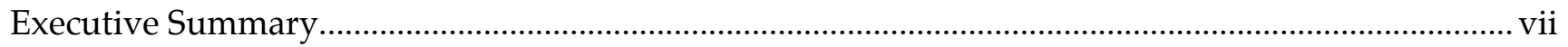

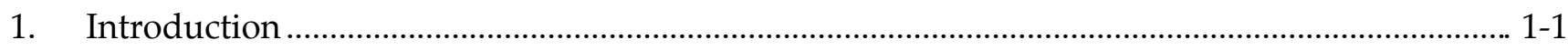

2. SB3: Flow through a Horizontal Fracture................................................................................... 2-1

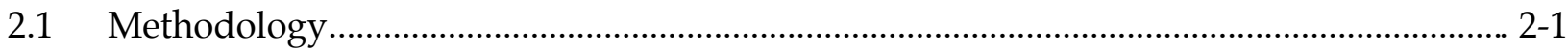

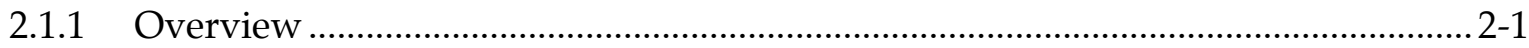

2.1.2 SB3 Block Preparation ....................................................................................... 2-2

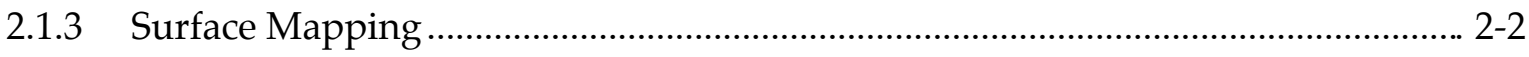

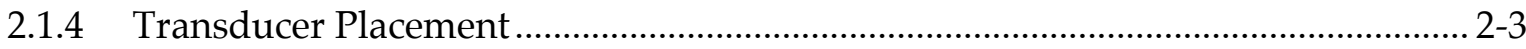

2.1.5 Thermocouple Placement ....................................................................................... 2-4

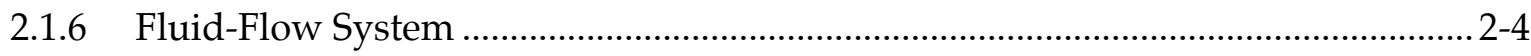

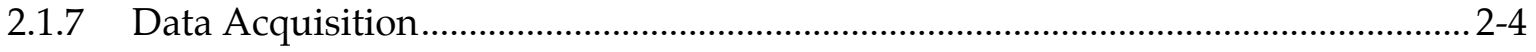

2.1.8 Corrosion Coupons................................................................................................... 2-5

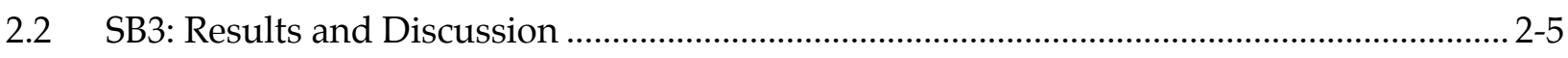

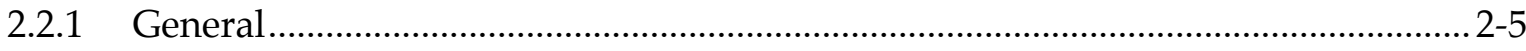

2.2.2 Fluid Flow versus Pressure Differential ............................................................... 2-9

2.2.3 Fluid Flow versus Axial Stress ........................................................................... 2-14

2.2.4 Fluid Flow versus Temperature............................................................................. 2-15

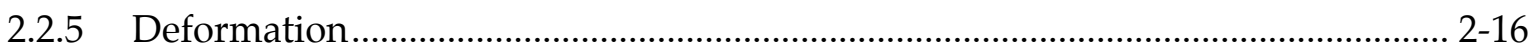

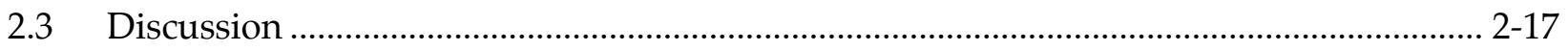

2.3.1 Fluid Flow in a Porous Rock with Uncorrelated Fracture Surfaces ..................... 2-17

2.3.2 Heat Transfer into the Fracture and Connected Porosity …................................. 2-19

2.3.3 Anisotropy of Mechanical Properties .................................................................. 2-21

3. SB4: Flow through a Vertical Fracture …................................................................................. $3-1$

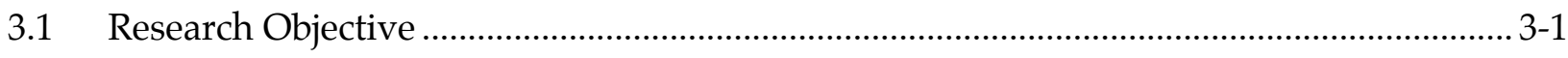

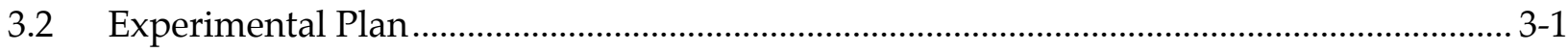

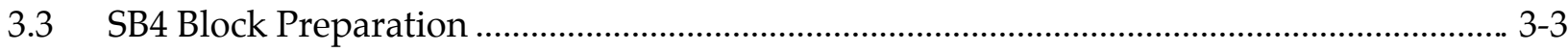

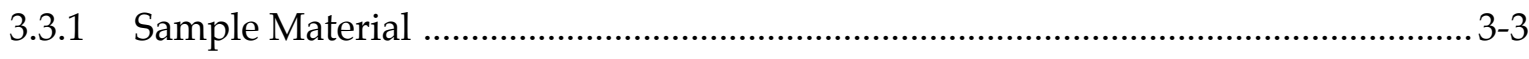

3.3.2 Specimen Preparation.................................................................................... 3-3 


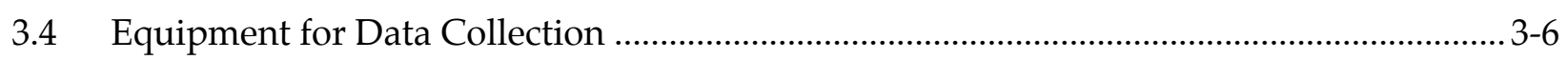

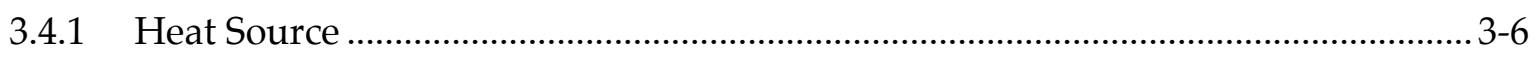

3.4.2 Temperature Measurements ...................................................................................... 3-6

3.4.3 Displacement Measurements ............................................................................. 3-7

3.4.4 Fluid-Flow Measurements................................................................................. 3-8

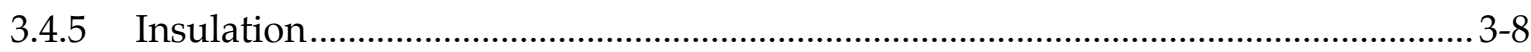

3.4.6 Loading Apparatus and Load Measurements........................................................ 3-9

3.4.7 Data-Acquisition System.................................................................................. 3-9

3.4.8 Surface Profilometry ……………………………………………………... 3-10

3.4.9 Thermocouple Location Measurements ............................................................... 3-11

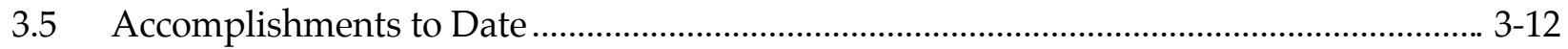

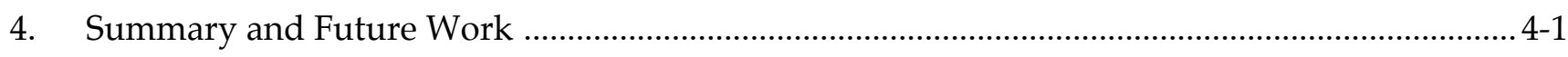

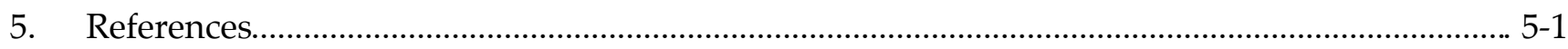




\section{Tables}

Table A-1. "Roadmap" table identifying where the deliverable acceptance criteria are met in the Level 4 deliverable Results of a Coupled Fracture-Flow Test at the 0.5-m Scale...... vi

Table 2-1. Weights, sizes, and locations of corrosion coupons for SB3.............................................. 2-5

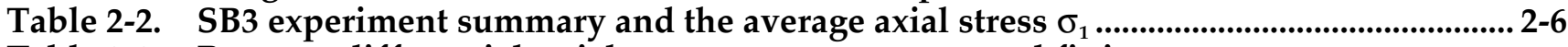

Table 2-3. Pressure differential, axial stress $\sigma_{1}$, temperature, and fitting parameters for water flow in a horizontal fracture ........................................................................... 2-10

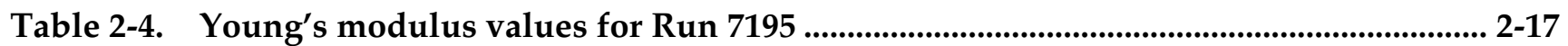

Table 2-5. Fitting parameters for typical temperature versus time data during cooling of the sample owing to fluid flowing through the fracture............................................................. 2-20

Table 3-1. Drying history of Blocks A and B ..................................................................................................3 3-4

Table 3-2. Displacement transducer (LVDT) locations ............................................................................ 3-5

Table 3-3. Thermocouple locations ........................................................................................................ 3-13 


\section{Figures}

Figure 2-1. Setup of the SB3 sample

Figure 2-2. Crack, fracture, and vug distribution of SB3

Figure 2-3. Surface topography data collected at $0.5-\mathrm{mm}$ intervals

Figure 2-4. Surface topography data collected at 0.05-mm intervals; three detail views (a), (b), (c)

Figure 2-5. Representative profile taken through the surface topography data

Figure 2-6. Layout of SB3 LVDTs

Figure 2-7. Layout of SB3 thermocouples

Figure 2-8. SB3 fluid-flow system

Figure 2-9. SB3 fluid-collection manifold

Figure 2-10. SB3 data-acquisition system

Figure 2-11. Total flow out of each port for Run 7195

Figure 2-12. Spatial representation of total flow in plane of fracture for SB3 during Run 7195

Figure 2-13. Initial fluid flow into the unsaturated rock for Experiment 719501

Figure 2-14. Flow versus time for Experiment 719601, showing an initial, small imbibition transient

Figure 2-15. Water flow rate versus pressure differential

Figure 2-16. Water flow rate versus axial stress

Figure 2-17. Water flow rate versus temperature

Figure 2-18. Temperature and cumulative water flow

Figure 2-19. Displacement data for first loading cycle of Run 7195

Figure 2-20. Stress-strain data for two transducers for the first loading cycle of Run 7195

Figure 2-21. Average stress-strain for long transducers measured during three loading cycles of Run 7195

Figure 2-22. Vertical and horizontal displacements across two major vugs

Figure 2-23. Typical fit of the heat flow equation for a semi-infinite solid with a known initial temperature and a constant temperature boundary condition

Figure 3-1. Specimen geometry, coordinate system and thermocouple array

Figure 3-2. Thermocouple locations for the central $(z=0)$ cross-sectional plane

Figure 3-3. Positions of the LVDT mounting holes

Figure 3-4. Photographs of the fracture surfaces for Block A (top) and Block B (bottom)

Figure 3-5. SB4 heater bar

Figure 3-6. Mounting technique for the LVDTs

Figure 3-7. Water manifold design, with manifolds attached to the top and bottom surfaces of the specimen along the trace of the fracture

Figure 3-8. Insulation of the loaded faces, consisting of three sheets of inch-thick G-10 phenolic resin board

Figure 3-9. The horizontal loading apparatus

Figure 3-10. Data-acquisition schematic

Figure 3-11. Areas of the Block A fracture plane selected for surface profiling

Figure 3-12. Surface topography of a $120 \times 300 \mathrm{~mm}$ area of the fracture surface of Block A profiled at $1.0-\mathrm{mm}$ resolution

Figure 3-13. Surface topography of the (a) inner, (b) middle, and (c) outer $10 \times 10 \mathrm{~mm}$ subsections profiled at $0.05-\mathrm{mm}$ resolution

Figure 3-14. Cross sections of SB4 fracture-surface topography, Block A

Figure 3-15. Mechanical jig for measuring thermocouple hole locations 


\section{Abbreviations and Acronyms}

$\begin{array}{ll}\text { 3-D } & \text { three-dimensional } \\ \text { DST } & \text { Drift-Scale Test } \\ \text { LBT } & \text { Large Block Test } \\ \text { LLNL } & \text { Lawrence Livermore National Laboratory } \\ \text { LVDT } & \text { linear voltage displacement transducer } \\ \text { NI } & \text { National Instruments } \\ \text { NFE } & \text { near-field environment } \\ \text { RTV } & \text { room-temperature vulcanizing } \\ \text { SB } & \text { Small Block, or Small-Block Test } \\ \text { TC } & \text { thermocouple } \\ \text { THCM } & \text { thermal-hydrologic-chemical-mechanical } \\ \text { THM } & \text { thermohydromechanical } \\ \text { TM } & \text { thermomechanical } \\ \text { YM } & \text { Yucca Mountain }\end{array}$




\section{Quality Assurance Information}

Table A-1 is the required "roadmap" that indicates where the deliverable-acceptance criteria are met in the Level 4 deliverable Results of a Coupled Fracture-Flow Test at the 0.5-m Scale.

Table A-1 "Roadmap" table identifying where the deliverable-acceptance criteria are met in the Results of a Coupled Fracture-Flow Test at the 0.5-m Scale

\begin{tabular}{|l|l|}
\hline \multicolumn{1}{|c|}{ Criterion } & \multicolumn{1}{c|}{ Section } \\
\hline \hline Submittal of a letter report & All \\
\hline $\begin{array}{l}\text { Description of thermomechanical and } \\
\text { thermohydrologic processes }\end{array}$ & $\begin{array}{l}\text { Executive Summary; Section 2.2; Section 2.3; } \\
\text { Section 3; Section 4 }\end{array}$ \\
\hline $\begin{array}{l}\text { Conclusions on rock mass deformability, inelastic } \\
\text { deformation, and rock mass permeability }\end{array}$ & Executive Summary; Section 2.3; Section 4 \\
\hline
\end{tabular}




\section{Executive Summary}

This report presents progress made on two experiments on 0.5-meter-scale blocks to determine thermohydromechanical (THM) behavior of fractured rock. We first present results for an experiment on sample SB3, including data for flow measurements through a horizontally oriented, artifical (saw-cut) fracture at a series of differential fluid pressures and temperatures under uniaxial stress conditions up to $14 \mathrm{MPa}$. We then present the experiment design and a progress report on the assembly of experiment SB4, flow through a vertically oriented fracture intersected by a line heat source.

The objective of this experimental program is to investigate the effect of coupled thermalhydrologic-chemical-mechanical (THCM) processes on the properties and behavior of a fractured rock mass at conditions that simulate those expected in the near-field environment (NFE), and to provide intermediate-scale test cases for computer model validation. The planned experiments include flow in small block samples with fractures, oriented both horizontally (Small Block 3, or SB3) and vertically (SB4), at conditions of elevated temperature and with compressive stress applied normal to the plane of the fracture. The final experiment in this series, SB5, will measure fluid flow in a fracture under a biaxial stress field. That experiment is designed to answer NFE questions relating to seepage and rock mass stability at NFE temperatures, shear stresses, and rock saturations.

The experimental phase of SB3 is complete. We presented initial results of our analysis at the 8th International High-Level Waste Management Conference (Blair and Costantino, 1998). We show that anisotropy in both flow and mechanical properties is correlated with the ash flow texture in the rock fabric. Flow in the plane of the fracture was anisotropic, with more flow along the direction of the rock fabric. More than 50 liters of water was caused to flow through the sample; mass balance of water flow into and out of the fracture showed some imbibition of water through the fracture surface and storage of water in connected porosity. However, the imbibition rate appeared to be much lower than that observed by Kneafsey and Pruess (1997), who show rapid imbibition of fluid into tuff through a fracture surface. Our result supports the recent work of Buscheck (Hardin et al., 1998) that shows that current simulations of fluid flow in the Topopah Spring tuff overestimate the effect of imbibition.

We also found that, for this fracture, increasing normal stress across the fracture from 0.1 to $14 \mathrm{MPa}$ did not substantially reduce the flow rate, indicating that flow in the plane of the fracture was due primarily to flow in channels that were unaffected by this stress. Profiling of the fracture surface indicated the presence of several channels of the order of millimeters in width and depth that carried water through the fracture surface. This is a significant conclusion for simulation of the THCM behavior of the porous tuffs of a potential repository: fracture permeability for uncorrelated fracture surfaces cannot be modeled using a cubic flow law with an aperture defined as the separation of the mean fracture surfaces. For a distribution of porosity size and aspect ratio above a percolation threshold, the fracture demonstrates significant permeability after the normal stress closes it. Even though this work was performed on a specimen containing an artificial fracture, we fully expect the same effect in a natural fracture, so long as the opposing surfaces are uncorrelated.

Thermal-response measurements at this intermediate scale show a significant effect on the heat budget of thermal short circuits ("heat pipes") along connected porosity in the rock. The water in the fracture serves as a heat source or sink for material far from the fracture 
through advective and conductive heat transport. Derived thermal diffusivities of the host rock agree well with published values.

The anisotropic SB3 sample was loaded in compression parallel to the rock fabric with a Young's modulus of $40 \mathrm{GPa}$ for compressive stress in the range 4-14 MPa. This value is much higher than the $20 \mathrm{GPa}$ observed in a similar sample of tuff loaded perpendicular to the rock fabric (Blair and Berge, 1996), indicating that, at the 0.5-m scale, the mechanical properties of the tuff have a significant anisotropy correlated with the rock fabric.

The design for experiment SB4 is complete and we are nearing completion of its assembly. This experiment is designed to study water flow in an artificial, vertical fracture with a line heat source over the range of uniaxial stress normal to the fracture from $0.1 \mathrm{MPa}$ to $10 \mathrm{MPa}$ and at temperatures from $20^{\circ}$ to $150^{\circ} \mathrm{C}$. Axial symmetry, known initial and boundary conditions for temperature and fluid flow, and known fracture and matrix displacements couple this experiment closely to THM model calculations of water flow in a reflux zone. The experiment is instrumented with more than 90 thermocouples to measure the three-dimensional (3-D) temperature field, 16 displacement transducers to measure fracture aperture and matrix displacements, 13 fluid-flow channels and 2 surface collection manifolds to track water mass balance, and load cells to measure mean stress normal to the fracture. The results of this experiment will provide an excellent means for validation of THM models. 


\section{Introduction}

To evaluate Yucca Mountain (YM) as a suitable repository location, it is crucial to understand the hydrologic response of fluids present in the proposed repository horizon to the construction of a repository and the subsequent storage of high-level radioactive waste. Moreover, recent analysis of site measurements implies that the rate of water infiltration into YM may have ranged as high as $30 \mathrm{~mm} / \mathrm{yr}$, although estimates for current flux range between 5 and $15 \mathrm{~mm} / \mathrm{yr}$. These estimates are much higher than previously thought, and review of data and analyses has so far confirmed the new estimates (Taylor, 1997). It is also known that the potential repository horizon at YM contains a significant number of fractures. This fact, coupled with higher estimates of the infiltration rate, has resulted in a revision of the general hydrologic model for YM; it is now thought that the significant flow regime at this site is episodic fast flow in fractures. This implies that surface water can travel deep into YM through fractures (Taylor, 1997). The hydrologic behavior of YM also depends on the amount of water imbibed into the host rock through the surfaces of fractures, and recent discussion (Hardin et al., 1998) indicates that the values of imbibition currently used in many hydrologic models need to be re-evaluated.

In addition to the above developments, recent results from the Large Block Test (LBT) (Lin et al., 1995) at Fran Ridge near Yucca Mountain indicate that the metastable thermal regimes established when heating partially saturated fractured rock can be dramatically perturbed by small fluctuations in water infiltration or by small changes in the thermal or mechanical boundary conditions. Such perturbations include temperature excursions and mechanical movements that are not currently accounted for in models used to simulate the behavior of the potential repository.

Some aspects of the coupled THM behavior of fractured rock are already known. Several investigators have shown that increasing stress across fractures causes a reduction in fracture aperture and, therefore, in fluid flow; flow in a fracture can be related, to the first order, to the cube of the fracture aperture (Raven and Gale, 1985). Moreover, heating the rock generally increases stress and reduces the fracture aperture. More recent work indicates that occurrence of shear displacements across a fracture may also influence fracture permeability. Work by Barton et al. (1995) indicates that shear displacements across a fracture may enhance fracture permeability, and that the magnitudes of changes in fracture permeability due to shear displacements may exceed those due to normal displacements. Finally, although a preliminary understanding of flow in single fractures is now available, it also is widely accepted that the hydrologic behavior of a fractured rock mass is controlled by a few wellconnected fractures in the rock mass.

In other recent work, Blair et al. (1997) linked several concepts to predict zones where permeability may be changed in the Drift-Scale Test (DST); these concepts included flow along critically stressed fractures (Barton et al. 1995), changes in fracture aperture, permeability changes due to sliding, mapped fracture sets, and the thermomechanical (TM) stress field. These studies indicate that TM effects on permeability may extend over significant portions of the heated region of a repository-in contrast to previous work in this area, which has indicated that TM effects may be limited to regions near the emplacement drifts. Further, Blair et al. predict enhanced permeability in regions of thermal or stress gradients; such enhanced permeability may accompany the thermal pulse as it travels outward from the heat source. Experiments are planned to investigate permeability changes in regions of elevated thermal or stress gradients. 
Given these recent developments, understanding flow in the fractured rock mass at YM is a critical requirement for viability assessment. Seepage into the repository clearly is dominated by the thermal field and the permeability of the fracture network in the NFE. The thermal field itself is perturbed significantly by "heat pipes" formed by fluid in fractures and connected porosity. The sum of these thermally induced stresses and the relaxation stresses owing to the drift excavation determines the rock mass stability.

Experiments on intermediate-scale $(0.5-\mathrm{m})$ samples contribute to the understanding of these phenomena, especially flow in fractures under well characterized thermal and mean stress fields. Results of these experiments provide phenomenological data on the fluid flow in fractured rocks at the characteristic temperature and stress conditions of the NFE. In addition, they contribute to the physical parameter database used in simulations of the potential repository. Finally, and most importantly, they provide laboratory controlled, intermediate-scale cases with known boundary and initial conditions for computer model validation tests.

The work presented here is a continuation of testing of small block samples previously reported in September 1996 (Blair and Berge, 1996) and in September 1997 (Blair and Costantino, 1997). Those reports documented the first of a series of four experiments designed to study coupled processes in the NFE of a nuclear waste repository, and provided new deformation, elastic-wave-velocity, thermal, and fluid-flow data that permit approximation of total rock-mass properties and behavior for welded tuff units that contain fractures and vugs. The earlier reports also provided guidance for input values used in equivalent continuum models of a repository.

In this report two fracture-flow experiments are described. The first, Small-Block Test 3 (SB3), is a series of fluid-flow measurements at stresses of $0.1 \mathrm{MPa} \leq \sigma_{1} \leq 14 \mathrm{MPa}$ normal to a horizontal fracture at temperatures in the range $20^{\circ} \mathrm{C} \leq \mathrm{T} \leq 140^{\circ} \mathrm{C}$. Data and significant portions of the analysis and discussion previously reported in September 1997 (Blair and Costantino, 1997) are repeated in this report for completeness. The experimental portion and the planned analysis for SB3 is complete. This report contains the final analysis for SB3.

The second experiment reported here is SB4. We describe the experiment design and provide initial data characterizing the fracture surface. 


\section{SB3: Flow through a Horizontal Fracture}

\subsection{Methodology}

\subsubsection{Overview}

Our objective in this task is to provide fundamental data and a phenomenological understanding of coupled processes in fractured rock systems. A sample with a natural, dominant, through-going fracture with correlated fracture surfaces is preferred, as this relates the laboratory experiment to in situ conditions. Although several blocks of rock have been obtained that have sufficient volume to make 0.5 -m-scale samples, none have contained a natural fracture suitable for laboratory flow testing. We therefore introduce an artificial fracture (saw cut) that has several advantages over a natural fracture from the experimental perspective.

The SB3 sample (see Figure 2-1) containing an artificial horizontal fracture was prepared using two right-prism blocks of Topopah Spring tuff having typical edge dimensions of $25 \mathrm{~cm}$. Figure 2-1a is a graphic display of the block made by integrating digital photographs of the block surfaces into a perspective rendering; this figure illustrates the surface features and the horizontal fracture. Figure $2-1 b$ shows the assembly used for Experiment 7051 . After completing this experiment, we modified the sample assembly to include a coating of flexible adhesive, overlaid by a neoprene jacket, on the surface of the sample to prevent pore water from exiting the sample at any point other than the fluid ports around the fracture. The jacketed sample assembly is shown in Figure 2-1c.

Figure 2-1. Setup of the SB3 sample

(a) Illustration of the SB3 sample for flow through a horizontal fracture. Fracture separation is exaggerated; fluid is injected into the fracture plane through small hole in the center of the top of the lower block. Some surface mounts for displacement transducers are visible.

(b) Laboratory setup for SB3, Experiment 7051. The radial flow field probes the effect of anisotropy of the rock fabric on the flow in the fracture. Diagnostics are average axial stress across the fracture plane, temperature at 12 points inside the sample, surface displacements along 16 baselines on the vertical surfaces of the sample, and fluid flow monitored at 38 locations at intervals of about $2.5 \mathrm{~cm}$ along the perimeter of the fracture.

(c) Laboratory setup for SB3, experiments subsequent to 7051. This is similar to the setup for Experiment 7051, but includes a neoprene jacket on the external vertical faces of the sample.

Uniaxial stress was applied normal to the fracture plane using a 300-ton press, as shown in Figure 2-1c. The sample assembly was heated using point-source heaters on copper plates at the top and bottom of the assembly and, in experiments for $T>100^{\circ} \mathrm{C}$, on the vertical sides of the sample. Fluid flow was generated by a point source in the plane of the fracture at its center, connected to a pressurized fluid reservoir using a small-diameter tube. 
The experiment plan for SB3 was to measure fluid flow and axial and Poisson strains as a function of axial stress to about $14 \mathrm{MPa}$ at temperatures from $20^{\circ} \mathrm{C}$ to $140^{\circ} \mathrm{C}$ to provide data for the deformation modulus of the fractured material and changes in hydrologic behavior.

\subsubsection{SB3 Block Preparation}

Owing to the difficulty in obtaining a 0.5 -m-scale sample with a suitable natural fracture, we made a sample with an artificial fracture. The sample is made of a $26.2 \times 24.5 \times 49.0 \mathrm{~cm}$ block cut from a boulder of Topopah Spring tuff excavated at the Large Block Test (LBT) site at Fran Ridge, near Yucca Mountain, Nevada (YM). The sample exhibits the typical Topopah Spring tuff fabric of subparallel vugs, in pink, and gray, densely welded tuff. The cuts were oriented so that the dominant fracture and vug major axes are parallel to a block face.

The original block was cut into two pieces at the midplane of the long direction to form the artificial fracture. The surfaces forming the fracture were ground parallel to within $0.025 \mathrm{~mm}$, then roughened using a beadblaster and $100-\mu \mathrm{m}$ silicon dioxide beads. A total of about $6 \mathrm{~mm}$ of material was removed from the internal surfaces during the cutting and grinding operations.

A slit about $3 \mathrm{~mm}$ wide, $150 \mathrm{~mm}$ long, and $25 \mathrm{~mm}$ deep at its deepest point was cut into the top surface of the bottom block at its centerline. The slit was intended to hold metal coupons for corrosion measurements, but subsequently was filled with grout to permit introduction of fluid at a point, rather than a line, source. A small opening (see Figure 2-2d in the following subsection) was left ungrouted to form the point source.

After preparation of the surfaces, the blocks were exposed to the ambient laboratory environment with no special temperature or humidity controls. For ease of reference, the faces of the blocks are labeled "North (N)," "West (W)," "East (E)," "South (S)," "Top (T)," and "Bottom (B)." These labels denote the orientation of the blocks in the laboratory rather than the specimen's in situ orientation. The N, W, S, and E faces form the vertical sides of the sample assembly. The B face of the upper block and the $T$ face of the lower block form the fracture. Load is applied to the T face of the top block and the B face of the bottom block.

\subsubsection{Surface Mapping}

Features intersecting the surfaces of the blocks were mapped by overlaying millimetergrid tracing paper, then transferring the measurements to a three-dimensional (3-D) computer graphics application for display and analysis. Additionally, digital photographs of the sample (Figure 2-2) illustrate that the crack, fracture, and vug distribution is not homogeneous. There is a clear anisotropy of the rock fabric from east to west, with the major axis of the oblate porosity parallel to the axial stress direction. The fabric in the fracture surface shows the cracks and vugs running generally east-west, so that we would expect higher flow in channels along the east and west faces.

Figure 2-2. Crack, fracture, and vug distribution of SB3

(a) north face; (b) west face; (c) bottom of top block (fracture surface); (d) top of bottom block (fracture surface); (e) south face; (f) east face; (g) bottom of the bottom block; and (h) top of the top block

Many of the properties of fractures depend on their surface roughness, and measurement of the surface roughness of the artificial fracture was done using a contacting stylus profilometer (Keller and Bonner, 1985). Because of time constraints, only a portion of the artificial 
fracture in the block forming the top part of the experimental assembly was measured. Visual observation (Figure 2-2c and Figure 2-2d) indicates that profiling a $120 \times 260 \mathrm{~mm}$ sub-area of the fracture surface at a resolution of $0.5 \mathrm{~mm}$, plus a smaller $10 \times 10 \mathrm{~mm}$ sub-area at a $0.05-\mathrm{mm}$ resolution, provides adequate short- and long-wavelength information to characterize the entire surface.

The surface topography data collected at 0.5-mm intervals are shown in Figure 2-3. In this figure, the shading represents the surface relief. Figure 2-3 shows that the surface contains numerous elongated pores, which are a few millimeters wide and a few tens of millimeters long. These high-aspect-ratio pores show preferential elongation in the east-west direction. A few larger pores are shown that have size of approximately $20 \mathrm{~mm} \times 10 \mathrm{~mm}$. These also show preferential alignment in the east-west direction.

Figure 2-3. Surface topography data collected at $0.5-\mathrm{mm}$ intervals

Shading represents surface relief.

A $10 \times 10 \mathrm{~mm}$ area of the surface was also profiled at $0.05 \mathrm{~mm}$ intervals; this is shown in Figure 2-4. These higher-resolution data indicate that the surface consists of a series of flattopped features that resemble mesas, separated by depressions that are $2-4 \mathrm{~mm}$ in width. Figure 2-4c also shows a more honeycombed nature of fracture and surface features.

Figure 2-4. Surface topography data collected at 0.05-mm intervals; three detail views (a), (b), (c)

Figure 2-5 shows a typical profile taken through the surface topography data in Figure 2-3. Cursory examination of the profiles indicates that a majority of the topographic features are about $1 \mathrm{~mm}$ in size, with channels that are $2-3 \mathrm{~mm}$ in depth.

\section{Figure 2-5. Representative profile taken through the surface topography data}

These surface-roughness data provide sufficient qualitative characterization of the artificial fracture so that meaningful correlation with natural fractures can be made. Although beyond the scope of the present work, these data also provide a quantitative measure of the anisotropy and hydrologic "short circuits" for flow across the fracture plane. Coupling these digital measurements ( $x-y-z$ topography) and the $x-y$ digital images of the photographs permits correlation of flow through the 38 collection channels with the fracture surface geometry. These data also may be used to replicate the $x-y-z$ surface and to computer-model the measured flow through the collection channels.

\subsubsection{Transducer Placement}

Sixteen linear voltage displacement transducers (LVDTs) were mounted using aluminum brackets screwed into threaded inserts grouted into the block. The LVDTs were positioned, as shown in Figure 2-6, to measure axial displacement along a baseline the entire length of the two blocks, along a short baseline across the fracture, along perpendicular baselines having no surface imperfections, and along perpendicular baselines spanning the intersection of a large vug with the surface. Extensions of 3.18-mm-diameter quartz rod were affixed using high-temperature grout to LVDTs with baselines larger than the length of the transducers. Care was taken to ensure that the LVDTs were mounted parallel and normal, as appropriate, to the principal stress direction. 
Figure 2-6. Layout of SB3 LVDTs

\subsubsection{Thermocouple Placement}

Figure 2-7 shows twelve 1.57-mm-diameter Type J thermocouples that were mounted in 3.18-mm-diameter holes on a grid. The junctions of the thermocouples lie in a vertical plane parallel to the south face and at the center of the sample. The thermocouples were secured by grout or by epoxy, both for mechanical stability and to prevent fluid flow along a hole.

\section{Figure 2-7. Layout of SB3 thermocouples}

\subsubsection{Fluid-Flow System}

The fluid-flow system, shown in Figure 2-8, was composed of a pressurized reservoir, a point source at the center of the fracture, and a collection manifold along the fracture perimeter. Fluid pressure of up to 8psi was controlled to within \pm 0.1 psi using a regulator and laboratory compressed air. The fluid was introduced into a $2 \times 6 \times 10 \mathrm{~mm}$ "point source" by means of a 1.57-mm outside diameter by $1.12-\mathrm{mm}$ inside diameter stainless steel tube, grouted into a 3.18-mm hole in the bottom block parallel to and about $1 \mathrm{~cm}$ below the fracture. The fluid used for Experiment 7051 was tap water. Simulated J-13 well water (see Section 2.2.6) was used for subsequent experiments.

\section{Figure 2-8. SB3 fluid-flow system}

The source cavity is about $2 \times 6 \times 10 \mathrm{~mm}$, centered in the upper face of the bottom block.

The fluid was collected along the perimeter of the fracture using a simple manifold (see Figure 2-9) made of brass with copper and PVC tubing. Flow through the fracture at each face was collected into 10 equally spaced ports about $20 \mathrm{~mm}$ long, separated by about $4 \mathrm{~mm}$. The manifold was mounted to the blocks using Dow Corning 739 RTV Sealant, which also ensured there is no fluid flow between the ports. A length of PVC tubing carried the fluid to a collection container for that port, which was weighed to determine the amount of fluid exiting the fracture at the port (also see Figure 2-1b).

\section{Figure 2-9. SB3 fluid-collection manifold}

\subsubsection{Data Acquisition}

The data-acquisition system is shown in Figure 2-10. The 12 thermocouples (TCs) were connected to a National Instruments (NI) model SCXI 1100 multiplexer using a NI model SCXI 1303 isothermal terminal block with a precision reference temperature sensor. Temperature is accurate to $\pm 2.2^{\circ} \mathrm{C}$ and precise to better than $\pm 0.5^{\circ} \mathrm{C}$. The 16 LVDTs and the signal from the pressure transducer were connected similarly. The precision of the LVDT data was limited by the resolution of the A/D card to about 0.0005 inches $(0.0127 \mathrm{~mm})$. We find the average uniaxial stress, normal to the fracture, by measuring the total axial force using a calibrated load cell with $\pm 0.3 \%$ precision, then dividing by the macroscopic cross-section area of the block at $0.1 \mathrm{MPa}$. A NI NB MIO-16L $\pm 10 \mathrm{~V}$ 12-bit A/D card in a Macintosh MacIIfx computer read, displayed, and stored the data using NI LabView software. We measured fluid pressure to about \pm 0.1 psi by observing a Bourdon pressure gauge. As noted above, we found the volume of fluid collected at each port by weighing and dividing by its density. 
Figure 2-10. SB3 data-acquisition system

\subsubsection{Corrosion Coupons}

Ten small coupons of 1020 carbon steel were placed in natural or machined cavities in the top surface of the bottom block. Comparison of unreacted and reacted weights and chemical analysis at the end of the experiment will permit an assessment of the corrosion resistance when exposed to the rock fluid-pressure-temperature-time conditions. Initial weights, sizes, and locations of the coupons are given in Table 2-1.

Table 2-1. Weights, sizes, and locations of corrosion coupons for SB3 (DTN LL980802204243.020)

Locations are relative to the northeast corner of the top of the bottom block.

\begin{tabular}{|c|c|c|c|c|c|c|}
\hline \multirow[t]{2}{*}{ Coupon } & \multirow[t]{2}{*}{ Coupon ID } & \multirow[t]{2}{*}{ Initial Weight (g) } & \multirow{2}{*}{$\begin{array}{c}\text { Dimensions } \\
\text { (mm) }\end{array}$} & \multirow{2}{*}{$\begin{array}{l}\text { Area } \\
\left(\mathrm{mm}^{2}\right)\end{array}$} & \multicolumn{2}{|c|}{ Location (mm) } \\
\hline & & & & & $x$ & $y$ \\
\hline$B$ & 0087 & 0.4313 & 6.56 diam. & 33.8 & 196 & 109 \\
\hline C & 0087 & 0.4985 & $6.75 \times 6.23$ & 42.1 & 53.3 & 208 \\
\hline $\mathrm{D}$ & 0087 & 0.5846 & $6.66 \times 7.22$ & 48.1 & 53.3 & 25.4 \\
\hline$E$ & 0065 & 0.4323 & 6.66 diam. & 43.8 & 211 & 147 \\
\hline $\mathrm{F}$ & 0065 & 0.4294 & 6.63 diam. & 43.5 & 158 & 73.7 \\
\hline $\mathrm{G}$ & 0065 & 0.6085 & $7.45 \times 6.84$ & 51.0 & 196 & 237 \\
\hline $\mathrm{H}$ & 0065 & 0.5755 & $7.14 \times 6.57$ & 46.9 & 224 & 73.7 \\
\hline J & 0086 & 0.4304 & 6.58 diam. & 34.0 & 53.3 & 147 \\
\hline $\mathrm{K}$ & 0086 & 0.4310 & 6.61 diam. & 34.3 & 170 & 48.3 \\
\hline L & 0086 & 0.5119 & $6.29 \times 6.66$ & 41.9 & 104 & 135 \\
\hline M & 0086 & 0.5287 & $6.53 \times 6.53$ & 42.6 & 211 & 208 \\
\hline
\end{tabular}

\subsection{SB3: Results and Discussion}

\subsubsection{General}

We conducted 81 experiments under various combinations of axial stress, temperature, and upstream flow pressure (Table 2-2). Temperature and stress were monitored continuously from July 14, 1997, through March 11, 1998, with breaks at August 22-26, 1997; September 3 through October 20, 1997; December 15, 1997, through January 29, 1998; and February 28 through March 4, 1998. Each computer-recorded data record included the time, and voltages for 16 LVDT signals and their common excitation voltage, 13 thermocouples (12 in the sample and one to record room temperature), load cell excitation and output signal, hydraulic ram pressure, and heater power. 
Table 2-2. SB3 experiment summary and the average axial stress $\sigma_{1}$ (DTN LL980802204243.020)

\begin{tabular}{|c|c|c|c|c|c|c|}
\hline Data File & Date & $\begin{array}{c}\begin{array}{c}\text { Start Time } \\
\text { (dd:hh:mm) }\end{array}\end{array}$ & $\begin{array}{c}\text { Stop Time } \\
\text { (dd:hh:mm) }\end{array}$ & $\begin{array}{c}\text { Flow } \\
\text { Pressure (psi) }\end{array}$ & $\begin{array}{c}\sigma_{1} \\
(\mathrm{MPa})\end{array}$ & $T\left({ }^{\circ} \mathrm{C}\right)$ \\
\hline 719501 & $7 / 14 / 97$ & $14: 13: 47$ & $14: 15: 46$ & 2 & 0.0 & 20 \\
\hline 719501 & $7 / 15 / 97$ & 15:08:16 & $15: 16: 00$ & 2 & 0.0 & 20 \\
\hline 719502 & $7 / 16 / 97$ & $16: 08: 07$ & $16: 13: 07$ & 2 & 0.0 & 20 \\
\hline 719502 & $7 / 16 / 97$ & $16: 13: 16$ & $16: 16: 15$ & 2 & 0.5 & 20 \\
\hline 719502 & $7 / 17 / 97$ & 17:08:32 & $17: 16: 21$ & 2 & 0.5 & 20 \\
\hline 719503 & 7/18/97 & 18:08:55 & $18: 16: 23$ & 2 & 0.5 & 20 \\
\hline 719504 & $7 / 18 / 97$ & $18: 16: 50$ & $21: 08: 48$ & 0 & 0.5 & 20 \\
\hline 719505 & 7/21/97 & 21:09:05 & $21: 14: 18$ & 2 & 0.5 & 20 \\
\hline 719505 & $7 / 21 / 97$ & $21: 14: 38$ & $21: 16: 38$ & 2 & 1.0 & 20 \\
\hline 719505 & $7 / 22 / 97$ & $22: 10: 15$ & 22:13:20 & 2 & 1.0 & 20 \\
\hline 719505 & $7 / 22 / 97$ & $22: 13: 20$ & $22: 16: 23$ & 3 & 1.0 & 20 \\
\hline 719505 & 7/23/97 & 23:08:52 & 23:13:07 & 5 & 1.0 & 20 \\
\hline 719505 & 7/23/97 & 23:13:07 & $23: 16: 08$ & 6 & 1.0 & 20 \\
\hline 719505 & 7/24/97 & 24:08:38 & $24: 14: 30$ & 2 & 2.0 & 20 \\
\hline 719505 & $7 / 24 / 97$ & $24: 14: 30$ & $24: 15: 00$ & 3 & 2.0 & 20 \\
\hline 719506 & 7/24/97 & $24: 15: 00$ & $24: 16: 35$ & 3 & 2.0 & 20 \\
\hline 719506 & $7 / 25 / 97$ & $25: 08: 42$ & $25: 13: 33$ & 5 & 2.0 & 20 \\
\hline 719506 & $7 / 25 / 97$ & $25: 14: 07$ & $25: 15: 52$ & 6 & 2.0 & 20 \\
\hline 719507 & $7 / 25 / 97$ & $25: 16: 40$ & 28:08:25 & 0 & 2.0 & 20 \\
\hline 719508 & 7/28/97 & 28:08:52 & 28:09:37 & 6 & 2.0 & 20 \\
\hline 719508 & $7 / 28 / 97$ & 28:09:37 & $28: 11: 00$ & 0 & 0.0 & 20 \\
\hline 719508 & $7 / 28 / 97$ & $28: 11: 00$ & $28: 16: 36$ & 2 & 3.0 & 20 \\
\hline 719508 & 7/28/97 & 28:16:36 & 29:09:31 & 0 & 2.0 & 20 \\
\hline 721201 & 7/29/97 & $29: 15: 14$ & $30: 06: 44$ & 0 & 2.0 & 20 \\
\hline 721202 & 7/30/97 & $30: 11: 47$ & $30: 15: 55$ & 2 & 4.0 & 20 \\
\hline 721203 & $7 / 31 / 97$ & $31: 08: 40$ & $31: 11: 20$ & 3 & 4.0 & 20 \\
\hline 721204 & $7 / 31 / 97$ & $31: 11: 20$ & $31: 14: 14$ & 5 & 4.0 & 20 \\
\hline 721205 & $7 / 31 / 97$ & $31: 14: 14$ & $31: 17: 00$ & 6 & 4.0 & 20 \\
\hline 721301 & $8 / 1 / 97$ & $1: 08: 45$ & $1: 13: 30$ & 2 & 8.0 & 20 \\
\hline 721302 & $8 / 1 / 97$ & $1: 13: 30$ & $1: 15: 16$ & 3 & 8.0 & 20 \\
\hline 721303 & $8 / 1 / 97$ & $1: 15: 30$ & $1: 16: 22$ & 5 & 8.0 & 20 \\
\hline 721304 & $8 / 1 / 97$ & $1: 16: 47$ & $1: 17: 12$ & 6 & 8.0 & 20 \\
\hline 721601 & $8 / 4 / 97$ & 4:08:57 & $4: 12: 45$ & 2 & 0.0 & 20 \\
\hline 721601 & $8 / 4 / 97$ & 4:13:44 & $4: 14: 30$ & 6 & 0.0 & 20 \\
\hline
\end{tabular}




\begin{tabular}{|c|c|c|c|c|c|c|}
\hline Data File & Date & $\begin{array}{c}\text { Start Time } \\
\text { (dd:hh:mm) }\end{array}$ & $\begin{array}{l}\text { Stop Time } \\
\text { (dd:hh:mm) }\end{array}$ & $\begin{array}{c}\text { Flow } \\
\text { Pressure (psi) }\end{array}$ & $\begin{array}{c}\sigma_{1} \\
(\mathrm{MPa})\end{array}$ & $T\left({ }^{\circ} \mathrm{C}\right)$ \\
\hline 721603 & $8 / 5 / 97$ & $5: 09: 27$ & $5: 11: 48$ & 2 & 0.5 & 20 \\
\hline 721603 & $8 / 5 / 97$ & $5: 13: 20$ & $5: 14: 05$ & 6 & 0.5 & 20 \\
\hline 721603 & $8 / 5 / 97$ & $5: 14: 05$ & $5: 16: 24$ & 2 & 1.0 & 20 \\
\hline 721603 & $8 / 6 / 97$ & 6:09:13 & $6: 10: 20$ & 6 & 1.0 & 20 \\
\hline 721603 & $8 / 6 / 97$ & $6: 10: 33$ & $6: 13: 09$ & 2 & 2.0 & 20 \\
\hline 721603 & $8 / 6 / 97$ & $6: 13: 38$ & $6: 14: 43$ & 6 & 2.0 & 20 \\
\hline 721603 & $8 / 6 / 97$ & $6: 15: 01$ & $6: 17: 11$ & 2 & 4.0 & 20 \\
\hline 721604 & $8 / 7 / 97$ & 7:09:35 & $7: 10: 56$ & 6 & 4.0 & 20 \\
\hline 721604 & $8 / 7 / 97$ & $7: 13: 12$ & $7: 13: 46$ & 2 & 8.0 & 20 \\
\hline 721604 & $8 / 7 / 97$ & $7: 16: 00$ & $7: 17: 11$ & 6 & 8.0 & 20 \\
\hline 723801 & $8 / 26 / 97$ & $26: 10: 05$ & $26: 12: 30$ & 2 & 0.0 & 20 \\
\hline 723801 & $8 / 26 / 97$ & $26: 12: 59$ & $26: 13: 26$ & 6 & 0.0 & 20 \\
\hline 723802 & $8 / 26 / 97$ & $26: 14: 30$ & $26: 15: 42$ & 2 & 1.0 & 20 \\
\hline 723901 & $8 / 27 / 97$ & 27:09:50 & $27: 10: 54$ & 6 & 1.0 & 20 \\
\hline 723901 & $8 / 27 / 97$ & $27: 11: 30$ & $27: 13: 54$ & 2 & 3.0 & 20 \\
\hline 723901 & $8 / 27 / 97$ & 27:13:55 & $27: 14: 34$ & 6 & 3.0 & 20 \\
\hline 730401 & $10 / 31 / 97$ & $31: 08: 55$ & $31: 16: 45$ & 2 & 0.0 & 50 \\
\hline 730701 & $11 / 3 / 97$ & $3: 10: 00$ & $10: 11: 50$ & 4 & 0.0 & 50 \\
\hline 730701 & $11 / 3 / 97$ & 3:13:55 & $3: 16: 25$ & 6 & 0.0 & 50 \\
\hline 730901 & $11 / 5 / 97$ & $5: 10: 45$ & $5: 15: 45$ & 2 & 2.0 & 50 \\
\hline 731101 & $11 / 7 / 97$ & 7:09:35 & $7: 16: 00$ & 2 & 4.0 & 50 \\
\hline 732301 & $11 / 19 / 97$ & $19: 14: 10$ & 19:16:30 & 2 & 4.0 & 50 \\
\hline 733701 & $12 / 3 / 97$ & $3: 10: 30$ & $3: 13: 30$ & 2 & 0.0 & 75 \\
\hline 733801 & $12 / 4 / 97$ & 4:09:50 & $4: 12: 10$ & 2 & 2.0 & 75 \\
\hline 733801 & $12 / 4 / 97$ & $4: 14: 20$ & $4: 16: 45$ & 2 & 4.0 & 75 \\
\hline 733901 & $12 / 5 / 97$ & $5: 10: 00$ & $5: 13: 00$ & 2 & 4.0 & 75 \\
\hline 804101 & 2/9/98 & $9: 10: 15$ & 9:13:15 & 2 & 2.0 & 110 \\
\hline 804101 & $2 / 10 / 98$ & 10:09:00 & $10: 12: 00$ & 2 & 6.0 & 110 \\
\hline 804101 & $2 / 10 / 98$ & $10: 14: 00$ & $10: 17: 00$ & 2 & 8.0 & 110 \\
\hline 804102 & $2 / 9 / 98$ & $9: 15: 30$ & 9:18:00 & 2 & 4.0 & 110 \\
\hline 804201 & $2 / 11 / 98$ & 11:09:30 & $11: 12: 30$ & 2 & 10.0 & 100 \\
\hline 804301 & $2 / 12 / 98$ & $12: 09: 45$ & $12: 12: 15$ & 2 & 12.0 & 110 \\
\hline 804301 & $2 / 12 / 98$ & $12: 14: 00$ & $12: 17: 00$ & 2 & 14.0 & 110 \\
\hline 805101 & 2/20/98 & $20: 07: 45$ & $20: 11: 45$ & 2 & 2.0 & 140 \\
\hline 805401 & 2/23/98 & 23:08:30 & $23: 12: 30$ & 2 & 4.0 & 140 \\
\hline 805401 & 2/23/98 & $23: 13: 00$ & $23: 16: 00$ & 2 & 6.0 & 140 \\
\hline
\end{tabular}




\begin{tabular}{|c|c|c|c|c|c|c|}
\hline Data File & Date & $\begin{array}{l}\text { Start Time } \\
\text { (dd:hh:mm) }\end{array}$ & $\begin{array}{l}\text { Stop Time } \\
\text { (dd:hh:mm) }\end{array}$ & $\begin{array}{c}\text { Flow } \\
\text { Pressure (psi) }\end{array}$ & $\begin{array}{c}\sigma_{1} \\
\text { (MPa) }\end{array}$ & $T\left({ }^{\circ} \mathrm{C}\right)$ \\
\hline 805401 & 2/24/98 & 24:08:45 & $24: 11: 45$ & 2 & 8.0 & 140 \\
\hline 805501 & $2 / 24 / 98$ & $24: 13: 30$ & $24: 16: 30$ & 2 & 10.0 & 140 \\
\hline 805601 & $2 / 25 / 98$ & $25: 08: 45$ & $25: 11: 45$ & 2 & 12.0 & 140 \\
\hline 805602 & $2 / 25 / 98$ & $25: 15: 15$ & $25: 17: 15$ & 2 & 14.0 & 140 \\
\hline 806401 & $3 / 5 / 98$ & 5:16:00 & 5:18:30 & 2 & 2.0 & 20 \\
\hline 806801 & 3/9/98 & 9:09:00 & 9:12:00 & 2 & 4.0 & 20 \\
\hline 806801 & $3 / 9 / 98$ & 9:12:15 & 9:15:15 & 2 & 6.0 & 20 \\
\hline 806801 & $3 / 9 / 98$ & $9: 15: 30$ & $9: 17: 00$ & 2 & 8.0 & 20 \\
\hline 806901 & 3/10/98 & 10:08:00 & 10:11:00 & 2 & 10.0 & 20 \\
\hline 806901 & $3 / 10 / 98$ & $10: 11: 15$ & $10: 13: 45$ & 2 & 12.0 & 20 \\
\hline 806901 & $3 / 10 / 98$ & $10: 14: 00$ & $10: 16: 00$ & 2 & 14.0 & 20 \\
\hline
\end{tabular}

The experimental matrix consisted of five nominal temperatures $\left(20^{\circ}, 50^{\circ}, 75^{\circ}, 110^{\circ}\right.$, and $\left.140^{\circ} \mathrm{C}\right)$, nine axial stresses $(0,1,2,4,6,8,10,12$, and $14 \mathrm{MPa})$, and five flow differential pressures $(2,3,4,5$, and 6 psi). Water flow was measured at each condition until steady state flow was assured. After initial saturation for $T<100^{\circ} \mathrm{C}$, this period generally was about 3 hours. For $T>100^{\circ} \mathrm{C}$, steady flow was indeterminate because of steam loss through the sides of the blocks. In these cases, flow measurements usually were made for about 3 hours.

A grid of fluid collection ports was used to characterize flow in the plane of the fracture. The use of a grid of fluid collection ports with spatial resolution greater than the typical hydrologic network path permits quasi-quantitative analysis of flow at the sample boundary. This method was chosen because channeling is commonly observed in fracture flow experiments (Tsang, 1984). At steady state, such a network provides (for $T<100^{\circ} \mathrm{C}$ ) lower and upper bounds on the flow under specific temperature and stress conditions. The lower bound, representing flow through the connected porosity of the nonfractured matrix, can be estimated by measuring flow at compressive stresses large enough to close the fracture aperture. The upper bound, representing flow through an open aperture formed by parallel plane surfaces, normally can be estimated by extrapolating maximum flow measurements at compressive stresses less than that required to close the fracture completely. Combining these quasi-quantitative flow data with estimates of the aperture from stress-strain measurements, the surface roughness from direct measurements, and limiting assumptions on the flow path, permits estimates of lower and upper bounds on the permeability. However, flow-path assumptions, required to estimate both the length of the flow path from the point source to the collection point and the effective cross-sectional area of the flow, are problematic. Fracture-surface imaging, and tomographic imaging of the volume near the fracture surface, can be used to identify possible flow paths not in the fracture plane. As will be discussed below, flow through the fracture in this porous rock, with its uncorrelated fracture surfaces, can be described in terms of a parallel-plane law only by using a lumped-parameter, effective permeability. Nevertheless, the spatial resolution of the collection grid and surface observation of the fracture provide a phenomenological description of the dominant flow paths.

For these experiments, the amount of fluid entering and exiting the sample was monitored manually. The input side of the fluid flow system consisted of a pressurized 
reservoir equipped with a sight tube. Fluid entering the sample over a time interval was determined by manually recording the level of fluid in the sight tube at the beginning and end of the interval. Fluid flowing out of the sample through each of the 38 ports was collected in a jar, and the amount of fluid flowing out of the sample was determined by summing the weights of the fluid collected in the jars at appropriate intervals. Typical data are shown in Figure 2-11.

\section{Figure 2-11. Total flow out of each port for Run 7195}

A more useful visualization of the correlation of the flow pattern to the fracture-surface texture is shown in Figure 2-12. All but a small fraction of the water was collected in 15 of the ports, with five of the ports dominating the flow. Figure 2-12 shows that the dominant flow paths were in the center of each face and were oriented in the laboratory east-west and north-south directions. This pattern is consistent with the analysis of the surface topography.

Figure 2-12. Spatial representation of total flow in plane of fracture for SB3 during Run 7195 (DTN LL980802304243.021)

This representation assumes linear flow paths between the injection point at the center of the fracture plane and each port. The highest flows occur in the east-west direction, which is parallel to the textural anisotropy shown in Figure 2-3.

\subsubsection{Fluid Flow versus Pressure Differential}

The starting condition for the initial flow experiment, 719501, was with the rock in "lab dry" condition. The two blocks making up the sample had been stored for several months inside a laboratory under normal temperature and humidity conditions. The initial saturation is not known. However, porosity calculations using sample weight, external dimensions, and the nominal value of $2.55 \mathrm{~g} / \mathrm{cm}^{3}$ grain density for TSw2 resulted in a porosity that is typical of the rock in dry condition (i.e., the saturation condition reached asymptotically over time while heating at $35^{\circ} \mathrm{C}$ under vacuum). The initial flux of water into the fracture, therefore, is partitioned into flux into the unsaturated rock through the fracture surface and flux out of the fracture into the collection manifold, as shown in Figure 2-13. The rock near the boundary condition of $100 \%$ saturation (the fluid-filled fracture) imbibes water according to Richards' equation (Flint et al., 1994; Richards, 1931; Warrick and Broadbridge, 1992; Zimmerman et al., 1993; Zimmerman et al., 1990), which has a solution with a strong, short-term flow proportional to $t^{1 / 2}$ and a weaker, long-term flow proportional to $t$. Though we did not measure the short-term transient, it is evident (Figure 2-13) that approximately $110 \mathrm{~g}$ of water was imbibed into the dry, porous rock abutting the fracture plane. This strong transient lasted less than 30 minutes. After the transient, the flux into and out of the fracture was linear in time. Subsequently, water flux into the fracture still was partitioned into diminished flow into the matrix, with the bulk of the flow through the fracture. This difference is manifest by the slightly larger value of the slope of the input water curve than that for the output water curve. 
Figure 2-13. Initial fluid flow into the unsaturated rock for Experiment 719501 (DTN LL980802304243.021)

Approximately $110 \mathrm{~g}$ of water was imbibed into the dry, porous rock along the fracture plane. This transient lasted no longer than 30 minutes. Subsequently, water flux into the fracture very nearly equaled water flux out of the fracture. $R$ is the correlation coefficient for the linear regression.

Water mass flux balance in all following experiments for $T<100^{\circ} \mathrm{C}$ showed a smaller initial transient flow of water into the matrix, followed by a small (over the time period of the measurements) loss to the partially saturated matrix. Data for the second experiment, 719601, are typical of subsequent experiments and are shown in Figure 2-14.

Figure 2-14. Flow versus time for Experiment 719601, showing an initial, small imbibition transient

We summarize the water mass balance in Table 2-3 and in Figure 2-15. For each experiment, water flow into the block ("input") and water flow out of the block, as collected in the 38 ports of the collection manifold ("output"), are fitted to straight lines. The intercepts, $m_{0}$, are of no particular significance owing to the selection and weighting statistics of the data used for the fit. However, the slopes, $m_{1}$, are the mass flow rates and can be used to draw conclusions about imbibition into the rock from the $100 \%$ saturated boundary condition at the fracture surface.

Table 2-3. Pressure differential, axial stress $\sigma_{1}$, temperature, and fitting parameters for water flow in a horizontal fracture (DTN LL980802204243.020)

$m_{0}$ is the intercept and $m_{1}$ the slope of the cumulative water flow versus time curve.

\begin{tabular}{|l|c|c|c|c|c|c|c|}
\hline Data File & $\begin{array}{c}\Delta \boldsymbol{P} \\
(\mathbf{p s i})\end{array}$ & $\sigma_{1}(\mathbf{M P a})$ & $\boldsymbol{T}\left({ }^{\circ} \mathbf{C}\right)$ & $\begin{array}{c}\text { Input } / \\
\text { Output }\end{array}$ & $\boldsymbol{m}_{\mathbf{0}}(\mathbf{g})$ & $\begin{array}{c}\boldsymbol{m}_{1} \\
(\mathbf{g} / \mathbf{m i n})\end{array}$ & $\begin{array}{c}\text { Corr. } \\
\text { Coeff. }\end{array}$ \\
\hline \hline 719501 & 2 & 0.0 & 20 & $\mathrm{I}$ & 39.2 & 4.72 & 0.99963 \\
\hline 719501 & 2 & 0.0 & 20 & $\mathrm{O}$ & -69.0 & 4.69 & 0.99962 \\
\hline 719601 & 2 & 0.0 & 20 & $\mathrm{I}$ & 25.2 & 4.21 & 0.99956 \\
\hline 719601 & 2 & 0.0 & 20 & $\mathrm{O}$ & -7.47 & 4.15 & 0.99975 \\
\hline 719701 & 2 & 0.5 & 20 & $\mathrm{O}$ & 7.59 & 3.62 & 0.99959 \\
\hline 719701 & 2 & 0.5 & 20 & $\mathrm{I}$ & 1.90 & 3.39 & 0.99962 \\
\hline 719701 & 2 & 0.0 & 20 & $\mathrm{O}$ & 20.6 & 3.94 & 0.99942 \\
\hline 719701 & 2 & 0.0 & 20 & $\mathrm{I}$ & 16.3 & 3.97 & 0.99922 \\
\hline 719801 & 2 & 0.5 & 20 & $\mathrm{I}$ & 53.5 & 2.78 & 0.99684 \\
\hline 719801 & 2 & 0.5 & 20 & $\mathrm{O}$ & 34.9 & 2.65 & 0.99892 \\
\hline 719901 & 2 & 0.5 & 20 & $\mathrm{I}$ & 25.1 & 1.72 & 0.99670 \\
\hline 719901 & 2 & 0.5 & 20 & $\mathrm{O}$ & 12.6 & 1.63 & 0.99907 \\
\hline 720201 & 2 & 1.0 & 20 & $\mathrm{O}$ & 8.26 & 4.34 & 0.99934 \\
\hline 720201 & 2 & 1.0 & 20 & $\mathrm{I}$ & 7.07 & 4.48 & 0.99945 \\
\hline
\end{tabular}




\begin{tabular}{|c|c|c|c|c|c|c|c|}
\hline Data File & $\begin{array}{c}\Delta P \\
(p s i)\end{array}$ & $\sigma_{1}(\mathrm{MPa})$ & $T\left({ }^{\circ} \mathbf{C}\right)$ & $\begin{array}{l}\text { Input / } \\
\text { Output }\end{array}$ & $m_{0}(g)$ & $\begin{array}{c}m_{1} \\
(\mathrm{~g} / \mathrm{min})\end{array}$ & $\begin{array}{l}\text { Corr. } \\
\text { Coeff. }\end{array}$ \\
\hline 720201 & 2 & 0.5 & 20 & 0 & 68.1 & 4.34 & 0.99261 \\
\hline 720201 & 2 & 0.5 & 20 & I & -1.63 & 5.01 & 0.99950 \\
\hline 720301 & 3 & 1.0 & 20 & O & -3.37 & 8.08 & 0.99988 \\
\hline 720301 & 3 & 1.0 & 20 & I & 15.6 & 8.21 & 0.99970 \\
\hline 720301 & 2 & 1.0 & 20 & $\mathrm{O}$ & 0.369 & 4.57 & 0.99945 \\
\hline 720301 & 2 & 1.0 & 20 & 1 & 12.1 & 4.33 & 0.99778 \\
\hline 720401 & 5 & 1.0 & 20 & I & 49.2 & 13.7 & 0.99955 \\
\hline 720401 & 5 & 1.0 & 20 & 0 & 64.1 & 12.3 & 0.99839 \\
\hline 720501 & 3 & 2.0 & 20 & 0 & 6.57 & 7.98 & 0.99982 \\
\hline 720501 & 3 & 2.0 & 20 & 1 & 5.78 & 7.97 & 0.99966 \\
\hline 720501 & 2 & 2.0 & 20 & 0 & -7.5 & 4.73 & 0.99988 \\
\hline 720501 & 2 & 2.0 & 20 & 1 & 7.99 & 4.87 & 0.99983 \\
\hline 720601 & 6 & 2.0 & 20 & 0 & -123 & 15.3 & 0.99397 \\
\hline 720601 & 6 & 2.0 & 20 & 1 & -120 & 15.8 & 0.99362 \\
\hline 720601 & 5 & 2.0 & 20 & 0 & -374 & 13.5 & 0.99309 \\
\hline 720601 & 5 & 2.0 & 20 & 1 & -218 & 14.2 & 0.99708 \\
\hline 720901 & 2 & 2.5 & 20 & 0 & 59.6 & 3.36 & 0.99367 \\
\hline 720901 & 2 & 2.5 & 20 & I & 28.4 & 3.37 & 0.99868 \\
\hline 720901 & 6 & 2.0 & 20 & 0 & 14.3 & 15.0 & 0.99373 \\
\hline 720901 & 6 & 2.0 & 20 & 1 & 37.3 & 11.9 & 0.96477 \\
\hline 721101 & 2 & 4.0 & 20 & 1 & 21.9 & 5.28 & 0.99825 \\
\hline 721101 & 2 & 4.0 & 20 & 0 & -25.3 & 4.52 & 0.99063 \\
\hline 721201 & 5 & 4.0 & 20 & 0 & 58.9 & 16.7 & 0.99719 \\
\hline 721201 & 5 & 4.0 & 20 & 1 & 46.3 & 16.7 & 0.99757 \\
\hline 721201 & 3 & 4.0 & 20 & 0 & 13.9 & 9.16 & 0.99970 \\
\hline 721201 & 3 & 4.0 & 20 & I & 11.4 & 9.33 & 0.99930 \\
\hline 721201 & 6 & 4.0 & 20 & 1 & 245 & 13.2 & 0.91521 \\
\hline 721201 & 6 & 4.0 & 20 & 0 & 222 & 14.5 & 0.94543 \\
\hline 721301 & 6 & 8.0 & 20 & 1 & 46.5 & 15.8 & 0.95815 \\
\hline 721301 & 6 & 8.0 & 20 & 0 & 14.5 & 17.7 & 0.99786 \\
\hline 721301 & 2 & 8.0 & 20 & 0 & 7.25 & 6.22 & 0.99908 \\
\hline 721301 & 2 & 8.0 & 20 & 1 & 3.04 & 6.00 & 0.99944 \\
\hline 721301 & 5 & 8.0 & 20 & 1 & 32.2 & 15.9 & 0.98602 \\
\hline 721301 & 3 & 8.0 & 20 & 0 & 2.72 & 9.73 & 0.99975 \\
\hline 721301 & 3 & 8.0 & 20 & 1 & 19.5 & 9.34 & 0.99705 \\
\hline 721301 & 5 & 8.0 & 20 & 0 & 18.8 & 17.4 & 0.99584 \\
\hline
\end{tabular}




\begin{tabular}{|c|c|c|c|c|c|c|c|}
\hline Data File & $\begin{array}{c}\Delta P \\
(p s i)\end{array}$ & $\sigma_{1}(\mathbf{M P a})$ & $T\left({ }^{\circ} \mathrm{C}\right)$ & $\begin{array}{l}\text { Input / } \\
\text { Output }\end{array}$ & $m_{0}(g)$ & $\begin{array}{c}m_{1} \\
(g / m i n)\end{array}$ & $\begin{array}{l}\text { Corr. } \\
\text { Coeff. }\end{array}$ \\
\hline 721601 & 6 & 0.0 & 20 & 1 & 20.8 & 18.3 & 0.99825 \\
\hline 721601 & 6 & 0.0 & 20 & 0 & 0.686 & 19.9 & 1.0000 \\
\hline 721601 & 2 & 0.0 & 20 & 1 & -7.23 & 6.01 & 0.99901 \\
\hline 721601 & 2 & 0.0 & 20 & 0 & -32.5 & 6.04 & 0.99925 \\
\hline 721701 & 6 & 0.5 & 20 & I & 10.2 & 19.9 & 0.99863 \\
\hline 721701 & 2 & 1.0 & 20 & 0 & -10.8 & 6.31 & 0.99803 \\
\hline 721701 & 2 & 1.0 & 20 & 1 & -5.5 & 6.13 & 0.99964 \\
\hline 721701 & 2 & 0.5 & 20 & 0 & 4.84 & 5.48 & 0.99949 \\
\hline 721701 & 2 & 0.5 & 20 & 1 & 4.60 & 5.36 & 0.99967 \\
\hline 721701 & 6 & 0.5 & 20 & 0 & -12.3 & 22.3 & 0.99843 \\
\hline 721801 & 2 & 2.0 & 20 & 1 & 3.38 & 5.41 & 0.99943 \\
\hline 721801 & 2 & 4.0 & 20 & 0 & -2.82 & 5.85 & 0.99976 \\
\hline 721801 & 2 & 2.0 & 20 & 0 & -10.5 & 5.97 & 0.99910 \\
\hline 721801 & 6 & 1.0 & 20 & 0 & -3.27 & 22.0 & 0.99954 \\
\hline 721801 & 6 & 1.0 & 20 & 1 & 13.5 & 20.0 & 0.99929 \\
\hline 721801 & 2 & 4.0 & 20 & 1 & 0.0666 & 5.49 & 1.0000 \\
\hline 721801 & 6 & 2.0 & 20 & 0 & -12.7 & 23.4 & 0.99775 \\
\hline 721801 & 6 & 2.0 & 20 & I & -4.52 & 20.9 & 0.99958 \\
\hline 721901 & 2 & 8.0 & 20 & I & -29.6 & 4.27 & 0.99413 \\
\hline 721901 & 6 & 8.0 & 20 & O & -37.0 & 21.0 & 0.99874 \\
\hline 721901 & 6 & 8.0 & 20 & 1 & -47.2 & 21.9 & 0.99688 \\
\hline 721901 & 6 & 4.0 & 20 & 0 & -22.7 & 22.4 & 0.99701 \\
\hline 721901 & 6 & 4.0 & 20 & 1 & 3.96 & 21.0 & 0.99993 \\
\hline 721901 & 2 & 8.0 & 20 & 0 & -28.7 & 4.58 & 0.99513 \\
\hline 723801 & 6 & 0.0 & 20 & 1 & -10.7 & 22.0 & 0.99824 \\
\hline 723801 & 2 & 1.0 & 20 & 0 & -16.1 & 7.38 & 0.99366 \\
\hline 723801 & 2 & 1.0 & 20 & 1 & -9.83 & 6.49 & 0.99833 \\
\hline 723801 & 2 & 0.0 & 20 & 0 & 8.34 & 6.46 & 0.99923 \\
\hline 723801 & 2 & 0.0 & 20 & 1 & -2.48 & 6.45 & 0.99985 \\
\hline 723801 & 6 & 0.0 & 20 & 0 & -30.3 & 22.5 & 0.99100 \\
\hline 723901 & 2 & 3.0 & 20 & 0 & -15.6 & 4.67 & 0.98687 \\
\hline 723901 & 6 & 1.0 & 20 & 1 & -16.2 & 22.2 & 0.99961 \\
\hline 723901 & 6 & 1.0 & 20 & 0 & -34.2 & 22.6 & 0.99872 \\
\hline 723901 & 6 & 3.0 & 20 & I & 2.88 & 22.9 & 0.99984 \\
\hline 723901 & 6 & 3.0 & 20 & 0 & -10.9 & 25.8 & 0.99815 \\
\hline 723901 & 2 & 3.0 & 20 & I & -12.7 & 4.84 & 0.98796 \\
\hline
\end{tabular}




\begin{tabular}{|c|c|c|c|c|c|c|c|}
\hline Data File & $\begin{array}{c}\Delta P \\
(p s i)\end{array}$ & $\sigma_{1}(\mathrm{MPa})$ & $T\left({ }^{\circ} \mathbf{C}\right)$ & $\begin{array}{l}\text { Input / } \\
\text { Output }\end{array}$ & $m_{0}(g)$ & $\begin{array}{c}m_{1} \\
(\mathrm{~g} / \mathrm{min})\end{array}$ & $\begin{array}{l}\text { Corr. } \\
\text { Coeff. }\end{array}$ \\
\hline 730401 & 2 & 0.0 & 50 & 0 & -20.8 & 5.91 & 0.99860 \\
\hline 730401 & 2 & 0.0 & 50 & I & -3.93 & 6.02 & 0.99974 \\
\hline 730401 & 2 & 4.0 & 50 & O & -30.4 & 6.11 & 0.99809 \\
\hline 730401 & 2 & 4.0 & 50 & I & -15.3 & 6.32 & 0.99952 \\
\hline 730701 & 6 & 0.0 & 50 & I & 10.6 & 21.7 & 0.99969 \\
\hline 730701 & 4 & 0.0 & 50 & 0 & -16.9 & 14.8 & 0.99951 \\
\hline 730701 & 4 & 0.0 & 50 & I & 5.99 & 15.3 & 0.99974 \\
\hline 730701 & 6 & 0.0 & 50 & 0 & 16.7 & 21.4 & 0.99966 \\
\hline 730901 & 2 & 2.0 & 50 & 0 & -1.79 & 6.66 & 0.99983 \\
\hline 730901 & 2 & 2.0 & 50 & 1 & -15.8 & 6.46 & 0.99968 \\
\hline 731101 & 2 & 4.0 & 50 & 0 & 15.3 & 6.63 & 0.99976 \\
\hline 731101 & 2 & 4.0 & 50 & I & 34.5 & 6.46 & 0.99962 \\
\hline 732301 & 2 & 4.0 & 50 & 0 & -30.4 & 6.11 & 0.99809 \\
\hline 732301 & 2 & 4.0 & 50 & 1 & -15.3 & 6.32 & 0.99952 \\
\hline 733701 & 2 & 0.0 & 75 & 1 & -6.55 & 6.39 & 0.99966 \\
\hline 733701 & 2 & 0.0 & 75 & 0 & 1.93 & 6.14 & 0.99965 \\
\hline 733801 & 2 & 2.0 & 75 & 1 & -24.2 & 6.32 & 0.99896 \\
\hline 733801 & 2 & 2.0 & 75 & 0 & -18.5 & 6.40 & 0.99942 \\
\hline 733801 & 2 & 4.0 & 75 & I & -4.30 & 6.31 & 0.99989 \\
\hline 733801 & 2 & 4.0 & 75 & 0 & -1.72 & 6.40 & 0.99990 \\
\hline 733901 & 2 & 4.0 & 75 & 1 & -14.5 & 6.37 & 0.99969 \\
\hline 733901 & 2 & 4.0 & 75 & 0 & -4.38 & 6.34 & 0.99974 \\
\hline 804001 & 2 & 2.0 & 110 & 1 & 19.0 & 6.92 & 0.99952 \\
\hline 804001 & 2 & 2.0 & 110 & 0 & -41.1 & 4.58 & 0.99657 \\
\hline 804001 & 2 & 4.0 & 110 & 0 & -1.74 & 5.56 & 0.99983 \\
\hline 804001 & 2 & 4.0 & 110 & I & 8.77 & 6.57 & 0.99967 \\
\hline 804101 & 2 & 8.0 & 110 & 1 & 21.6 & 5.39 & 0.99937 \\
\hline 804101 & 2 & 6.0 & 110 & 0 & -9.35 & 4.12 & 0.99947 \\
\hline 804101 & 2 & 6.0 & 110 & 1 & 37.3 & 5.92 & 0.99706 \\
\hline 804101 & 2 & 8.0 & 110 & 0 & 12.8 & 4.58 & 0.99936 \\
\hline 804201 & 2 & 10 & 110 & 0 & -9.89 & 2.20 & 0.99737 \\
\hline 804201 & 2 & 10 & 110 & I & 24.8 & 4.68 & 0.99873 \\
\hline 804301 & 2 & 14 & 110 & 0 & 3.58 & 4.32 & 0.99990 \\
\hline 804301 & 2 & 14 & 110 & I & 31.4 & 5.48 & 0.99853 \\
\hline 804301 & 2 & 12 & 110 & 0 & -3.89 & 3.79 & 0.99978 \\
\hline 804301 & 2 & 12 & 110 & 1 & 15.6 & 6.29 & 0.99919 \\
\hline
\end{tabular}




\begin{tabular}{|l|c|c|c|c|c|c|c|}
\hline Data File & $\begin{array}{c}\Delta \boldsymbol{P} \\
(\mathbf{p s i})\end{array}$ & $\sigma_{1}$ (MPa) & $\boldsymbol{T}\left({ }^{\circ} \mathbf{C}\right)$ & $\begin{array}{c}\text { Input } / \\
\text { Output }\end{array}$ & $\boldsymbol{m}_{\mathbf{0}}$ (g) & $\begin{array}{c}\boldsymbol{m}_{\mathbf{1}} \\
(\mathbf{g} / \mathbf{m i n})\end{array}$ & $\begin{array}{c}\text { Corr. } \\
\text { Coeff. }\end{array}$ \\
\hline \hline 805101 & 2 & 2.0 & 140 & $\mathrm{I}$ & 50.8 & 7.87 & 0.99932 \\
\hline 805101 & 2 & 2.0 & 140 & $\mathrm{O}$ & -47.7 & 3.62 & 0.99834 \\
\hline 805401 & 2 & 4.0 & 140 & $\mathrm{O}$ & -30.5 & 2.26 & 0.99112 \\
\hline 805401 & 2 & 8.0 & 140 & $\mathrm{O}$ & -20.4 & 3.40 & 0.99757 \\
\hline 805401 & 2 & 8.0 & 140 & $\mathrm{I}$ & 4.38 & 7.63 & 0.99982 \\
\hline 805401 & 2 & 6.0 & 140 & $\mathrm{I}$ & -9.21 & 5.13 & 0.99970 \\
\hline 805401 & 2 & 6.0 & 140 & $\mathrm{O}$ & 8.48 & 2.59 & 0.99894 \\
\hline 805401 & 2 & 4.0 & 140 & $\mathrm{I}$ & 18.4 & 6.42 & 0.99942 \\
\hline 805501 & 2 & 10 & 140 & $\mathrm{O}$ & -1.88 & 3.99 & 0.99998 \\
\hline 805501 & 2 & 10 & 140 & $\mathrm{I}$ & 27.4 & 6.66 & 0.99919 \\
\hline 805602 & 2 & 12 & 140 & $\mathrm{O}$ & -18.0 & 2.16 & 0.99513 \\
\hline 805602 & 2 & 12 & 140 & $\mathrm{I}$ & 14.6 & 6.09 & 0.99949 \\
\hline 805602 & 2 & 14 & 140 & $\mathrm{O}$ & -18.0 & 2.16 & 0.99513 \\
\hline 805602 & 2 & 14 & 140 & $\mathrm{I}$ & 14.6 & 6.09 & 0.99949 \\
\hline 806401 & 2 & 2.0 & 20 & $\mathrm{I}$ & 47.1 & 7.36 & 0.99961 \\
\hline 806401 & 2 & 2.0 & 20 & $\mathrm{O}$ & -23.1 & 6.86 & 0.99958 \\
\hline 806801 & 2 & 6.0 & 20 & $\mathrm{I}$ & 19.0 & 6.87 & 0.99948 \\
\hline 806801 & 2 & 6.0 & 20 & $\mathrm{O}$ & 9.97 & 6.91 & 0.99969 \\
\hline 806801 & 2 & 4.0 & 20 & $\mathrm{I}$ & 6.94 & 7.88 & 0.99921 \\
\hline 806801 & 2 & 4.0 & 20 & $\mathrm{O}$ & -8.64 & 7.75 & 0.99927 \\
\hline 806901 & 2 & 12 & 20 & $\mathrm{I}$ & 8.80 & 5.65 & 0.99900 \\
\hline 806901 & 2 & 14 & 20 & $\mathrm{O}$ & 2.32 & 4.82 & 0.99914 \\
\hline 806901 & 2 & 14 & 20 & $\mathrm{I}$ & 2.05 & 4.94 & 0.99898 \\
\hline 806901 & 2 & 10 & 20 & $\mathrm{I}$ & 26.6 & 6.14 & 0.99981 \\
\hline 806901 & 2 & 10 & 20 & $\mathrm{O}$ & 18.5 & 6.06 & 0.99995 \\
\hline 806901 & 2 & 12 & 20 & $\mathrm{O}$ & -0.337 & 5.37 & 0.99931 \\
\hline
\end{tabular}

Figure 2-15. Water flow rate versus pressure differential (DTN LL980802204243.020) The data at each $\Delta P$ are for various axial stress and temperature conditions.

\subsubsection{Fluid Flow versus Axial Stress}

The water mass flow rate also depends on the effective fracture flow impedance and the pressure differential across the flow path. Figure 2-15 shows the expected correlation between the flow rate and the driving pressure differential. Figure 2-16, however, shows a surprising non-dependence of the flow rate on the fracture aperture. Figure 2-16 is a summary of the water flow rates as a function of the axial stress, at several differential pressures along the fracture. 
Figure 2-16. Water flow rate versus axial stress

The lines are drawn as an aid to the eye, only. Water flow rate is independent of mean fracture aperture, as parameterized through axial stress, owing to the intersection of rock porosity with the uncorrelated fracture surfaces.

The effective fracture aperture is a lumped parameter that describes the impedance of the fracture to flow. Both chemical and physical processes affect the flow impedance. The time constants of chemical reactions, which may increase or decrease the impedance through dissolution or deposition of material, generally are much longer than our experimental times and will not be considered here. The physical processes are driven by the fracture-surface topography and the stress-field interaction with the fracture surface. The normal component of the stress field opens or closes the fracture, while the shear component causes three distinct effects. The shear displacement may simply cause the two surfaces to move closer or further apart as the asperities become correlated or uncorrelated. Second, for adequately large shear and normal stresses, the asperities are broken, resulting not only in the two surfaces moving closer but also in deposition of debris into porosity and accumulation in the flow path, constricting the flow. Finally, and of particular significance in porous rocks, a shear displacement results in a loss of correlation between the two fracture surfaces. Above a percolation threshhold for the porosity, this effectively opens all of the porosity that intersects the fracture surface to the flow. Further application of normal stress to the uncorrelated fracture surface may decrease the mean separation of the two faces, but does not close the fracture because of flow through the porous network on the rock side of the mean fracture surface.

In this experiment, the artificial fracture surfaces are uncorrelated. We expect the application of axial (normal) stress to have an initial effect as the two blocks "seat," but subsequently to have a negligible influence on fluid flow. This is demonstrated in Figure 2-16.

\subsubsection{Fluid Flow versus Temperature}

For the time scales in these experiments, temperature is not expected to affect water flow significantly for $T<100^{\circ} \mathrm{C}$. For water in its liquid phase, the temperature dependence of physical properties, such as viscosity and surface tension, is weak. However, for temperatures greater than the boiling temperature, the water transport changes dramatically. We performed fluid-flow measurements at nominal temperatures of $20^{\circ}, 50^{\circ}, 75^{\circ}, 110^{\circ}$, and $140^{\circ} \mathrm{C}$. Flow data for $T<150^{\circ} \mathrm{C}$ are summarized in Figure 2-17.

Figure 2-17. Water flow rate versus temperature (DTN LL980802304243.021)

The flow rate is independent of temperature. For clarity, only data for fluid-pressure differentials of 2 and 6 psi are shown.

A remarkable effect on the temperature field in the rock owing to fluid flow is shown in Figure 2-18. Data for the 12 thermocouples in the rock and for the thermocouples mounted on the copper heat transfer plates on the top and bottom surfaces of the sample assembly are plotted, along with the water flow for two periods. The thermocouple numbers correspond to the scheme shown in Figure 2-7. While the introduction of water has an effect on local temperatures, the significance of this result lies in the fact that the effect is not monotonic with distance from the fracture surface. Thermocouples near the fracture registered small or no changes in temperature, while those farther away registered large changes. This "heat pipe" 
effect owes to advective heat transport by water in connected porosity and in fractures. Much the same effect has been observed in the field in the Large Block Test (Blair and Lin, 1997)

Figure 2-18. Temperature and cumulative water flow (DTN LL980802204243.020)

Nominal sample temperature is $75^{\circ} \mathrm{C}$. The experimental $T$ versus $t$ curves are excellent solutions to the heat-flow equation for the temperature of a semi-infinite slab with a constant-temperature boundary condition.

\subsubsection{Deformation}

The relative displacement of points on the vertical faces of the sample is measured by 16 LVDTs. The LVDTs were sited to measure displacement over long and short baselines across the fracture, Poisson strains in a surface area apparently free of large porosity, and Poisson strain across a large vug that intersected the surface (see Section 2.1.4). Of primary interest was the displacement of the mean fracture aperture and the effective elastic modulus of the fracture-rock assembly. Generally, the axial stress was held constant during a fluid flow run, then permitted to decrease owing to small leaks in the pressure system.

The sequence of axial loading for Run 7195, the initial loading of the sample, occurred in three cycles. During the first of these cycles the peak stress was $4 \mathrm{MPa}$, while the peak stress was $14 \mathrm{MPa}$ in the two later intervals. In each interval axial stress was applied cyclically, via a series of loading/ unloading sequences. At each of these stress levels, load was maintained while water flow was monitored. Figure 2-19 shows displacements of up to 0.015 inches $(0.381 \mathrm{~mm})$ under stresses to $4 \mathrm{MPa}$ for the first loading cycle of the sample. Solid symbols indicate transducers measuring over relatively long gage lengths that include both matrix material and the fracture, and open symbols indicate measurements primarily over the fracture. These displacements primarily owed to the fracture deformation and were plastic, i.e., the fracture did not re-open after the load was removed. This initial behavior of the fracture is consistent with the results of Blair and Berge (1996).

Figure 2-19. Displacement data for first loading cycle of Run 7195 (DTN LL980802304243.021)

Solid symbols indicate transducers measuring over relatively long gage lengths that include both matrix material and the fracture, and open symbols indicate measurements primarily over the fracture.

(a) LVDTs 1, 2, and 3 (north face, western half)

(b) LVDTs 5, 6, and 7 (north face, eastern half)

(c) LVDTs 10 and 11 (south face, eastern half)

(d) LVDTs 13 and 14 (south face, western half)

(e) Axial stress

Stress-strain data for the first loading sequence of Run 7195 for two of the transducers measuring over long gage lengths are shown in Figure 2-20. Finally, Figure 2-21 shows the average longitudinal strain for all the long baseline transducers mounted on the sample. The initial softness of the rock is evident, followed by a stiffening to almost a linear elastic response above an axial stress of about $4 \mathrm{MPa}$. 
Figure 2-20. Stress-strain data for two transducers for the first loading cycle of Run 7195

Figure 2-21. Average stress-strain for long transducers measured during three loading cycles of Run 7195

Table 2-4 is a summary of our estimates for the effective elastic modulus for this initial loading. The value of $2.8 \mathrm{GPa}$ for the lowest stresses is consistent with our previous work on small blocks (Blair and Berge, 1996) and is considerably lower than values found in laboratory tests on small cores, which typically lack large fractures and vugs. The increase in Young's modulus seen here with increasing stress reflects the closure of fractures.

Table 2-4. Young's modulus values for Run 7195 (DTN LL980802204243.020)

\begin{tabular}{|c|c|}
\hline Axial Stress (MPa) & Young's Modulus (GPa) \\
\hline \hline $0-1$ & 2.8 \\
\hline $1-4$ & 17 \\
\hline $4-8$ & 40 \\
\hline
\end{tabular}

We also attempted to measure Poisson's ratio by measuring the vertical and horizontal deformation on the east and west faces of the sample. On the east face we placed transducers in orthogonal directions across a prominent vug (see Figure 2-2) to observe the influence of vugs on the Poisson behavior in the welded tuff. Data for the transducers used to monitor Poisson deformation are shown in Figure 2-22. The displacements across both the rock matrix and the vugs were too small in this experiment to find a reliable value for Poisson's ratio.

Figure 2-22. Vertical and horizontal displacements across two major vugs

\subsection{Discussion}

Two results of experiment SB3 are of exceptional importance in the coupled THCM phenomenology of fluid flow in Yucca Mountain. The first is the clear independence of fluid flow rate on the stress normal to the fracture. The second is the overriding effect of heat flow along heat pipes formed by fluid-filled porosity. We will discuss each of these, then turn to consideration of the several other rock and fracture properties measured in this experiment.

\subsubsection{Fluid Flow in a Porous Rock with Uncorrelated Fracture Surfaces}

Our initial experimental plan was to measure fracture flow $q$ using a test matrix defined by the cubic flow law for parallel planes, $q(x) \propto(\Delta P / \Delta x) A h^{3}$, where $P$ is pressure, $A$ is area, and $h$ is an effective separation of the planes. At each temperature in this experiment, we varied $\Delta P$ and $h$, with $\Delta x$ and $A$ constant. We controlled $\Delta P$ simply by adjusting the upstream water pressure and $h$ by adjusting the stress normal to the fracture, assuming the fracture to close as the stress increases. We increased the normal stress from 0.1 to $14 \mathrm{MPa}$ (at the upper end of stresses normal to fractures expected in Yucca Mountain), with the fracture closing by about $0.04 \mathrm{~cm}$ with no change in flow rate.

Examination of the fracture surface profile (Figure 2-3, Figure 2-4, and Figure 2-5) provides an immediate explanation of this observation. Even at the highest axial mean stress, when the axial load is carried by the surface area of a small fraction of the asperities in 
contact across the fracture surface, there is connected porosity with cross-sectional areas of the order of $1 \mathrm{~mm}^{2}$ through which water can flow. Surface profilometry measurements of the surface ground flat to better than $.025 \mathrm{~mm}$ preclude large (centimeter-scale) wavelength variations of the mean surface from flatness (i.e., we verified the assumption that the mean fracture surfaces are flat and parallel). However, the short (millimeter-scale) wavelength variation from flat parallel planes is complete and does not change with normal stress. Thus, the flow paths through the porosity intersecting the fracture are built into the fracture and are independent of the normal stress.

This phenomenology is not true for a fracture through a porous medium for which the facing fracture surfaces are correlated. For a correlated fracture (i.e., a fracture with the two surfaces displaced normal to the mean fracture plane) a normal compressive stress simply reassembles the fracture, resulting in a porosity connectivity that is identical to the unfractured state. However, upon normal displacement of the surfaces away from each other, the mean separation effectively connects the porosity intersecting the fracture. The water flow path then is a sum through the area created by the mean displacement plus the flow through porosity intersecting the fracture, now connected because of the mean displacement. Which of these terms dominates depends on the details of the matrix porosity and on the size of the mean separation. Nevertheless, the fluid flow rate changes with mean fracture surface displacement, a function of the stress normal to the fracture.

For an uncorrelated fracture, the interaction is somewhat different. For threshold values of the total porosity, coupled with a measure of the mean aspect ratio, the porosity intersecting the surface always is connected, even if it is unconnected in the native matrix. This means that (roughly), regardless of the stress normal to the fracture, there will be a fluid conduction path that is independent of the mean fracture surface displacement. The degree of connectivity depends on the total porosity and on the pore-size and -shape distribution. This is visualized easily by considering two random planes through the porous material. Each plane contains "holes" representing the intersection of the plane with a void. Upon overlaying the planes, the intersection of the voids represent fluid conduction paths. Above a percolation limit (defined by the total porosity and its mean aspect ratio), a fracture surface formed by these two planes contains conduction paths that remain open, even at large stresses normal to the fracture surface. As in the correlated fracture surface case, the total flow is a sum of the flows through the porosity intersecting the fracture surfaces and the normal displacement of the mean fracture surfaces. However, the fracture permeability never goes to zero, and flow occurs under all values of stress normal to the fracture.

In our experiment, the artificial fracture surfaces are uncorrelated because we sawcut the native rock, then ground the two surfaces, removing a total of about $6 \mathrm{~mm}$ of rock. In situ, the original fracture surfaces become uncorrelated because of shear displacements or timedependent effects, such as chemical deposition or erosion of surface asperities. This means that a shear displacement of the order of the spacing between unconnected porosity will create a connected porosity flow path that results in a residual flow, regardless of the normal stress subsequently applied. This residual flow may be significantly higher than the flow through the unfractured matrix, because a larger fraction of the matrix porosity is connected.

Shear displaced fracture surfaces become re-correlated (for the purpose of our discussion) when the notion of unconnected porosity is re-established. When chemical or debris deposition effectively seals the flow paths between the porosity that intersects the fracture surface, the local fracture appears as it would in the unfractured material. The surface correlation increases until the fracture heals. 
This phenomenology is of particular importance for rocks that have a porosity texture. The texture defines a plane of minimum matrix area, and therefore a weakness plane for shear failure. The geometry of shear failure in this plane results in two effects which enhance flow through the fracture. First, the density of the porosity intersecting a random plane in the host rock is highest in this failure plane. This provides the lowest impedance flow path of any random direction. Second, the preferred alignment of the porosity (with aspect ratios significantly different from one), results in a preferred flow direction within the fracture plane. We see this effect in SB3. Figure 2-3 and visual observation show the porosity to have an aspect ratio generally greater than $5: 1$, with the long axis generally oriented east-west. Figure 2-12 reflects this anisotropy in the dominating east-west flow volume through channels E5 and W6.

Computer models that employ a permeability based on a cubic flow law with an effective fracture separation must account for the flow through the porosity intersecting an uncorrelated fracture surface. This is particularly important if the model includes the effects of a shear displacement of the fracture. For rocks with macroscopic porosity (say mean pore size of the order of $1 \mathrm{~mm}$ typical dimension) greater than $10 \%$ or so, the bulk of the fluid flow is through this porosity for any normal stress supported by the fracture surfaces. Modeling the permeability of a fracture as a constant (equal to the matrix permeability) plus that owing to the normal displacement of the fracture surface, does not account for the enhanced flow through the porosity connected by the uncorrelated fracture. Even if the model retains a residual effective displacement to account for the shear displacement, the contribution owing to the porosity intersecting the fracture is lost. Of course, in lumped parameter models, all of this phenomenology is captured in a single number based on direct observation or by adjusting the parameter. At issue here is modeling the permeability of a sheared fracture knowing only the root-mean-square roughness of the fracture surface and the matrix porosity.

\subsubsection{Heat Transfer into the Fracture and Connected Porosity}

The second interesting observation from this intermediate-scale experiment is the dominance of high thermal conductivity paths ("heat pipes") in the heat budget. In isotropic, homogeneous materials, conductive heat flow is characterized by a single parameter. In isotropic, heterogeneous materials, some averaging of the parameters for the materials is undertaken, resulting in a single parameter characterization of the composite. The notion of high thermal conductance provided by a water-saturated path in a rock with low saturation is not new. However, the ability to characterize it in a controlled environment on the $0.5-\mathrm{m}$ scale offers some useful guidance to computer model phenomenology. The observation of heat pipes in the SB3 experiment was not a primary feature in planning the experiment. Consequently, the data do not provide for straightforward analysis; we discuss them only briefly.

Twelve thermocouples were mounted in a planar array in SB3 to monitor temperature uniformity. The plane was orthogonal to the fracture plane and located at approximately the center of the two block sample assembly. Heat from point-source heaters mounted on the top and bottom of the sample assembly was diffused to the entire respective surface by means of a 3.18-mm-thick copper plate. To reach $140^{\circ} \mathrm{C}$, eight additional point source heaters were mounted on the vertical faces of each of the two blocks. Thermal histories indicated that neither of these heater arrays provided a temperature distribution in the entire block constant to better than $10^{\circ} \mathrm{C}$. Thus the initial temperature of the block, used in the analysis below, was not uniform; although it was constant in time up to $t_{0}$, the beginning of water flow.

Figure 2-18 shows typical data for a water flow-thermal response episode. Initially, no water is flowing and the temperature at each thermocouple is constant. Upon initiation of 
flow of water from the room temperature reservoir, there is an immediate (of the order of 10s of seconds) response of specific thermocouples near the fracture, followed by thermocouples generally further from the fracture. The total heat capacity of the water (calculated from the flow rate and time) is adequate to form a cold boundary condition of some average temperature at the fracture plane. Upon cessation of flow, a similar response was observed, as heat flowed from the surrounding rock to the thermocouple position. However, neither the order, nor the magnitude of these responses was strictly correlated with the distance of the thermocouple from the fracture.

Each of the temperature-time curves could be fitted to the four-parameter solution to heat flow into a semi-infinite plane originally at temperature $T_{0}$, with boundary condition $T_{\mathrm{B}}$ (Carslaw and Jaeger, 1986, p. 58):

$$
T=T_{B}+\left(T_{0}-T_{B}\right) \operatorname{erf}\left[\frac{z}{2 \sqrt{\kappa t}}\right], \quad\left\{\begin{array}{l}
z \geq 0 \\
t \geq 0
\end{array}\right\} .
$$

Figure 2-23 shows the typical goodness of fit for an experiment with $T_{0}=75^{\circ} \mathrm{C}$. The results of the curve fits are shown in Table 2-6.

Figure 2-23. Typical fit of the heat flow equation for a semi-infinite solid with a known initial temperature and a constant temperature boundary condition

In Figure 2-23 and Table 2-6, $T_{0}$, the initial temperature of the rock at the thermocouple, and $z$, the distance from the boundary to the thermocouple, are fixed. $T_{\mathrm{B}}$, the temperature of the water in the fracture, and $\kappa$, the thermal diffusivity, are fitting parameters.

Table 2-5. Fitting parameters for typical temperature versus time data during cooling of the sample owing to fluid flowing through the fracture (DTN LL980802204243.020)

\begin{tabular}{|l|c|c|c|c|}
\hline Thermocouple & $\boldsymbol{z}(\mathbf{m})$ & $\boldsymbol{T}_{\mathbf{0}}\left({ }^{\circ} \mathbf{C}\right)$ & $\boldsymbol{T}_{\mathrm{B}}\left({ }^{\circ} \mathbf{C}\right)$ & $\kappa\left(\mathbf{m}^{2} \mathbf{s}^{-1} \times \mathbf{1 0}^{-6}\right)$ \\
\hline \hline 3 & 0.017 & 79 & 69.4 & .03 \\
\hline 4 & 0.017 & 76 & 56.9 & .48 \\
\hline 5 & 0.016 & 74 & 49.9 & 1.2 \\
\hline 9 & 0.236 & 76 & 67.2 & 8.8 \\
\hline 10 & 0.019 & 73 & 60.4 & .03 \\
\hline 11 & 0.082 & 74 & 58.0 & 2.6 \\
\hline 12 & 0.146 & 74.5 & 61.0 & 25 \\
\hline
\end{tabular}

In these fits, $T_{0}$ is the initial temperature of the thermocouple, $z$ is the distance of the thermocouple sensing point from the fracture plane, $T_{B}$ the temperature of the boundary at $z=0$, and $\kappa$ the thermal diffusivity. $T_{0}$ and $z$ are fixed for each thermocouple to their actual values. The two fitting parameters are $T_{\mathrm{B}}$ and $\kappa$. The boundary condition temperature ( $T$ of the water in the fracture) is not known and is not constant. The water warms from room temperature as it passes through the rock in its tubing to the injection point at the center of the fracture. Subsequently, it is heated as it flows through the fracture. While the accuracy of 
the fitting parameters is problematical owing to the poorly defined boundary condition, there are some phenomenological observations that may be made.

The thermal diffusivity $\kappa=K /(\rho c)$, where $K$ is thermal conductivity, $\rho$ is density and $c$ is specific heat. Substituting typical values for TSw2 $\left(K=1.5 \mathrm{~W} / \mathrm{m}-\mathrm{K} ; \rho c=2 \mathrm{~J} / \mathrm{cm}^{3}-\mathrm{K}\right)$, $\kappa=0.75 \times 10^{-6} \mathrm{~m}^{2} / \mathrm{s}$. The responses of Thermocouples 6 and 11 indicate a factor of $10-30$ higher thermal diffusivity than would be expected of the unsaturated rock. Although we do not wish to claim more for this analysis than it merits, it is apparent that heat flow into the host rock through water-filled, connected porosity can be observed and quantified in these intermediate-scale experiments. The heat flow can be modeled with good accuracy as flow into a semi-infinite solid with constant boundary temperature $T_{\mathrm{B}}(t, z=0)$.

Data with spatial resolution adequate to draw 3-D temperature-time contours will provide an excellent means to validate THM models. They also will provide the thermal and water mass flux fields as input to THCM models. Major objectives of the follow-on experiment to SB3 (SB4, described in Chapter 3) are to provide symmetry, boundary, and initial conditions conducive to computer modeling; and to make time- and spatially-resolved measurements of the temperature field. Successfully modeling the SB4 data should result in a significant increase in confidence in the use of a THCM code to predict coupled processes.

\subsubsection{Anisotropy of Mechanical Properties}

Results for the mechanical properties measured in this experiment indicate a marked anisotropy in Young's modulus.

It is instructive to discuss the results shown in Figure 2-21 and in Table 2-4 by contrasting and comparing these data with the results on sample SB1 (Blair and Berge, 1996). In SB1, the sample was prepared so that the uniaxial compression was normal to the plane of the rock fabric. The effective Young's modulus in this direction (normal to the major axes of the generally oblate spheroidal porosity) ranged from about $5 \mathrm{GPa}$ to about $30 \mathrm{GPa}$, depending on the location of the LVDT baseline. Interpretation of this result is relatively straightforward: transducer baselines spanning relatively high densities of the nonuniform porosity distribution measured the aggregate compression of many weak springs, while those spanning baselines with a relatively low density of porosity measured a smaller aggregate effect. Because the compression of an oblate spheroid along one of its major axes is much stiffer, the effect on the range of moduli measured for different baselines should be smaller.

For SB3, the uniaxial compression axis is generally along the major axes of the oblate spheroidal porosity. Since the dependence of the effective modulus on porosity spatial distribution is smaller in this case, measured values along different baselines have a smaller range, with an average of about $40 \mathrm{GPa}$ for axial stresses above about $4 \mathrm{MPa}$. Taking 15-20 GPa as an average of the range of effective moduli for SB1, the anisotropy in the modulus parallel to and perpendicular to the major axes of the porosity is of the order of $50 \%$. This anisotropy is significant in modeling the thermo-mechanical response of the NFE.

An axial stress of the order of $0.5 \mathrm{MPa}$ was sufficent to close this artificial fracture mechanically. As a result, the "aperture" of the fracture, defined as the separation of the planes describing the average asperity height, does not change significantly with axial stress. This is consistent with the observation that fluid flow is independent of axial stress (i.e., fracture "aperture"). We conclude that an uncorrelated fracture can have a stiffness similar to the host rock and still can form a low-impedance flow path for fluids; fracture conductance remains large when the fracture closes. 

(a)

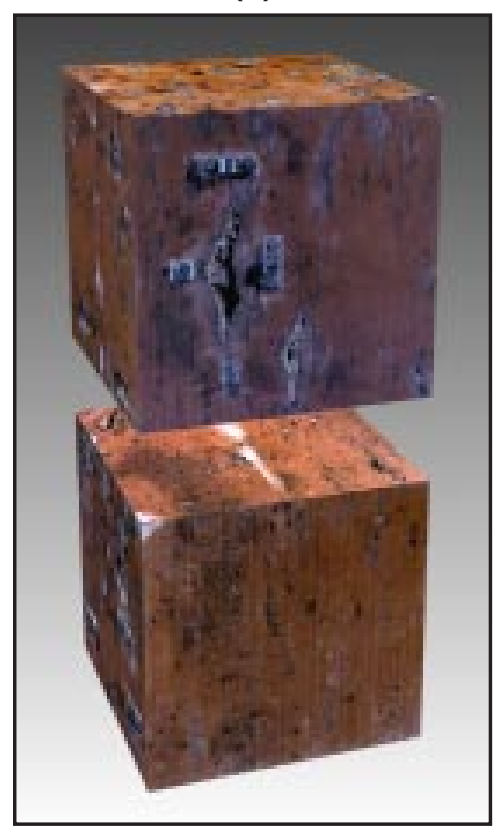

(b)

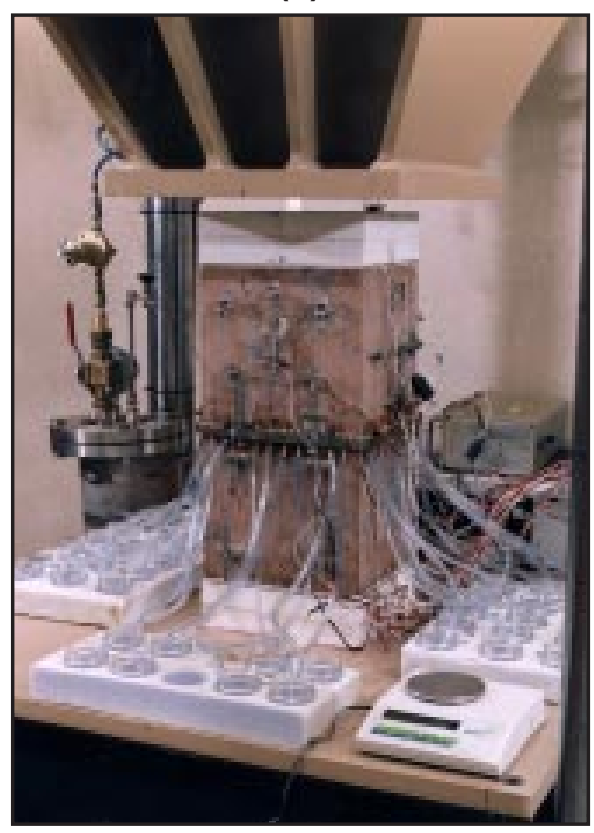

(c)

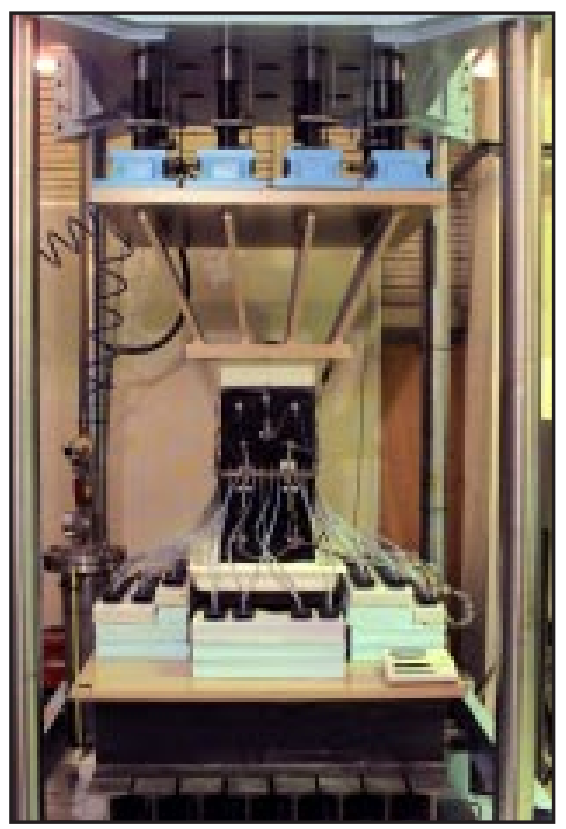

Figure 2-1. Setup of the SB3 sample

(a) Illustration of the SB3 sample for flow through a horizontal fracture. Fracture separation is exaggerated; fluid is injected into the fracture plane through small hole in the center of the top of the lower block. Some surface mounts for displacement transducers are visible.

(b) Laboratory setup for SB3, Experiment 7051. The radial flow field probes the effect of anisotropy of the rock fabric on the flow in the fracture. Diagnostics are average axial stress across the fracture plane, temperature at 12 points inside the sample, surface displacements along 16 baselines on the vertical surfaces of the sample, and fluid flow monitored at 38 locations at intervals of about $2.5 \mathrm{~cm}$ along the perimeter of the fracture. (c) Laboratory setup for SB3, experiments subsequent to 7051. This is similar to the setup for Experiment 7051, but includes a neoprene jacket on the external vertical faces of the sample. 


\section{Figures}

(a)

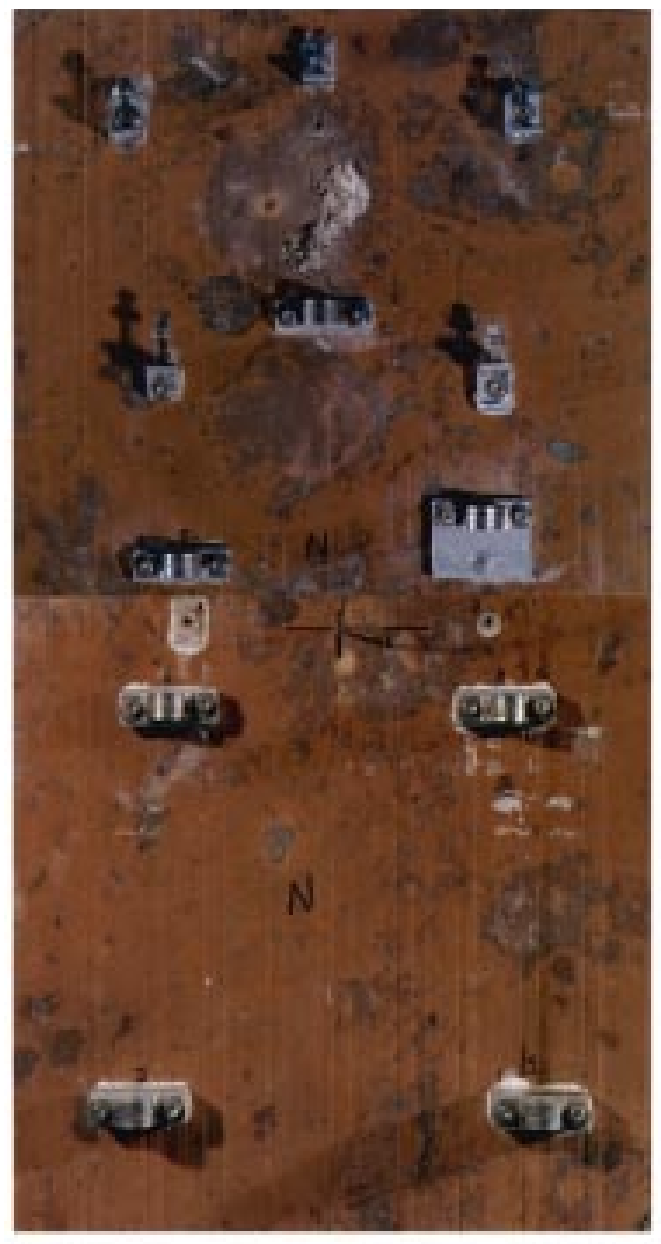

(c)

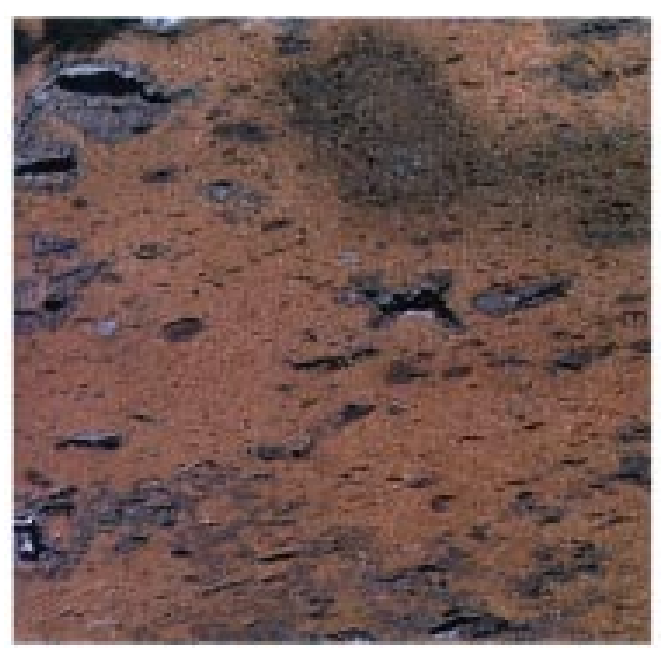

(b)

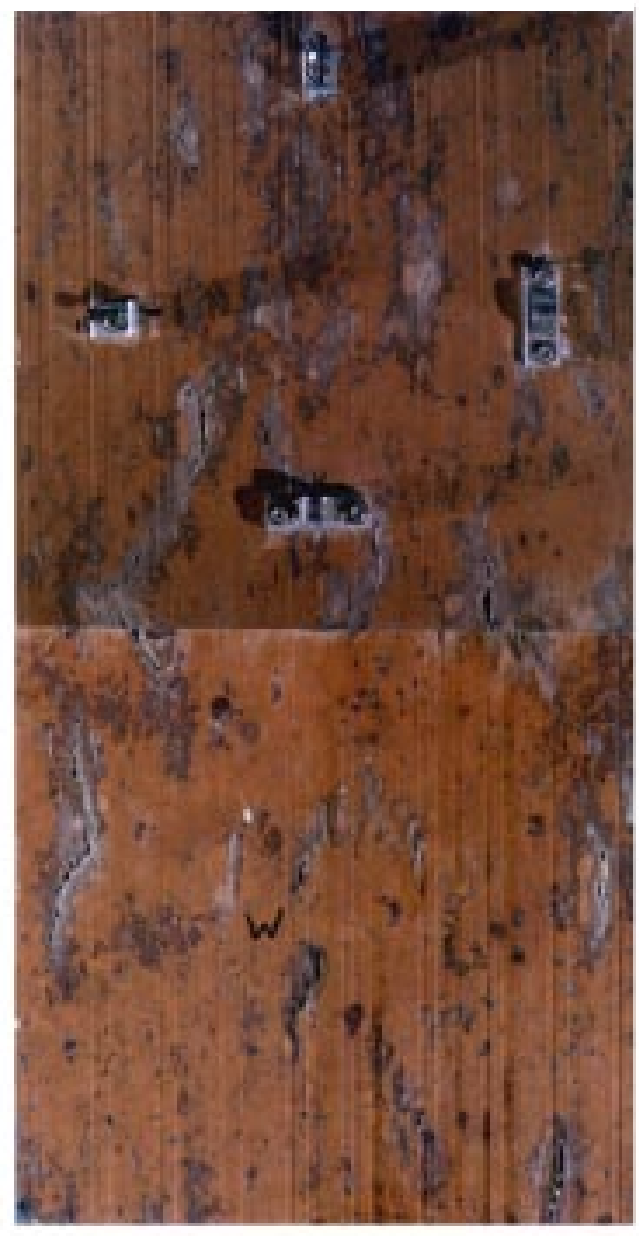

(d)

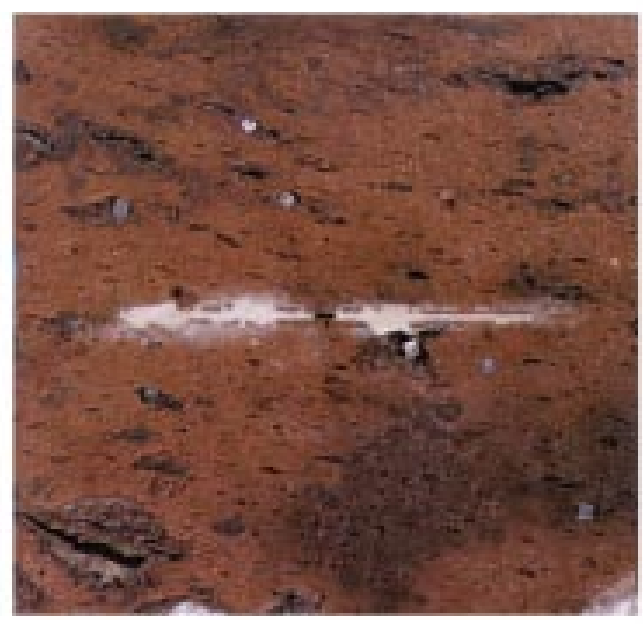

Figure 2-2. Crack, fracture, and vug distribution of SB3; (a) north face; (b) west face; (c) bottom of top block (fracture surface); (d) top of bottom block (fracture surface) 
(e)

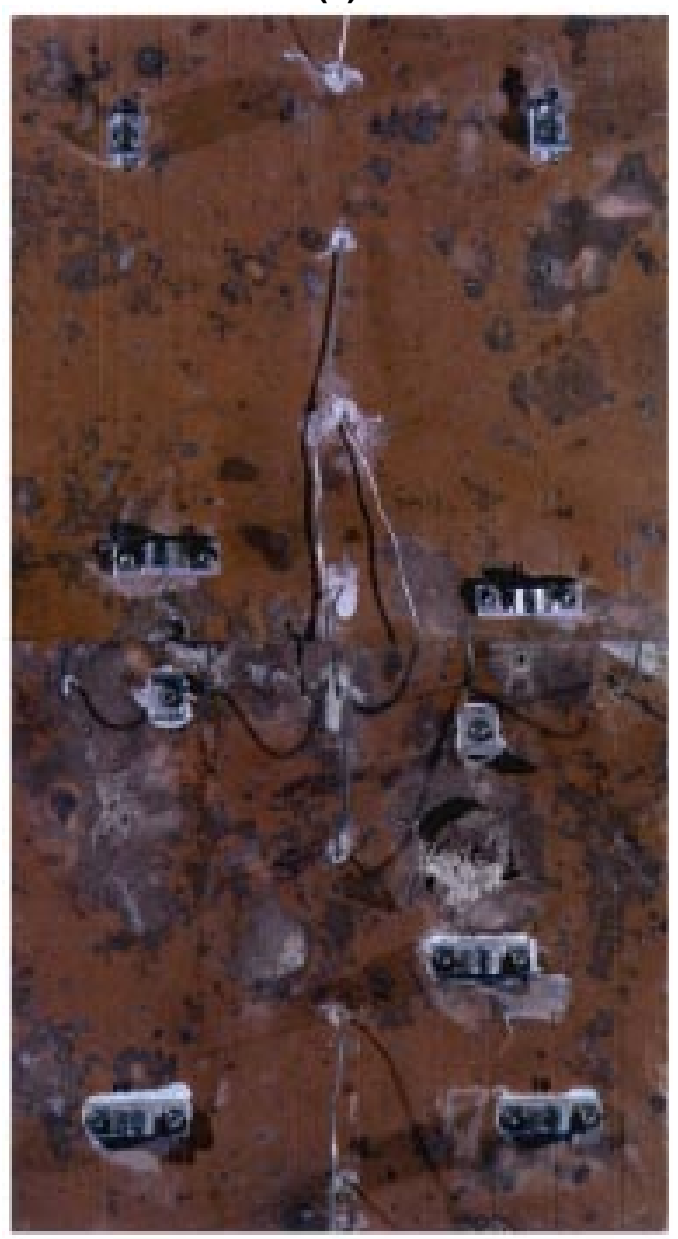

(g)

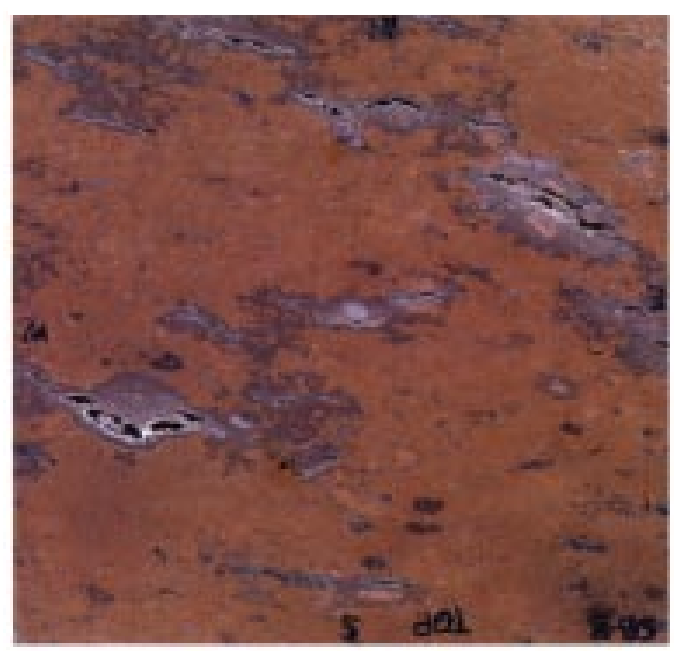

(f)

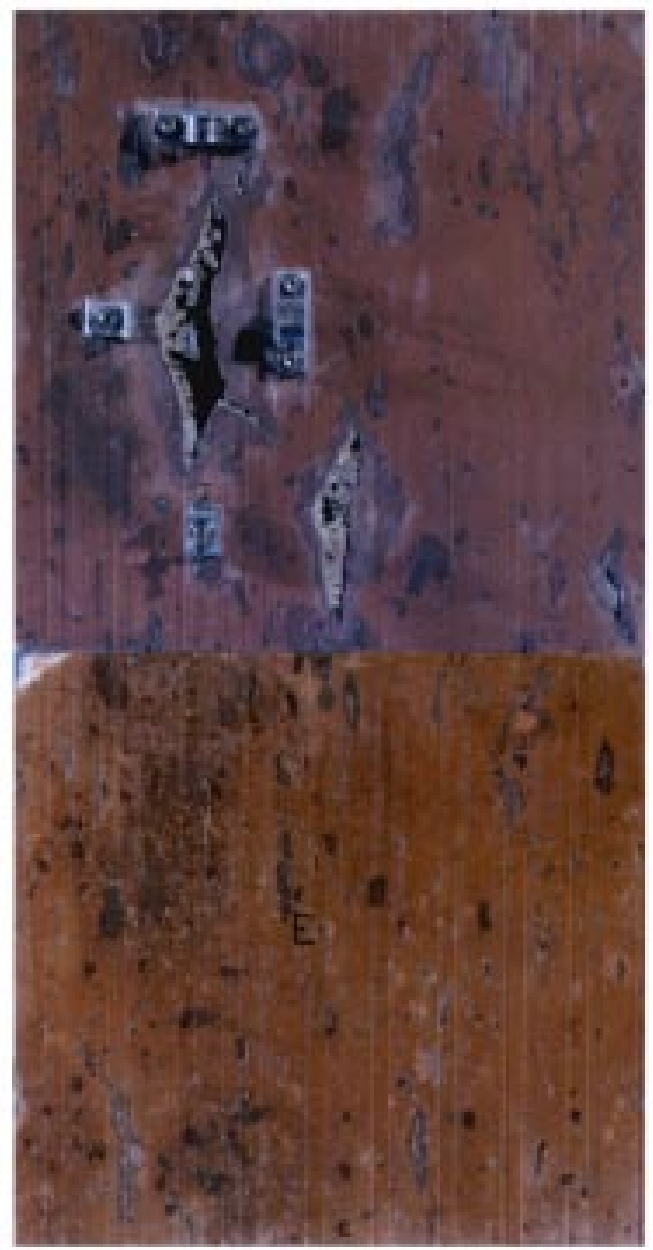

(h)

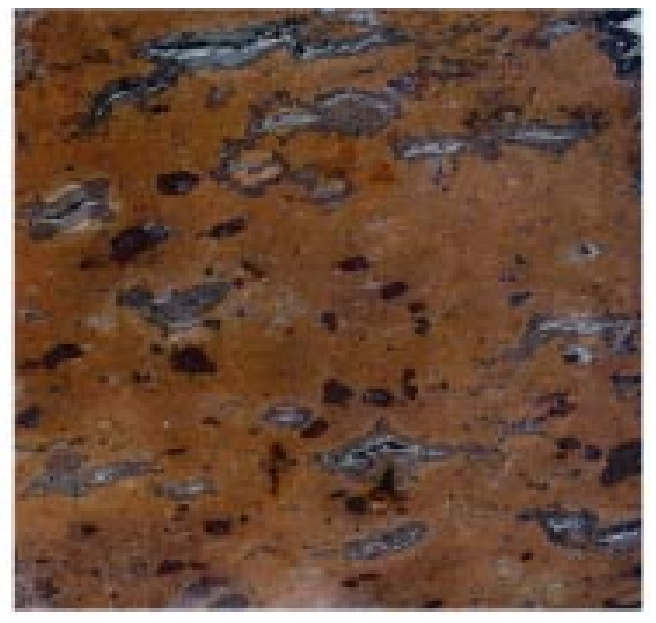

Figure 2-2. Crack, fracture, and vug distribution of SB3; (e) south face; (f) east face; (g) bottom of the bottom block; and (h) top of the top block 


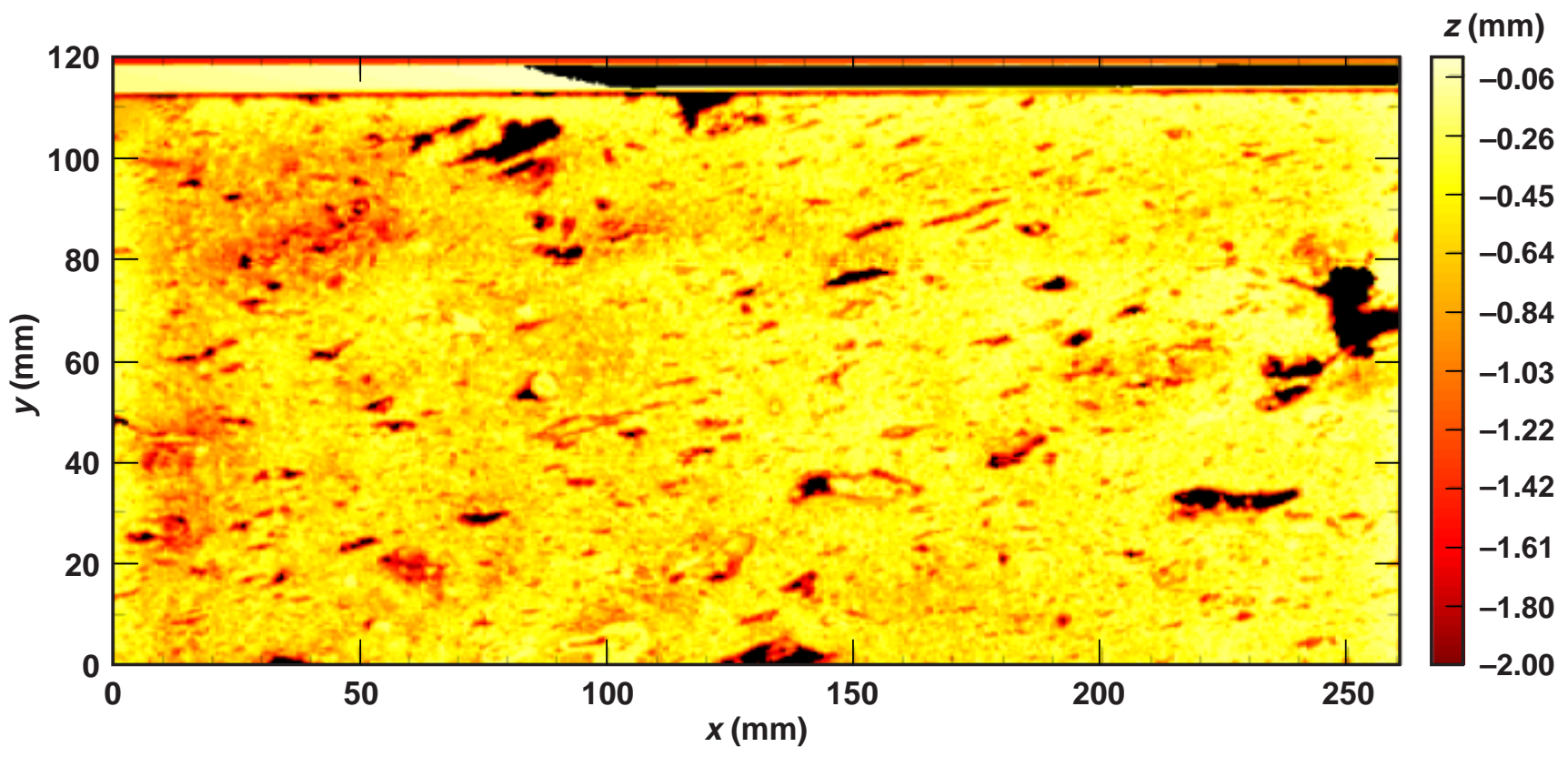

Figure 2-3. Surface topography data collected at 0.5-mm intervals; shading represents surface relief. 


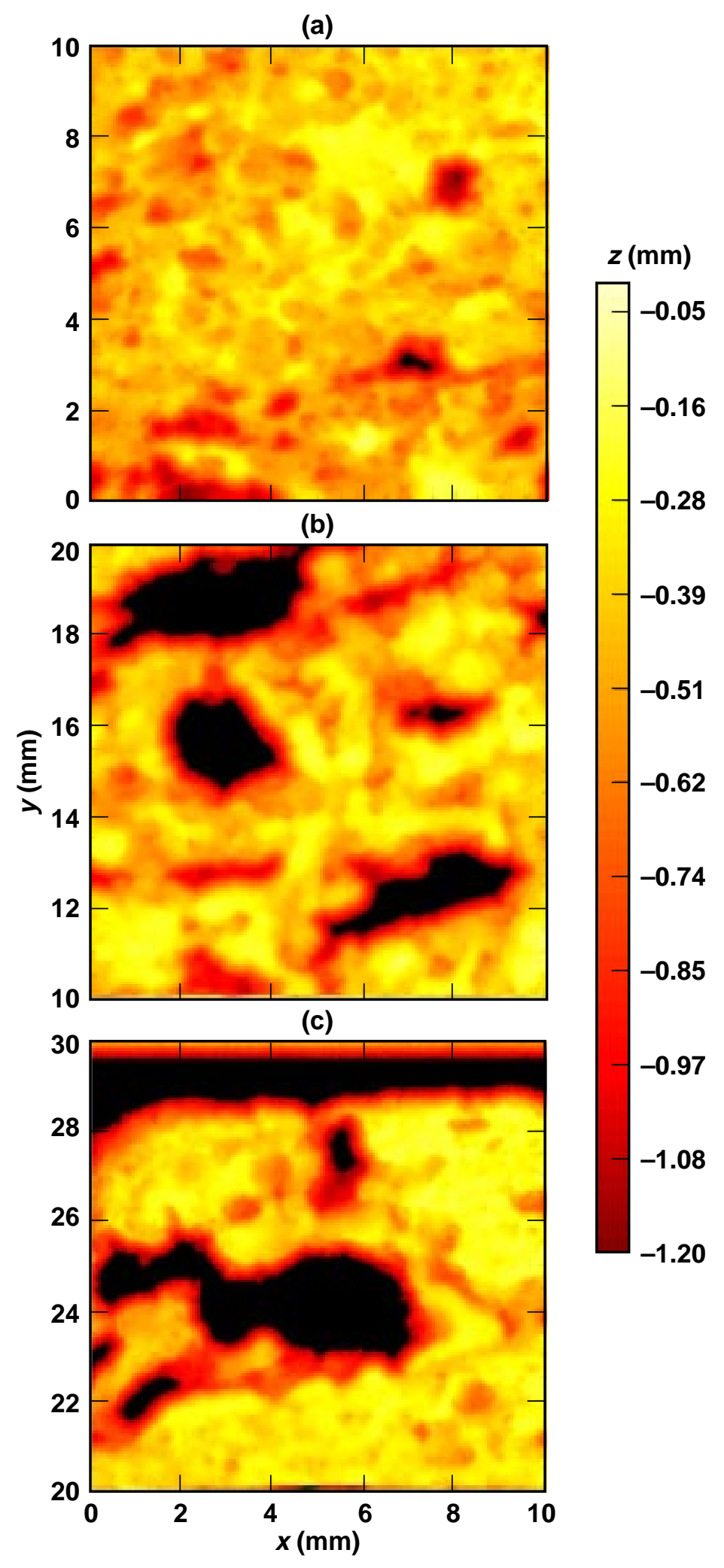

Figure 2-4. Surface topography data collected at 0.05-mm intervals; three detail views (a), (b), (c) 


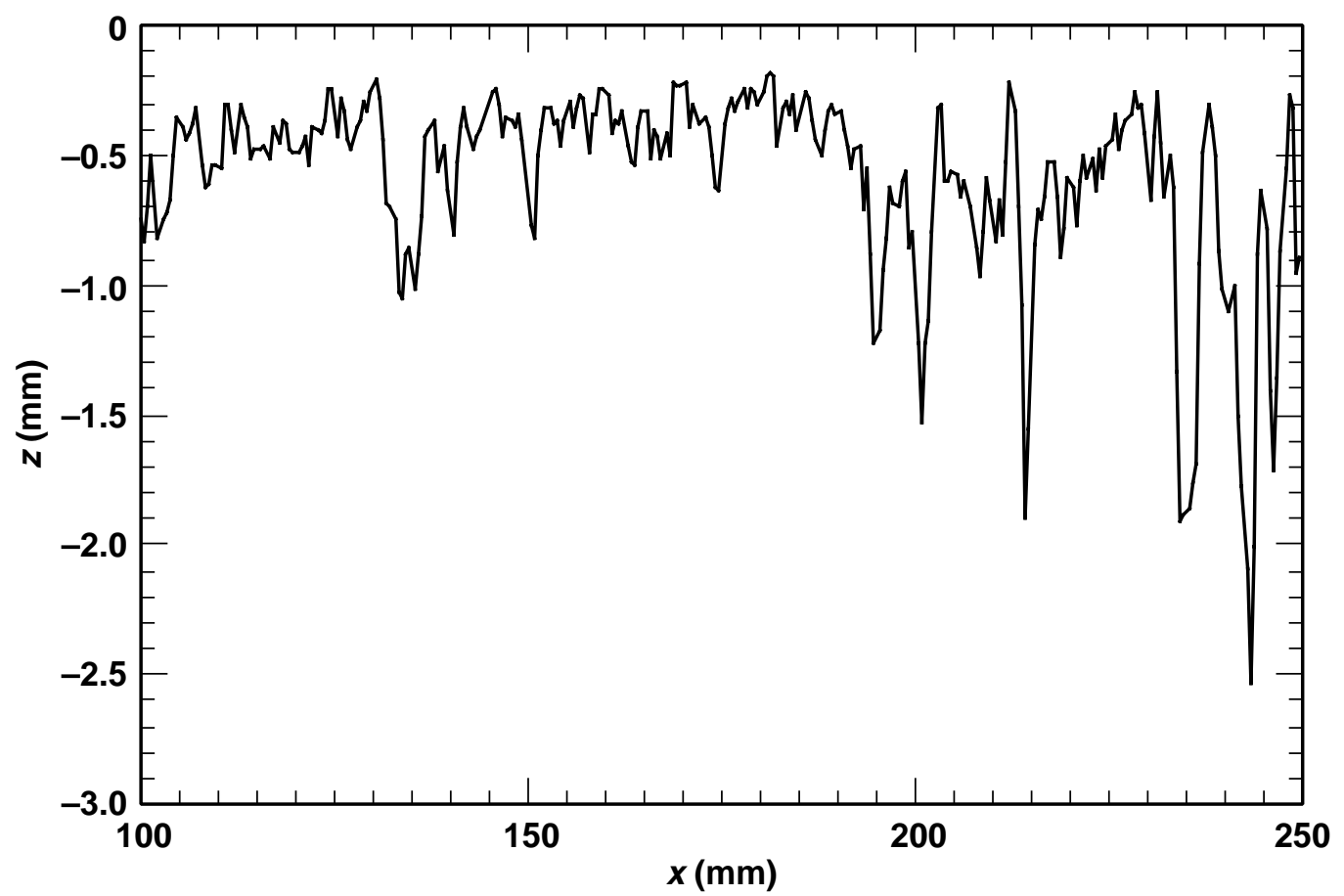

Figure 2-5. Representative profile taken through the surface topography data
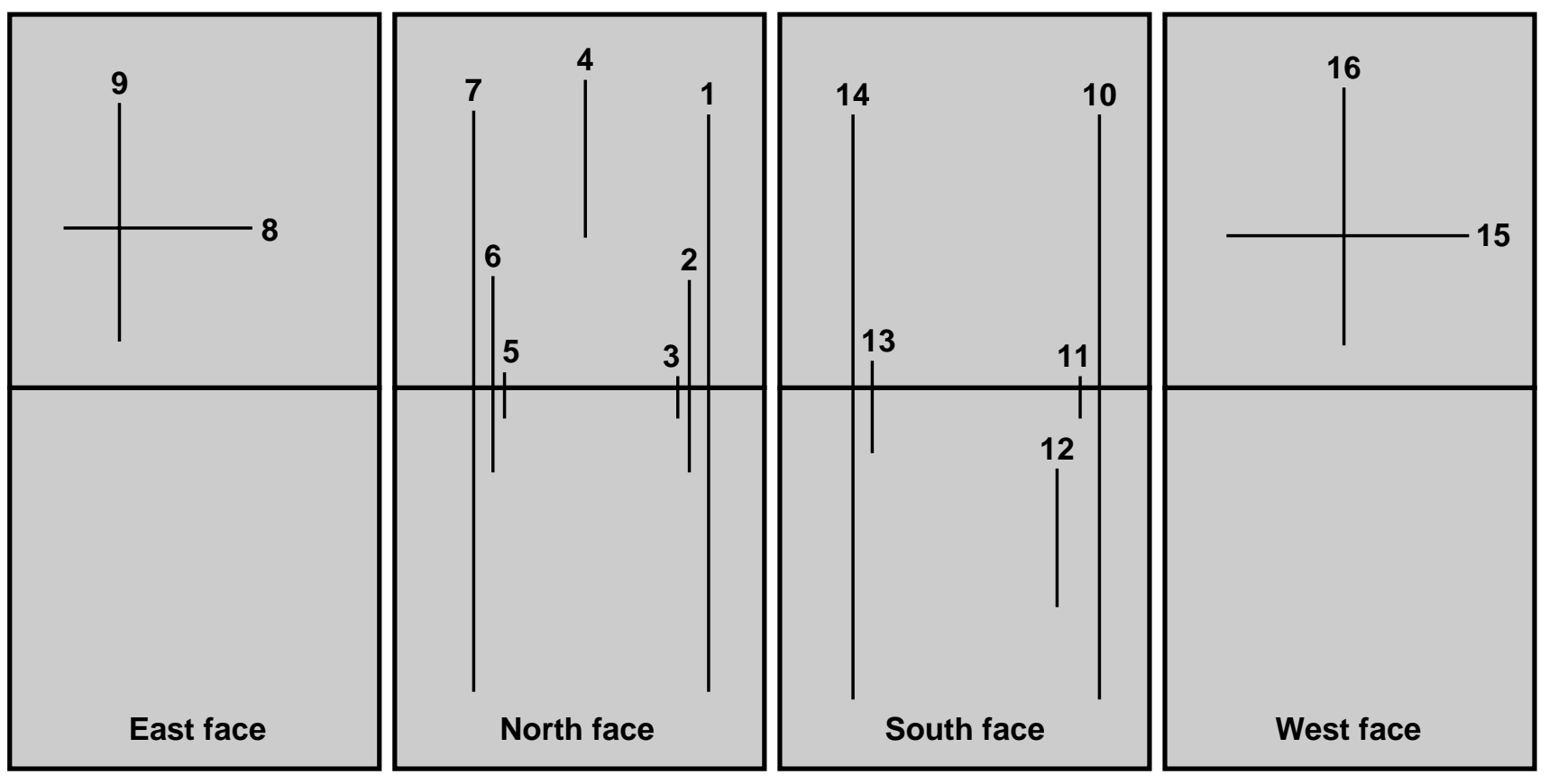

Figure 2-6. Layout of SB3 LVDTs 


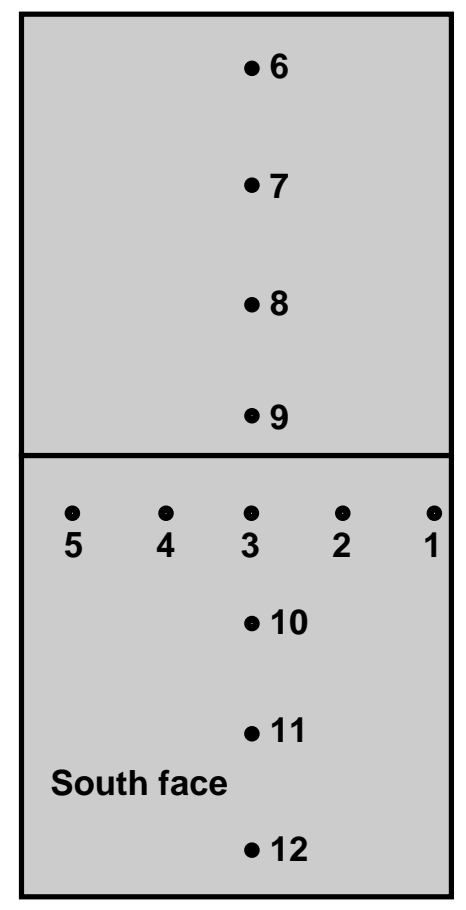

Figure 2-7. Layout of SB3 thermocouples

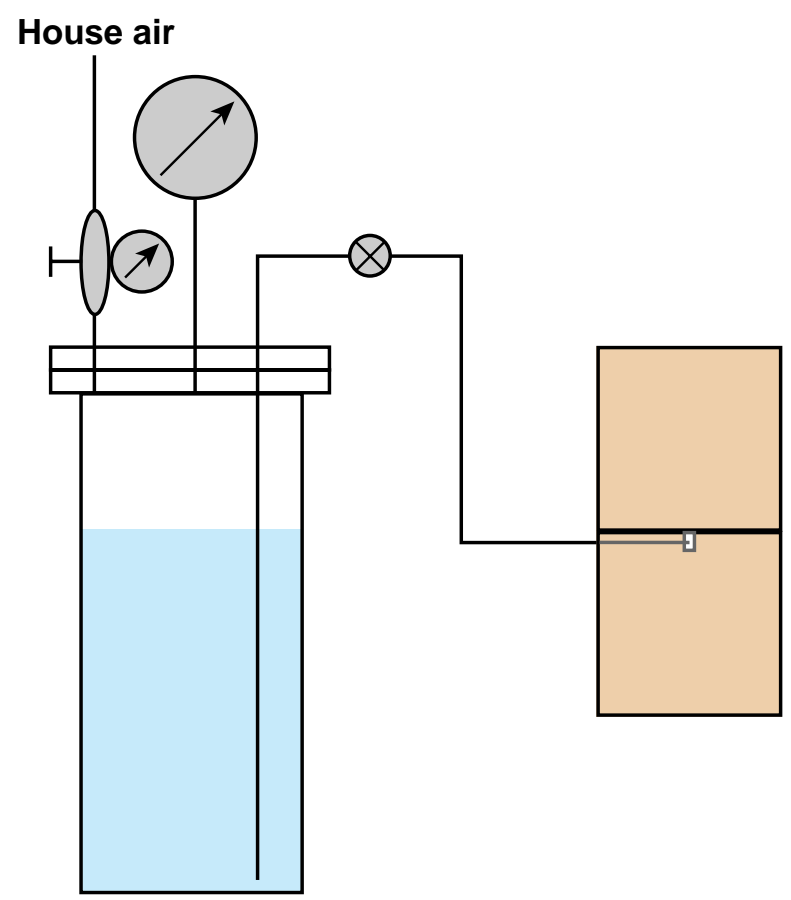

Figure 2-8. SB3 fluid-flow system; the source cavity is about $2 \times 6 \times 10 \mathrm{~mm}$, centered in the upper face of the bottom block. 

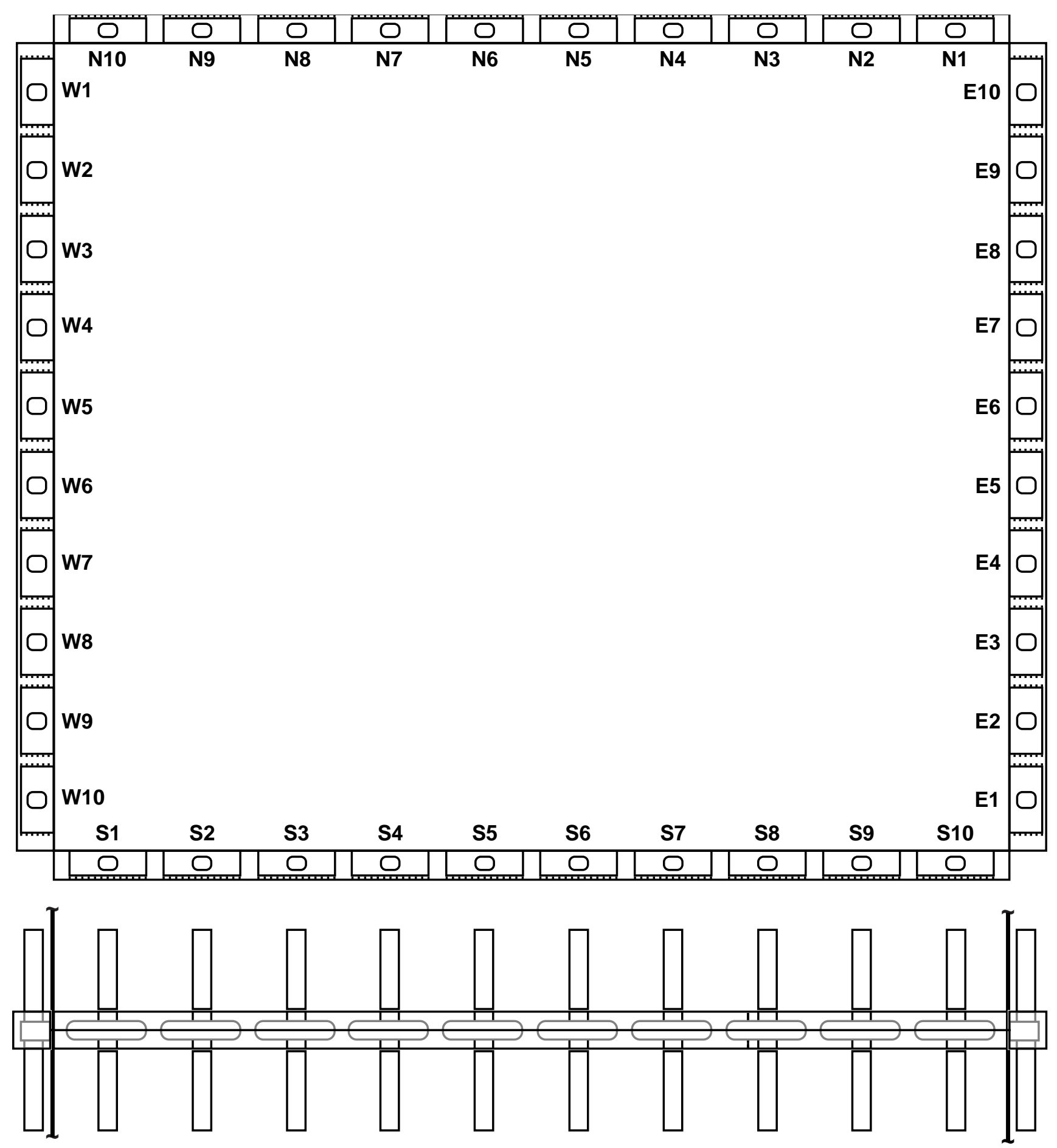

Figure 2-9. SB3 fluid-collection manifold 


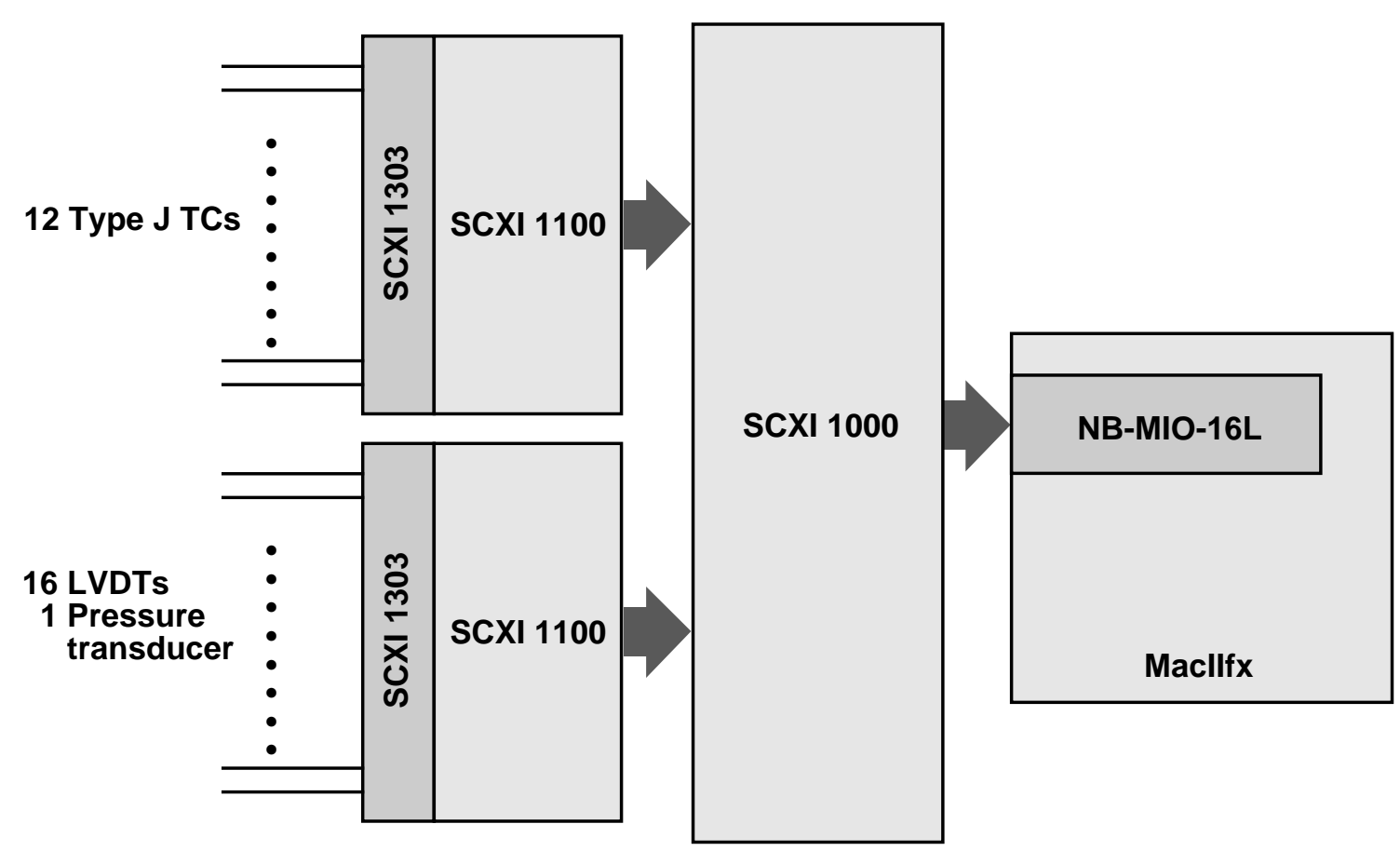

Figure 2-10. SB3 data-acquisition system

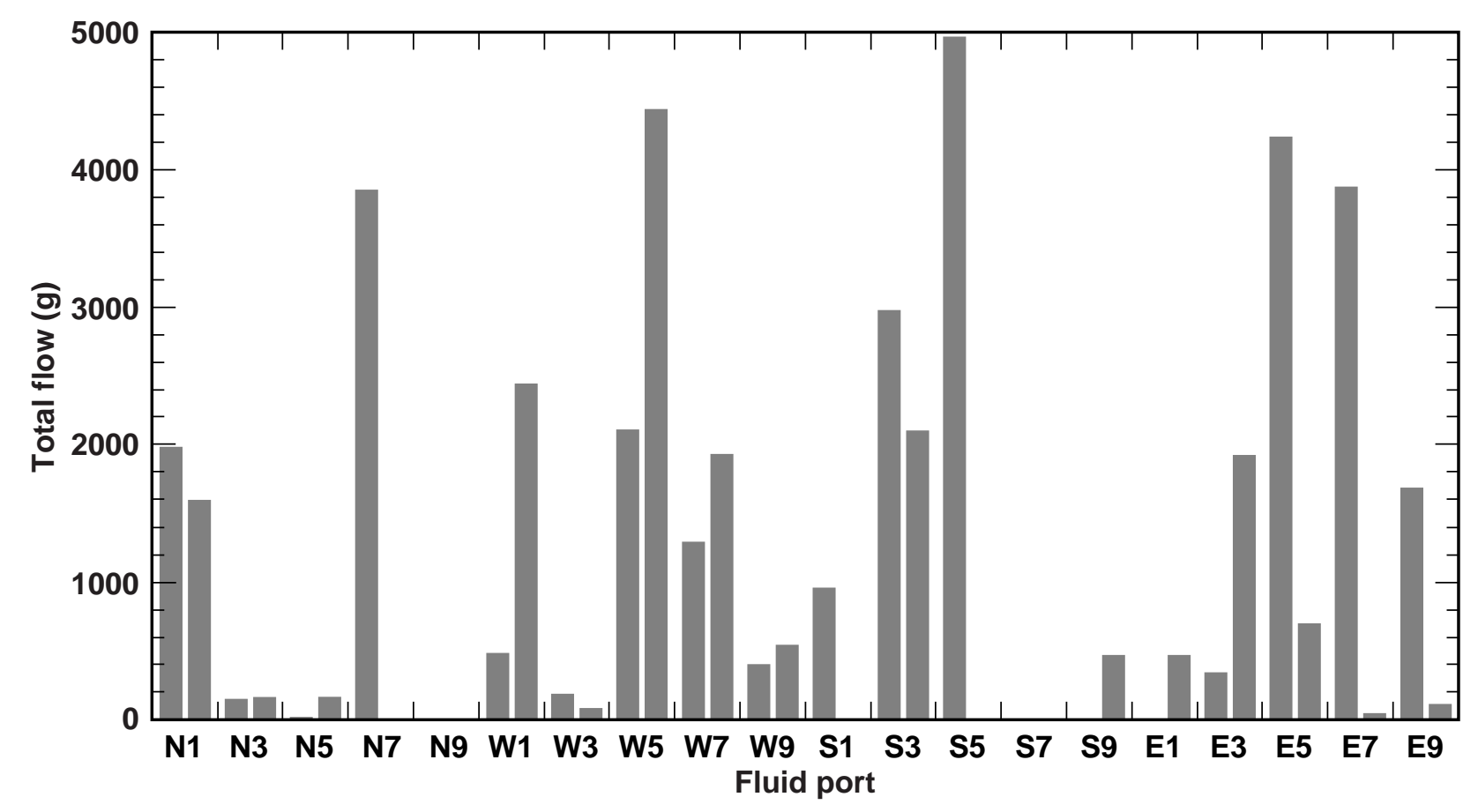

Figure 2-11. Total flow out of each port for Run 7195 


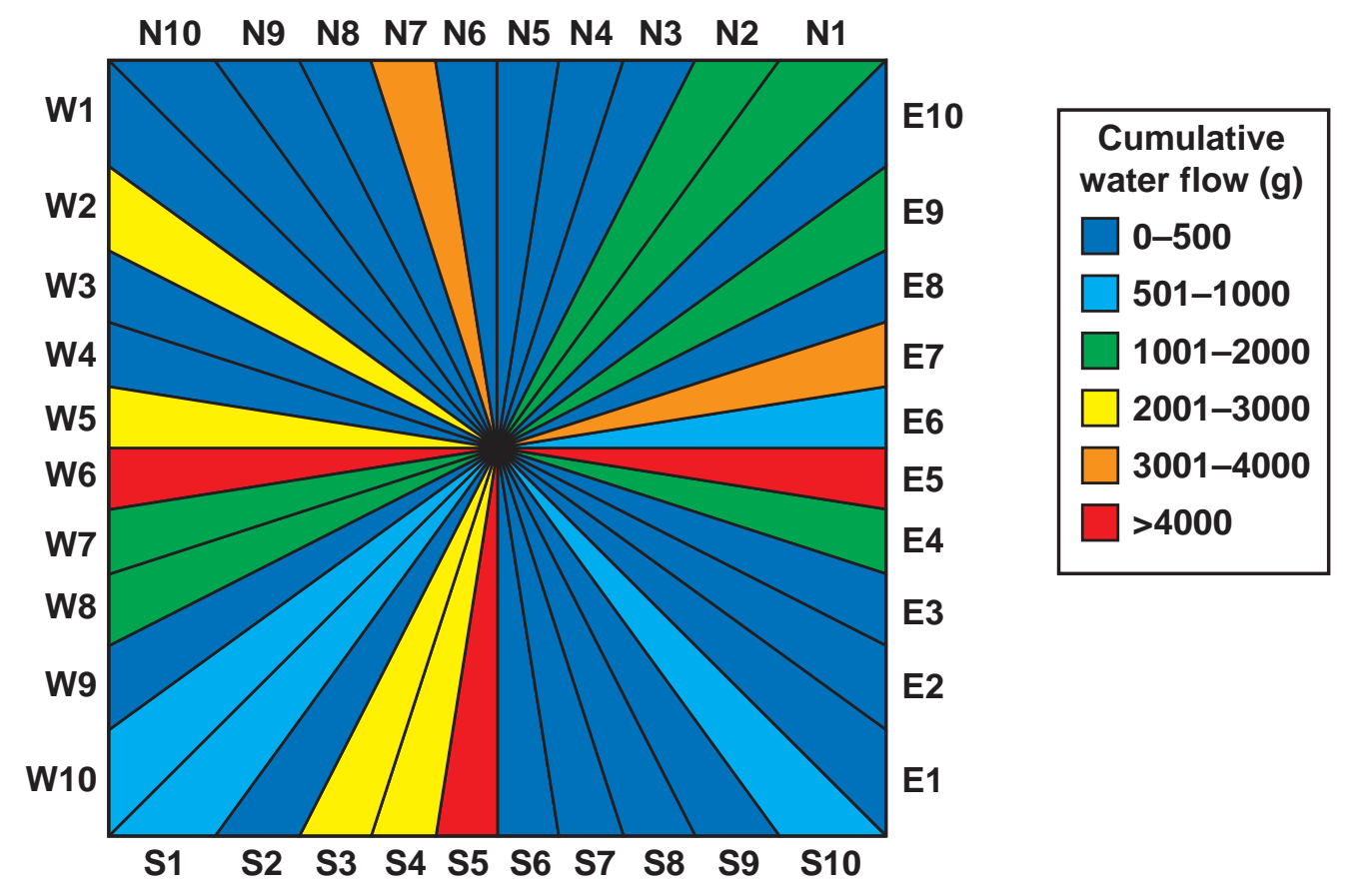

Figure 2-12. Spatial representation of total flow in plane of fracture for SB3 during Run 7195; this representation assumes linear flow paths between the injection point at the center of the fracture plane and each port. The highest flows occur in the east-west direction, which is parallel to the textural anisotropy shown in Figure 2-3.

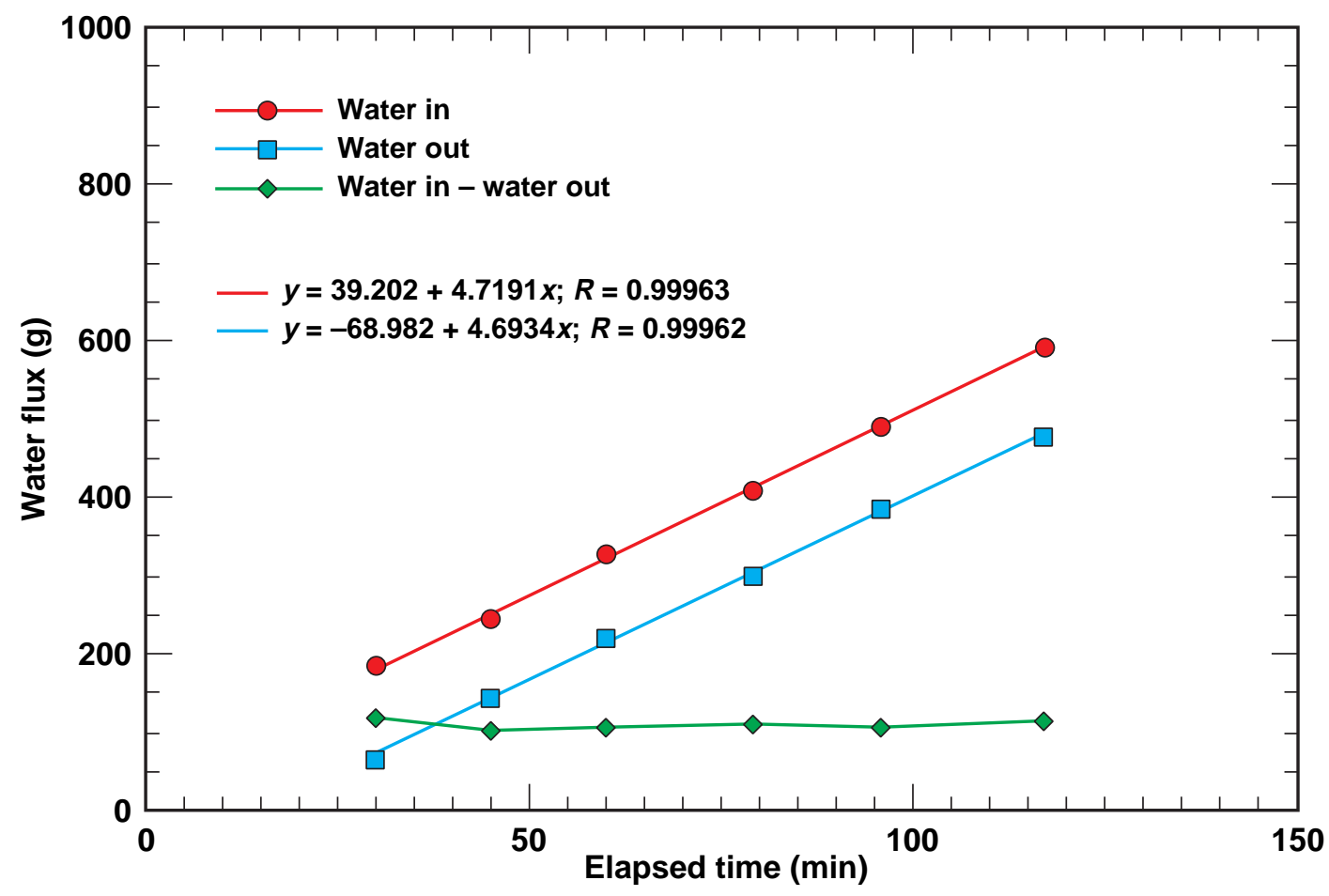

Figure 2-13. Initial fluid flow into the unsaturated rock for Experiment 719501. Approximately $110 \mathrm{~g}$ water was imbibed into the dry, porous rock along the fracture plane. This transient lasted no longer than $30 \mathrm{~min}-$ utes. Subsequently, water flux into the fracture very nearly equaled water flux out of the fracture. $R$ is the correlation coefficient for the linear regression. 


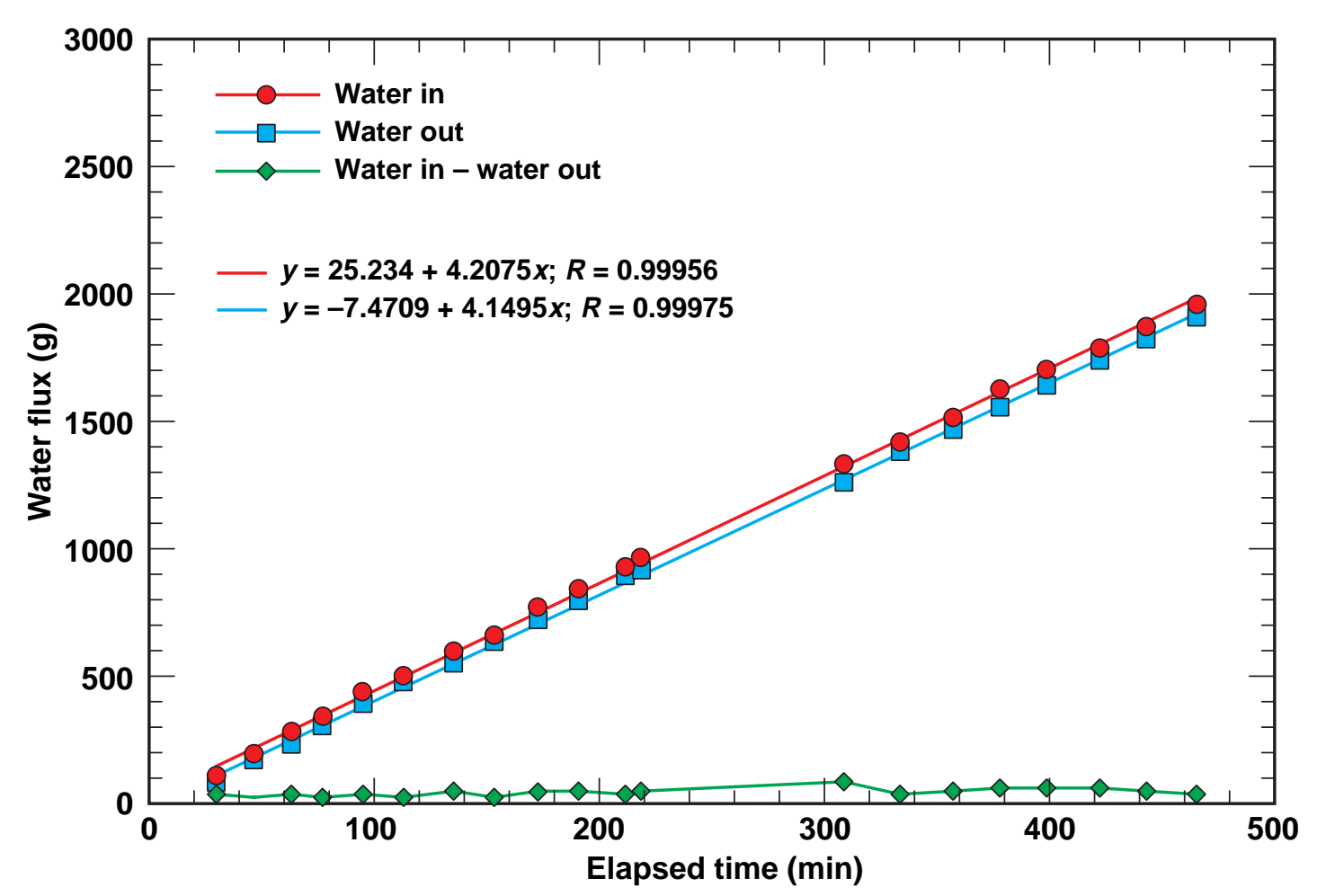

Figure 2-14. Flow versus time for Experiment 719601, showing an initial, small imbibition transient

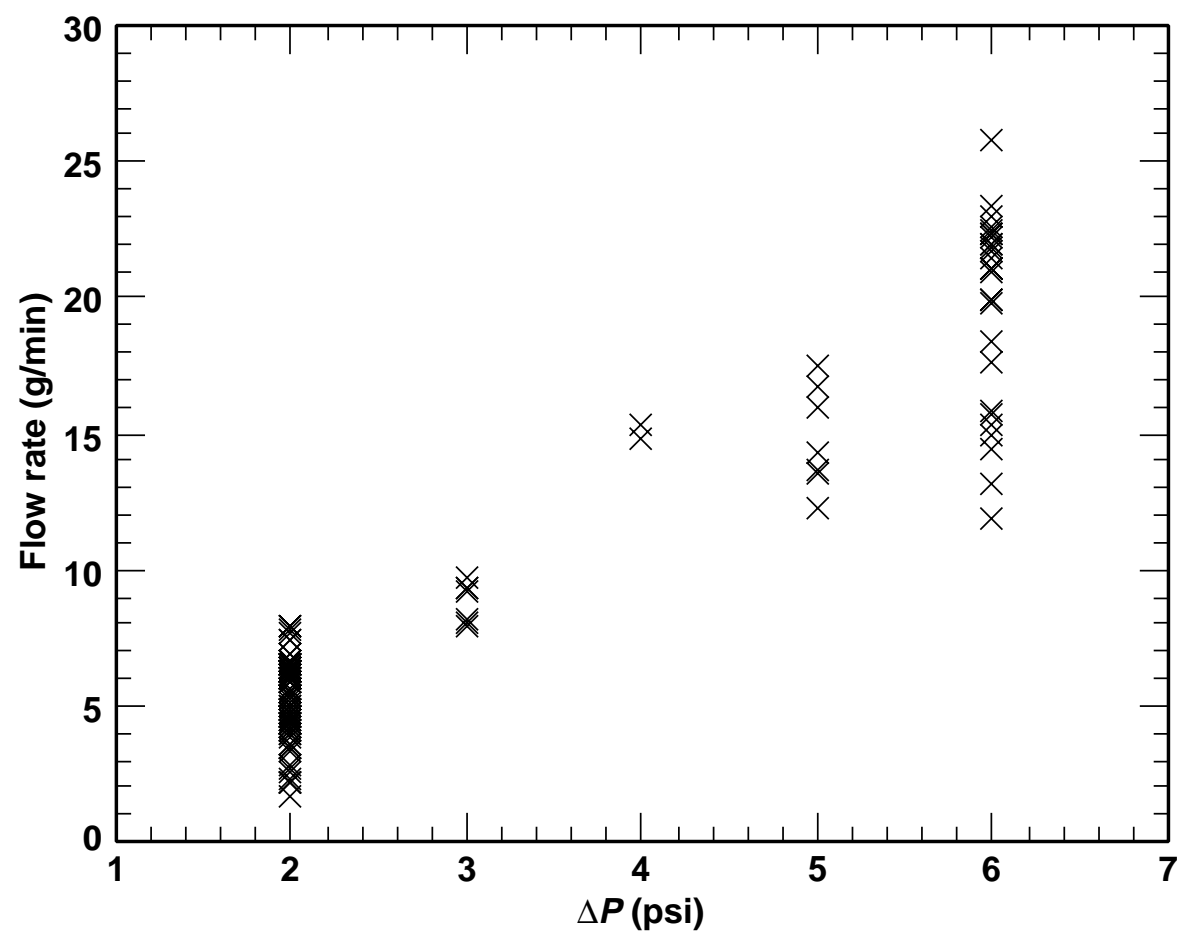

Figure 2-15. Water flow rate versus pressure differential; the data at each $\Delta P$ are for various axial stress and temperature conditions. 


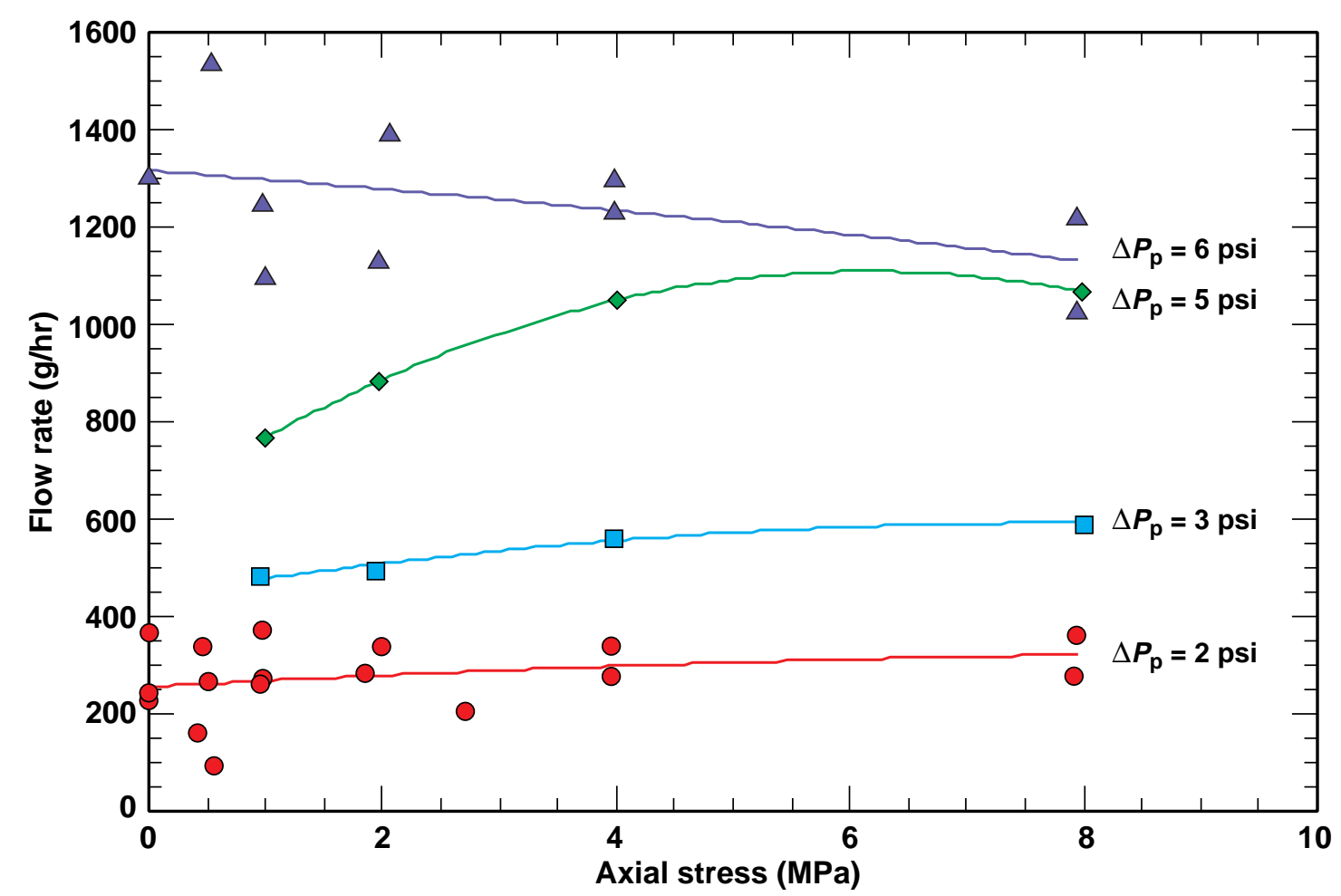

Figure 2-16. Water flow rate versus axial stress; the lines are drawn as an aid to the eye, only. Water flow rate is independent of mean fracture aperture, as parameterized through axial stress, owing to the intersection of rock porosity with the uncorrelated fracture surfaces.

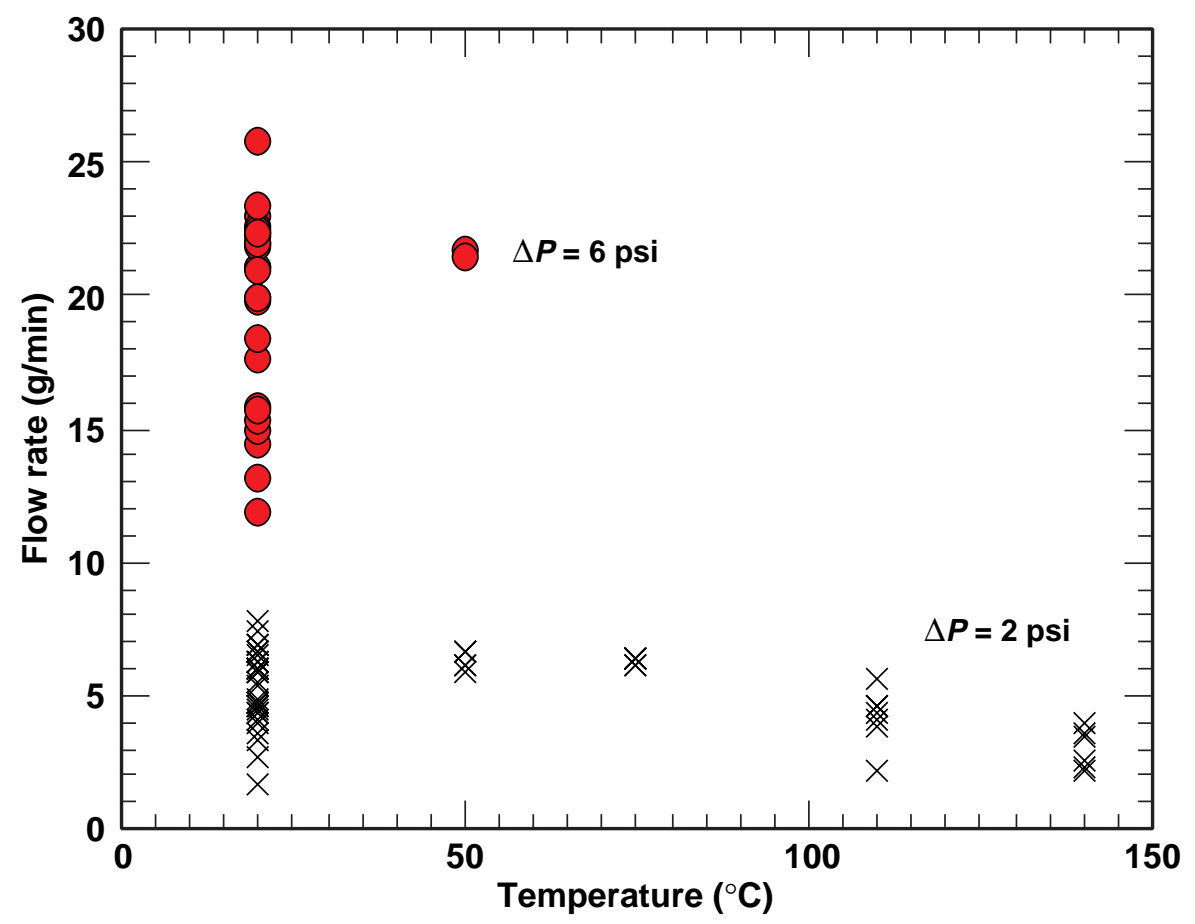

Figure 2-17. Water flow rate versus temperature. The flow rate is independent of temperature. For clarity, only data for fluid-pressure differentials of 2 and 6 psi are shown. 


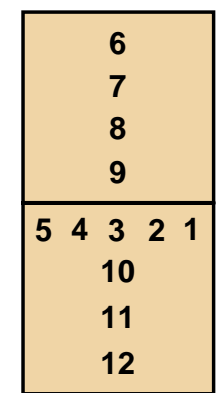

Thermocouple positions

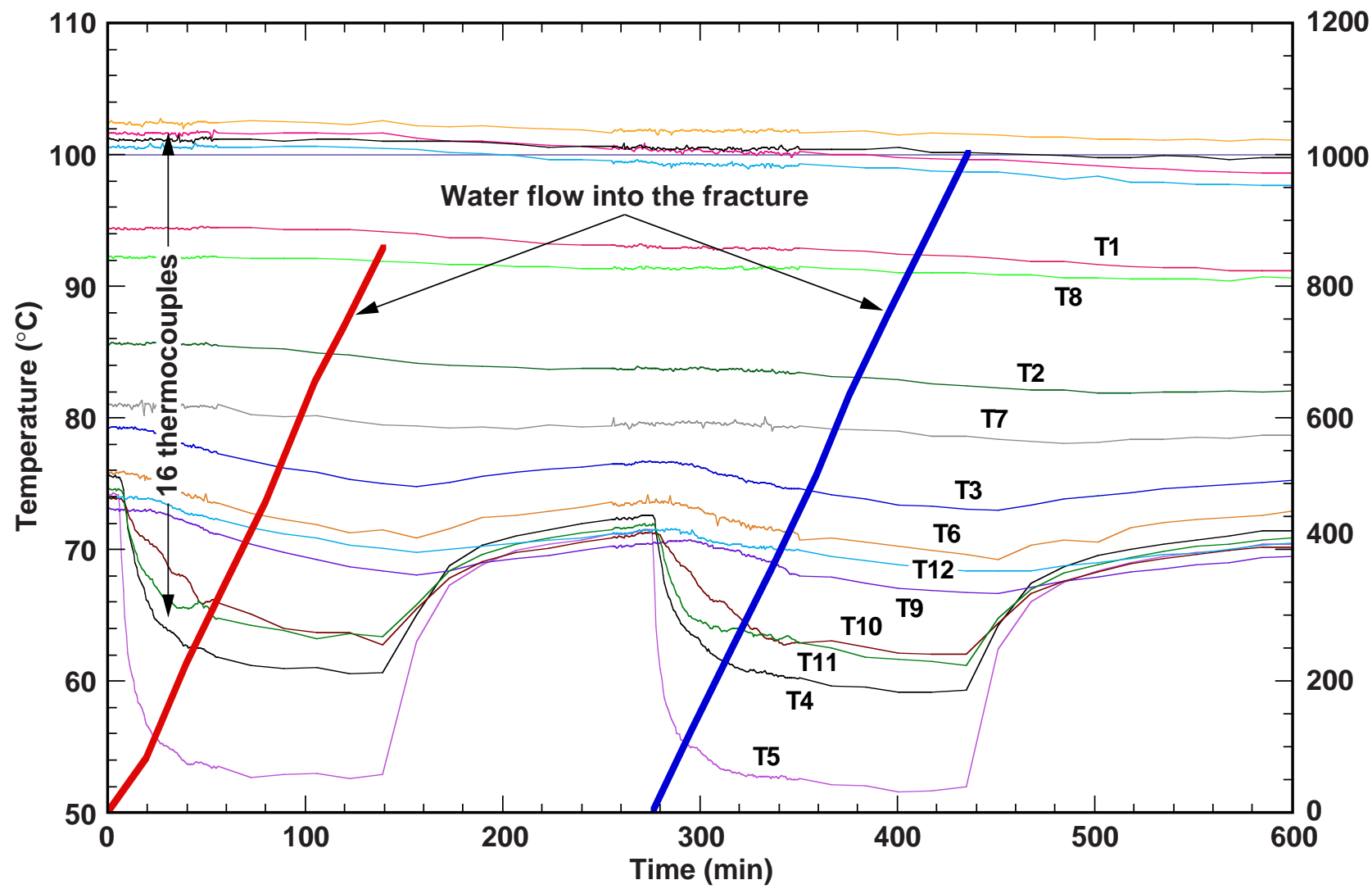

Figure 2-18. Temperature and cumulative water flow. Nominal sample temperature is $75^{\circ} \mathrm{C}$. The experimental $T$ versus $t$ curves are excellent solutions to the heat-flow equation for the temperature of a semi-infinite slab with a constant-temperature boundary condition. 
(a)

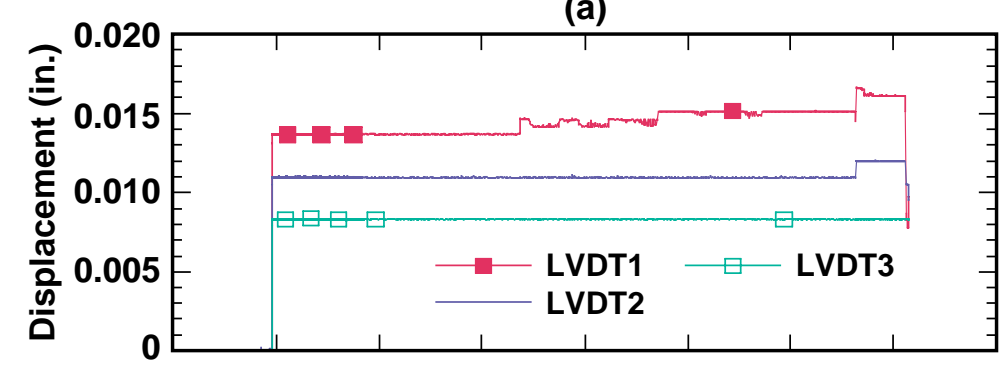

(b)

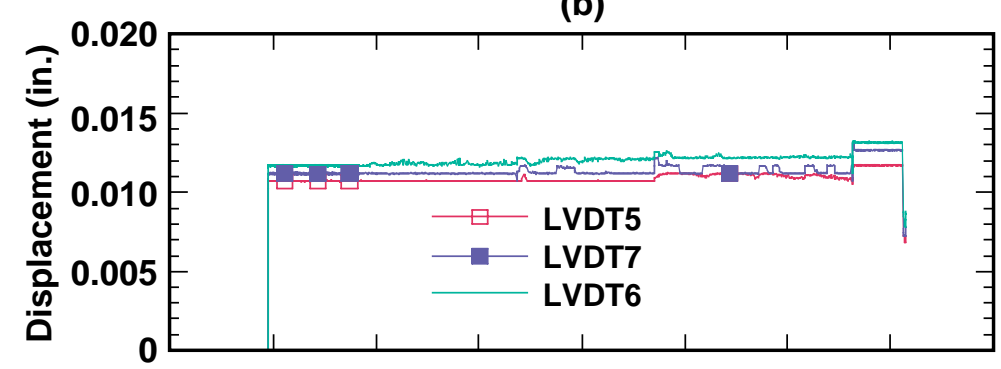

(c)

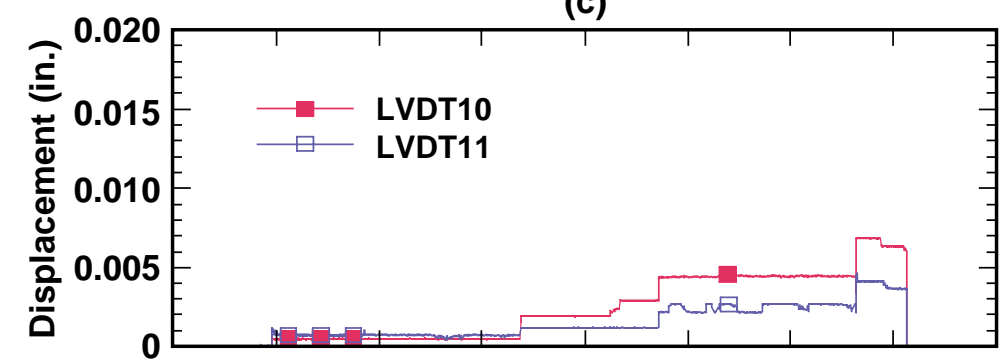

(d)

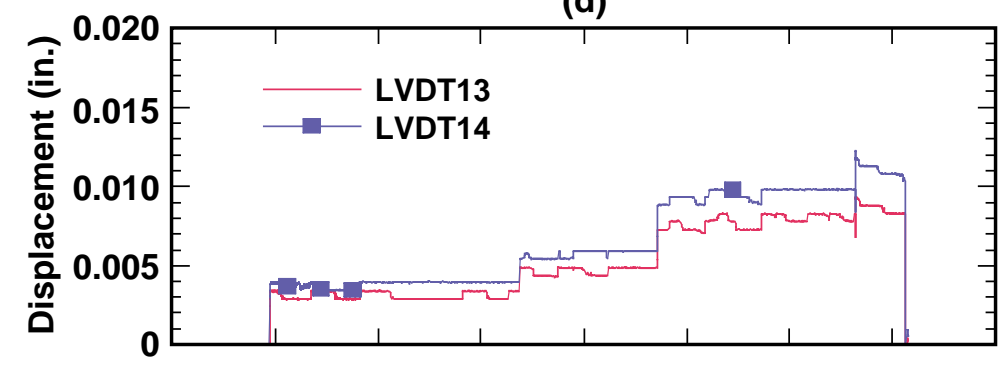

(e)

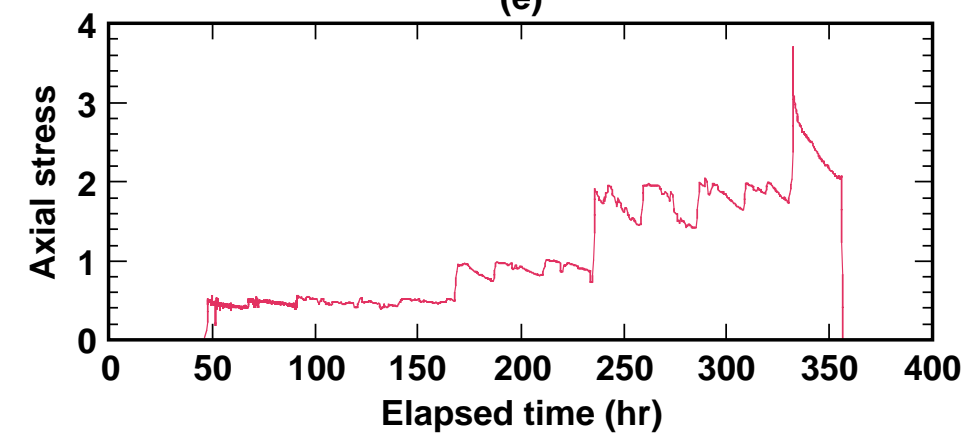

Figure 2-19. Displacement data for first loading cycle of Run 7195; solid symbols indicate transducers measuring over relatively long gage lengths that include both matrix material and the fracture, and open symbols indicate measurements primarily over the fracture. (a) LVDTs 1, 2, and 3 (north face, western half) (b) LVDTs 5, 6, and 7 (north face, eastern half) (c) LVDTs 10 and 11 (south face, eastern half) (d) LVDTs 13 and 14 (south face, western half) and (e) Axial stress 


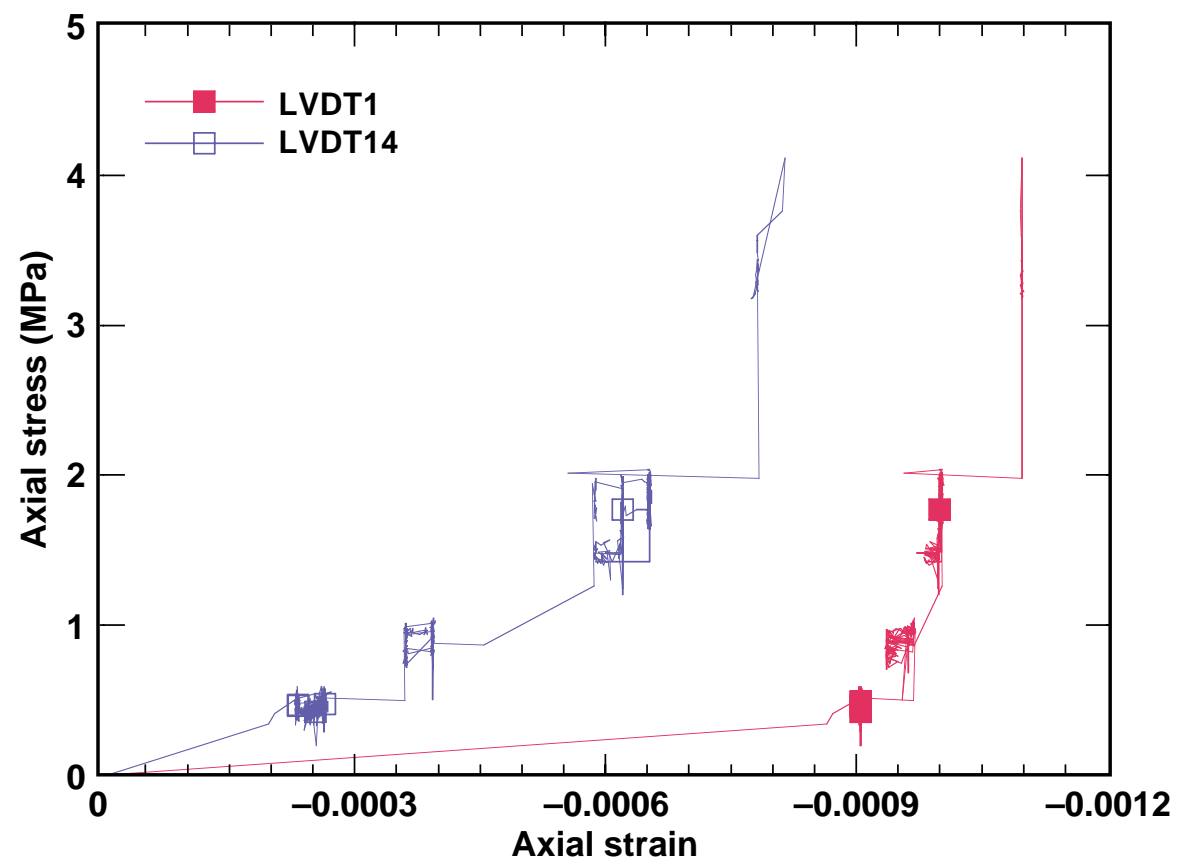

Figure 2-20. Stress-strain data for Transducers 1 and 14 for the first loading cycle of Run 7195

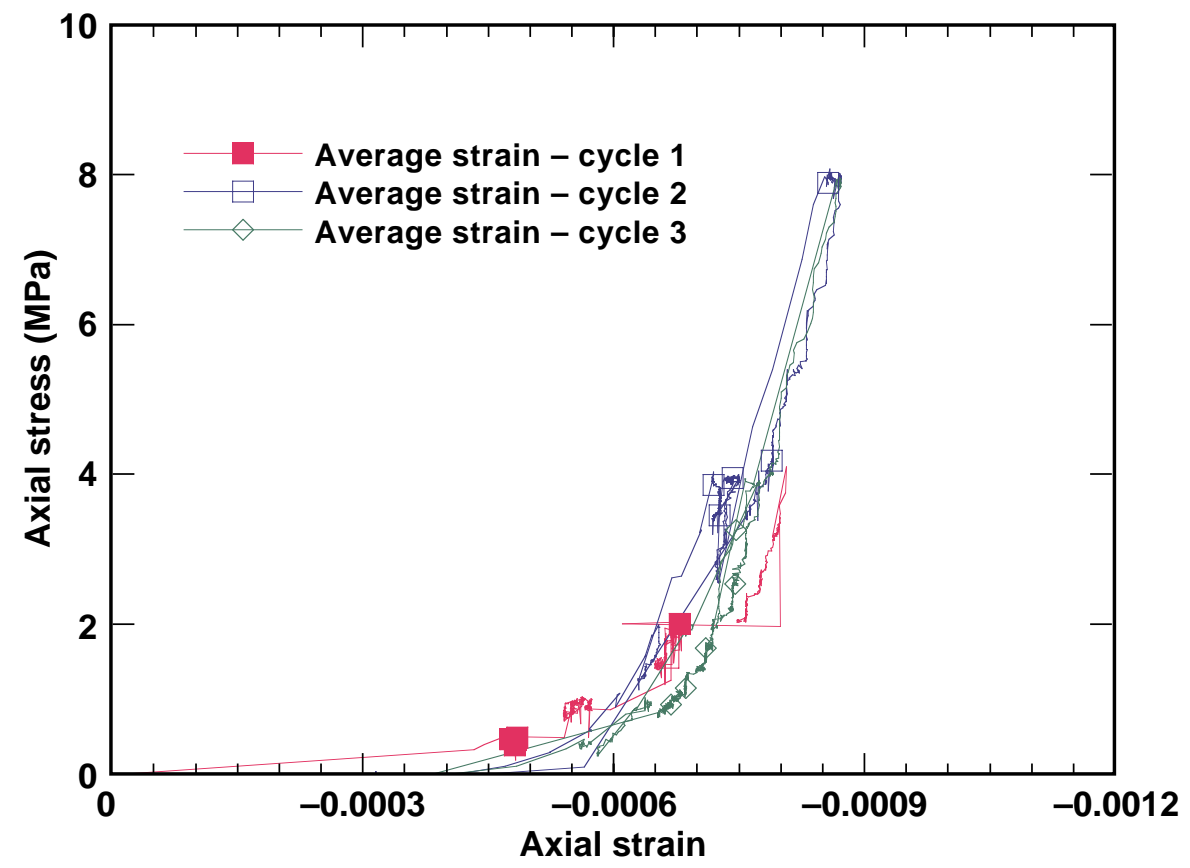

Figure 2-21. Average stress-strain for long transducers measured during three loading cycles of Run 7195 
(a)

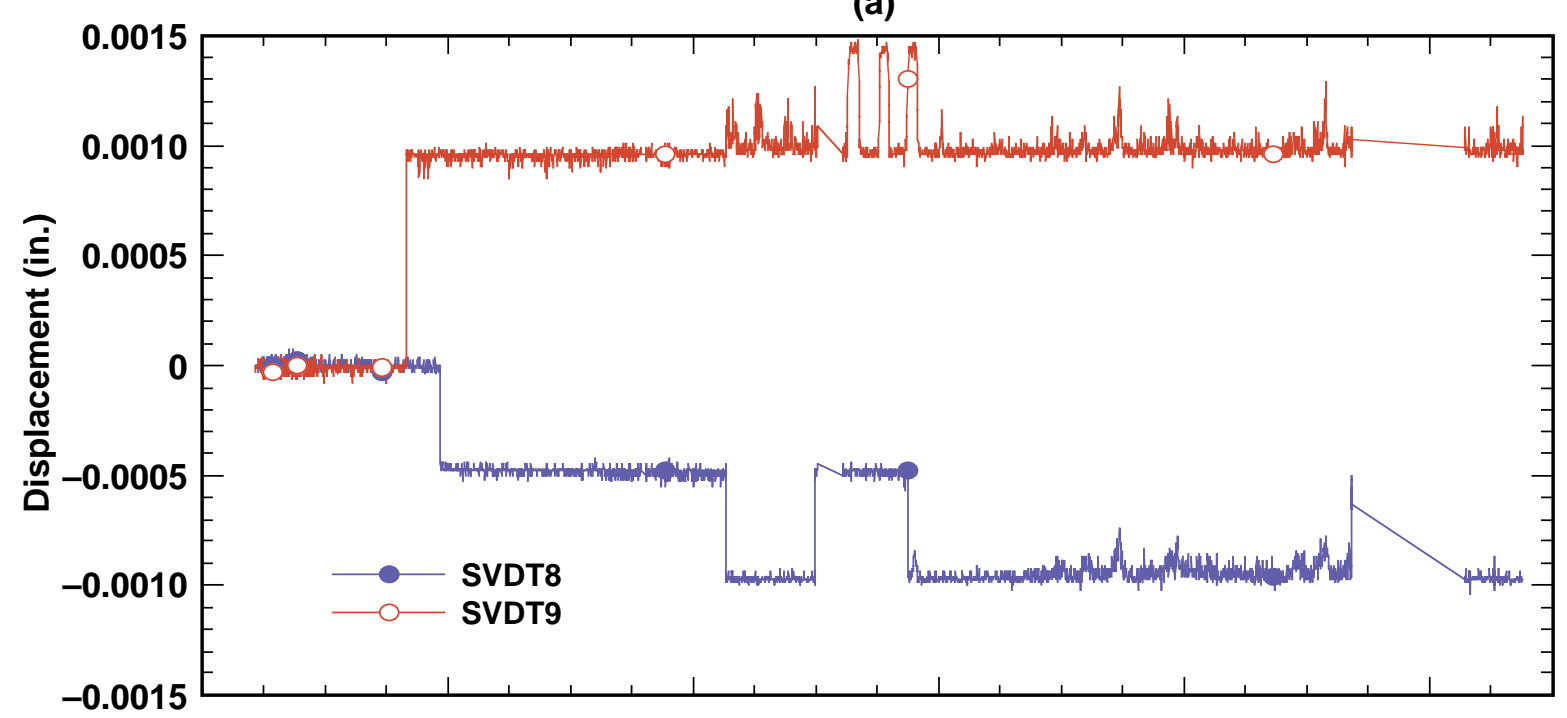

(b)

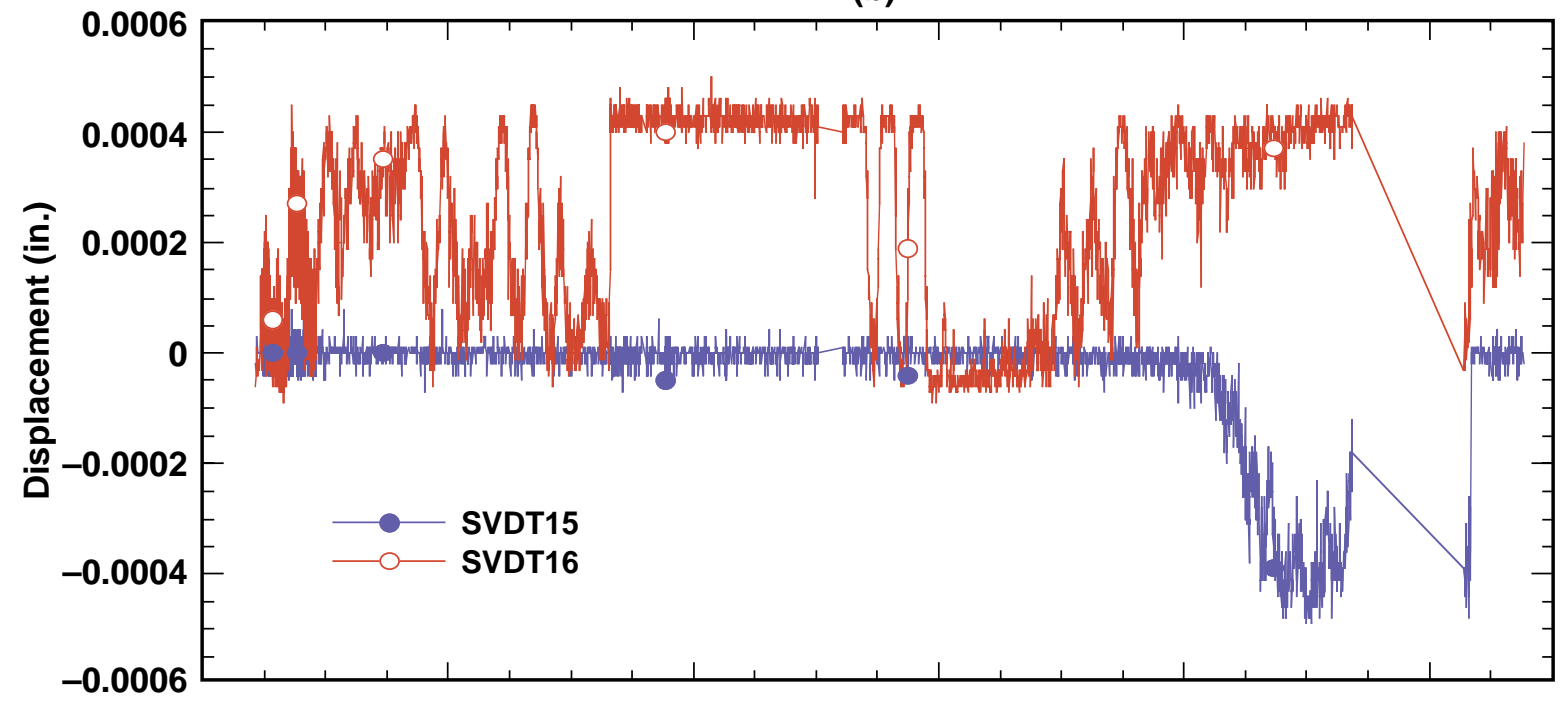

(c)

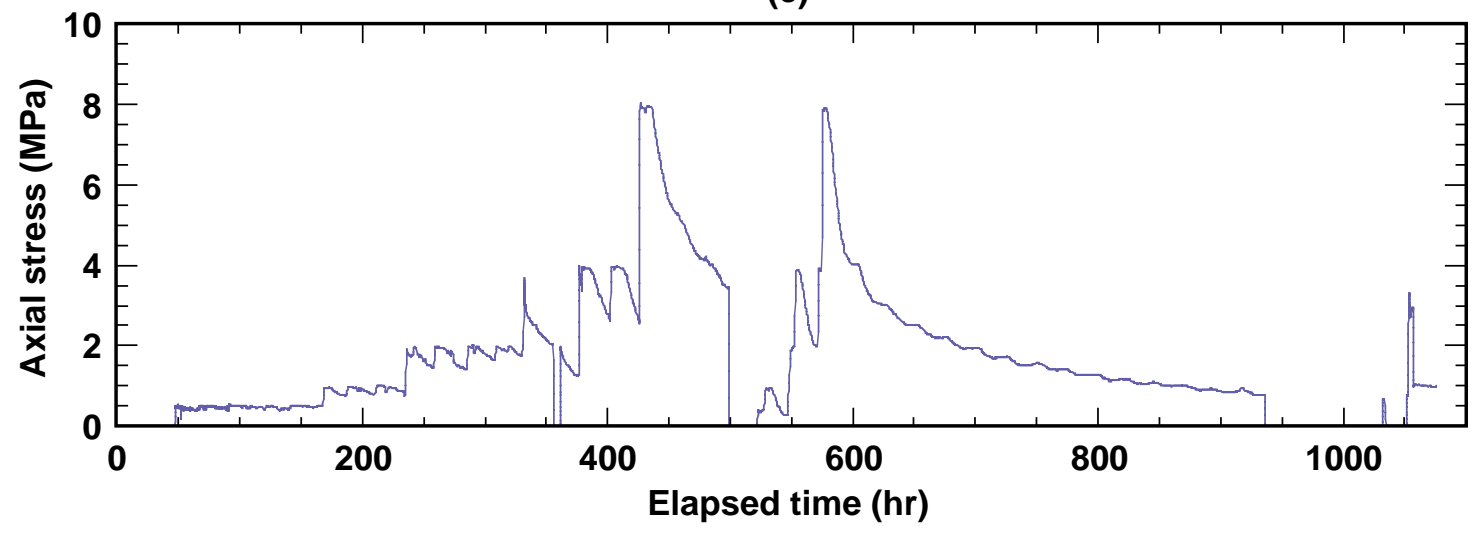

Figure 2-22. Vertical and horizontal displacements across two major vugs: (a) east face; (b) west face; (c) axial stress versus time 


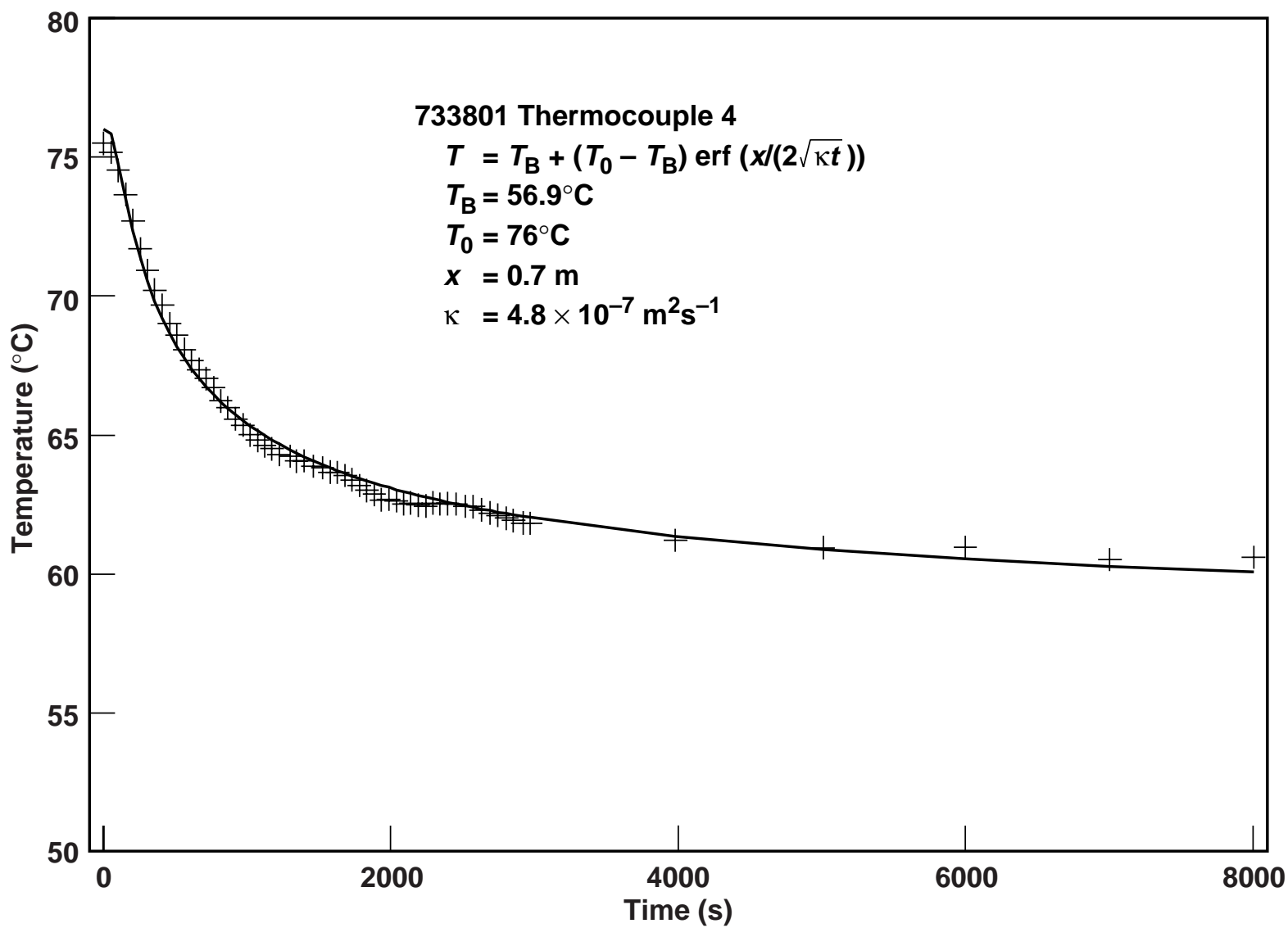

Figure 2-23. Typical fit of the heat flow equation for a semi-infinite solid with a known initial temperature and a constant temperature boundary condition. $T_{0}$, the initial temperature of the rock at the thermocouple, and $z$, the distance from the boundary to the thermocouple, are fixed. $T_{\mathrm{B}}$, the temperature of the water in the fracture, and $\kappa$, the thermal diffusivity, are fitting parameters. 



\section{SB4: Flow through a Vertical Fracture}

The present experiment continues the series of geomechanical and fluid flow experiments on 0.5-m-scale tuff specimens described in Chapter 2 and in previous reports (Blair and Berge, 1996; Blair and Costantino, 1997). As with the Small Block 3 (SB3) experiment, SB4 is concerned with fluid flow through an artificial fracture subjected to a normal load in a heated mass of Topopah Spring tuff. In the SB3 experiment, water was supplied by a point source at the center of a horizontal fracture that bisected the block, and heat was supplied by planar sources attached to the top and bottom block faces. Fluid flow was thus directed radially outward and heat flow was largely unidirectional, normal to the fracture plane, to provide relatively uniform temperatures over the fracture surface. In the SB4 experiment, the heat flow is to be directed radially outward from a line source at the center of the specimen, and the fluid flow is to be largely unidirectional, through a vertical fracture. The experimental geometry adopted in the SB3 experiment was ideal for investigating anisotropic flow, and the experimental results did indicate strongly anisotropic fluid flow as a result of the fracture surface texture. In the SB4 experiment, we have adopted a more realistic, linear fluid source and a radial heat flow pattern, as would be expected for a buried waste canister, and, in contrast to the SB3 experiment, significant temperature gradients will exist on the fracture plane. By raising the temperature of our heat source above the water boiling point, we can create a vapor zone in the center of the fracture and thereby study its effect on the fluid-flow pattern in the rock.

\subsection{Research Objective}

The experiment aims to characterize heat and fluid flow in a vertical, planar fracture subjected to thermal loading (to $150^{\circ} \mathrm{C}$ ) and compressive loading (to a few $\mathrm{MPa}$ ) in a $300 \mathrm{~mm}$ scale specimen of Topopah Spring tuff from the Nevada Test Site. The work is intended to provide an improved understanding of coupled thermohydromechanical processes in tuff under temperature and stress conditions that approximate those expected in the near-field environment at Yucca Mountain. In particular, the results are intended to assist computer modeling efforts by providing experimentally-derived constraints on the effects of stress and temperature on fluid flow in fractured tuff. The experimental design incorporates a simple geometry and known, well-controlled boundary conditions so that the heat and fluid flow data obtained in this experiment can provide a basis for numerical model validation.

\subsection{Experimental Plan}

Particular care has been taken in designing the SB4 experiment to permit a close comparison between experimental and numerical modelling results. The artificial fracture is vertical and is formed from two saw-cut surfaces that have been ground flat and parallel. Unlike the SB3 experiment, bead-blasting was not used to roughen the fracture surfaces. Displacements of the fracture surfaces are to be measured at ten points around the fracture perimeter so that the fracture aperature is known at all times. This design is intended to allow the fracture to be modelled to a very good approximation as two parallel plates having a known separation. The heat source is contained within a highly conductive metal bar that extends the entire length of the specimen axis. The cross section of the heater bar is small relative to its length and to the minimum diameter of the tuff specimen so that heat flow can be modelled as a 
line source in a cylinder of large diameter. Temperature will be measured at more than 90 points within the specimen so that heat flow histories are well-constrained.

The experimental work consists of a series of simple tests so understanding of the relations between stress, temperature and fluid flow can be built up incrementally. Each test should also provide an opportunity for numerical model validation under a different set of boundary conditions.

The initial test will involve a dry heating cycle, up to a peak temperature of $150^{\circ} \mathrm{C}$, to characterize heat flow in the tuff specimen in its dry state. The temperature histories from our array of more than 90 thermocouples will allow us to calculate thermal diffusivity in eight radial directions. Heat flow depends on water content, because water saturation increases the thermal conductivity of Topopah Spring tuff (DOE, 1990). More importantly, heat will be lost to the water flowing through the fracture and exiting the rock. The dry-state temperature data should provide a baseline that will allow us to account for the effects of water content and flow on heat flow in the tuff as later data sets become available. The temperature data from this test should also provide numerical modelers with an opportunity to validate the heat flow codes for the relatively simple case in which only conductive heat flow through the tuff matrix is expected.

The second test will be performed at room temperature and pressure with water supplied to the upper fracture surface. Water exiting the rock will be collected from the bottom of the fracture and from the specimen faces. These flow data should provide a second baseline that will allow us to account for the effects of thermal and mechanical loading as later data sets become available. During the second test the tuff specimen should become at least partially saturated as water infiltrates the porosity and natural fractures in the specimen. These data will provide an excellent estimate of the imbibition of water into the host rock as it flows through a fracture. They should also provide an opportunity to validate fluid-flow codes under relatively simple boundary conditions.

The third test will repeat the heating cycle of the first test, and, as with the first test, no water will be introduced at the top of the fracture. The new temperature data should indicate the impact of water intake on heat flow. Thermal loading should compress fractures and force water out of the rock. This test will provide an opportunity to measure the fluid outflow due to thermal loading. As temperatures rise, water vapor is expected to form near the heat source, migrate along the artificial fracture driven by the vapor pressure gradient, and then condense in the cooler portions of the fracture. This test will thus provide a chance to observe the reflux process under conditions of no applied load and no fluid recharge.

In the fourth test, flow measurements will be made at a series of loads to characterize fracture flow as a function of normal stress at room temperature. By comparison with flow data from the second test, it should be possible to account for the effect of mechanical loading on fracture flow in the specimen. Because the artificial fracture is highly planar, fluid flow might be expected to follow the well-known cubic flow law. However, results from SB3 indicate the fracture permeability is independent of the fracture aperture (as parameterized by the stress normal to the fracture). We will test this hypothesis in SB4. In addition, the test specimen contains a number of natural fractures at various orientations to the loading direction, and it will be of interest to assess the effect, if any, that the natural fracture system has on flow through the vertical fracture.

In the fifth test, we will repeat the room-pressure heating cycle of the third test but with water intake from the top of the fracture. A comparison of flow rates measured in this test with the data from the third test should allow us to account for the effect of thermal loading 
on flow in our specimen. The data should also provide an opportunity to validate computer models that simulate the effect of thermal loading on fracture flow. At the higher temperatures, it should be possible to observe the reflux phenomenon. If so, a comparison with our observations from the third test would provide a chance to assess the impact of fluid recharge on the reflux phenomenon.

The final test will repeat the earlier heating cycles with the fracture plane under a normal load and water intake from the top of the fracture. We will then attempt to analyze the temperature, flow, and deformation data from the later tests on the basis of the understanding gained from each of the previous tests. The final test should provide a fluid-flow data set, incorporating both mechanical and thermal loading, that will permit computer-model validation for Topopah Spring tuff under stress and temperature conditions that approximate those expected in the near-field environment.

\subsection{SB4 Block Preparation}

\subsubsection{Sample Material}

A block of Topopah Spring Tuff was collected from the vicinity of the Large Block Test site near Yucca Mountain at the Nevada Test Site. The block exhibits the typical Topopah Spring Tuff fabric of subparallel vugs, in pink, and gray densely-welded tuff composed primarily of alkali feldspar, plagioclase, and quartz. The vugs are filled with a variety of secondary minerals, which are generally white in color and softer than the tuff matrix. The secondary minerals are more easily eroded than the rock matrix, and we anticipate that erosion of the vug material during the course of the experiment may alter fracture permeability with time. The specimen also contains a number of partially open fractures, and a major open fracture exists near one end of the specimen.

\subsubsection{Specimen Preparation}

The tuff specimen was cut into an octagonal prism, $330 \times 330 \mathrm{~mm}$ in cross-section and $317.5 \mathrm{~mm}$ in length, then cut in half along its central axis to create an artificial fracture, before being shipped to Lawrence Livermore National Laboratory (LLNL). The octagonal shape was chosen because it provides near-radial symmetry about a line heater source and flat surfaces parallel to the fracture plane for compressive loading. The flat surfaces also simplify the installation of fluid ports and displacement transducers.

The specimen geometry is shown in Figure 3-1. The two pieces are named Block $\mathrm{A}$ and Block $\mathrm{B}$. The coordinate system is chosen so that the $x$-axis is normal to the fracture plane and along the direction of the applied load; the $y$-axis is vertical and forms one axis of the fracture; and the $z$-axis is the axis of radial symmetry, forms the second axis of the fracture plane, and contains the line heat source. The origin is at the specimen midpoint.

\section{Figure 3-1. Specimen geometry, coordinate system and thermocouple array}

The thermocouples are distributed over five cross-sectional planes at $z=-140,-70,0,70$, and $140 \mathrm{~mm}$, respectively.

Many saw marks could be seen on the surfaces of the blocks, including the fracture surfaces, when they were received at LLNL. Therefore, left and right vertical faces, seen looking down the $z$-axis, and the two fracture surfaces were smoothed and ground parallel to each other with a precision grinding machine at the LLNL optics laboratory. Cutting and grinding 
reduced width of the specimen to $317.5 \mathrm{~mm}$. A $12.5-\mathrm{mm}$ square channel was cut into the fracture surface of each block along the $z$-axis. When the blocks are fitted together, the combined channels create a void $12.5 \times 25.4 \times 318 \mathrm{~mm}$ intended to hold the heat source.

After being cut and ground, the blocks were dried in an oven at $66^{\circ} \mathrm{C}$ for 14 days and weighed at regular intervals with a 500-kg scale. The blocks were judged to be dry after four consecutive measurements showed no change in weight (Table 3-1). The dimensions of the blocks were measured and the total volume calculated to be 27.0 liters, yielding a dry bulk density of $2.30 \mathrm{~g} / \mathrm{cm}^{3}$. The specimen porosity was calculated to be $9.8 \%$ assuming a grain density of $2.55 \mathrm{~g} / \mathrm{cm}^{3}$ (DOE, 1990).

Table 3-1. Drying history of Blocks A and B (DTN LL980802304243.021)

\begin{tabular}{|l|c|c|c|c|c|c|}
\hline \multicolumn{1}{|c|}{ Date } & Time & Elapsed Time $(\mathbf{h r})$ & Room Temp $\left({ }^{\circ} \mathbf{C}\right)$ & Oven Temp $\left({ }^{\circ} \mathbf{C}\right)$ & Block A (kg) & Block B (kg) \\
\hline \hline $2 / 3 / 98$ & $17: 30$ & 0.00 & 12.9 & 66.5 & 31.4 & 31.3 \\
\hline $2 / 5 / 98$ & $14: 24$ & 45.25 & 15.1 & 66.2 & 31.3 & 31.2 \\
\hline $2 / 10 / 98$ & $14: 00$ & 164.50 & 11.4 & 67.2 & 31.2 & 31.1 \\
\hline $2 / 11 / 98$ & $16: 30$ & 191.00 & 15.1 & 65.9 & 31.1 & 31.0 \\
\hline $2 / 12 / 98$ & $14: 45$ & 213.25 & 13.8 & 67.7 & 31.1 & 31.0 \\
\hline $2 / 13 / 98$ & $10: 15$ & 232.75 & 15.9 & 66.6 & 31.1 & 31.0 \\
\hline $2 / 17 / 98$ & $15: 30$ & 334.00 & 14.4 & 66.8 & 31.1 & 31.0 \\
\hline
\end{tabular}

Ninety-nine holes were cored into the two blocks with a water-cooled, diamond-tipped core barrel to accommodate the thermocouples. As several of the block surfaces are rather irregular, the square channels intended for the heat source were used as a reference axis whenever possible in positioning the thermocouple holes. The holes are $3.18 \mathrm{~mm}$ in diameter and range in length from 10 to $125 \mathrm{~mm}$. The thermocouple holes are distributed over five cross-sectional planes, labeled B through F, at 70-mm intervals (shown in Figure 3-1). The bottoms of the holes are positioned to provide temperature measurements at approximately $45^{\circ}$ intervals at radial distances of 40,90 and $150 \mathrm{~mm}$ in the central cross-sectional plane (Plane D) and in Plane F, near the specimen end. Fewer thermocouple holes have been emplaced in the other planes, but there is complete $45^{\circ}$ coverage at a radial distance of $40 \mathrm{~mm}$ in each cross-sectional plane. We cored 35 holes completely through Block A; these holes will provide temperature data along the fracture surface in each of the cross-sectional planes at radial distances of 40,90 and $150 \mathrm{~mm}$ and at the rock/heater block interface. In all, 30 holes were cored to a nominal radial distance of $40 \mathrm{~mm}, 28$ holes to $90 \mathrm{~mm}$, and 26 holes to a radial distance of $150 \mathrm{~mm}$ (Figure 3-2).

Figure 3-2. Thermocouple locations for the central $(z=0)$ cross-sectional plane (DTN LL980802304243.021)

We cored 32 holes into the blocks to mount linear voltage displacement transducers (LVDTs). These holes are $12.5 \mathrm{~mm}$ in diameter, $12.5 \mathrm{~mm}$ deep, and arranged in pairs $76 \mathrm{~mm}$ apart. Most of the holes were cored into the ends of the blocks (Planes A and G) or into the top and bottom faces (Figure 3-3). Their positions and dimensions are given in Table 3-2. We also cored 16 holes into the top and bottom faces of the blocks to attach water manifolds for the flow measurements; these holes are $9.5 \mathrm{~mm}$ in diameter and $12.5 \mathrm{~mm}$ in length. Finally, 
we cored four holes into the blocks to attach sheets of G-10 phenolic resin board as insulation for the loaded faces. Physical properties of the G-10 material are given in Norplex (1998).

Figure 3-3. Positions of the LVDT mounting holes (DTN LL980802304243.021)

Holes are positioned in pairs $76 \mathrm{~mm}$ apart so that 10 LVDTs span the fracture and 6 LVDTs span solid portions of the rock in three orthogonal directions.

Table 3-2. Displacement transducer (LVDT) locations (DTN LL980802304243.021)

\begin{tabular}{|c|c|c|c|c|c|c|c|c|c|c|c|}
\hline \multirow[t]{2}{*}{ \# } & \multirow[t]{2}{*}{ Name } & \multirow[t]{2}{*}{ Type } & \multirow[t]{2}{*}{ Axis } & \multirow[t]{2}{*}{ Blocks } & \multicolumn{3}{|c|}{ Post 1 Coordinates } & \multicolumn{3}{|c|}{ Post 2 Coordinates } & \multirow{2}{*}{$\begin{array}{c}\text { Baseline } \\
(\mathrm{mm})\end{array}$} \\
\hline & & & & & $x(\mathbf{m m})$ & $y(\mathrm{~mm})$ & $z(\mathrm{~mm})$ & $x(\mathrm{~mm})$ & $y(\mathrm{~mm})$ & $z(\mathbf{m m})$ & \\
\hline 1 & DFX-BO & fracture & $x$ & $A, B$ & -39 & -165 & -119 & 39 & -165 & -122 & 78 \\
\hline 2 & DFX-D0 & fracture & $x$ & $A, B$ & -39 & -165 & 0 & 38 & -165 & 1 & 77 \\
\hline 3 & DFX-FO & fracture & $x$ & $A, B$ & -39 & -165 & 120 & 39 & -165 & 120 & 77 \\
\hline 4 & DFX-G1 & fracture & $x$ & $A, B$ & -39 & 83 & 159 & 38 & 83 & 159 & 77 \\
\hline 5 & DFX-G3 & fracture & $x$ & $A, B$ & -39 & -83 & 159 & 38 & -83 & 159 & 77 \\
\hline 6 & DFX-F4 & fracture & $x$ & $A, B$ & -38 & 165 & 119 & 39 & 165 & 119 & 77 \\
\hline 7 & DFX-D4 & fracture & $x$ & $A, B$ & -38 & 165 & 0 & 39 & 165 & 0 & 77 \\
\hline 8 & DFX-B4 & fracture & $x$ & $A, B$ & -38 & 165 & -119 & 39 & 165 & -120 & 77 \\
\hline 9 & DFX-A3 & fracture & $x$ & $A, B$ & -39 & 82 & -159 & 39 & 88 & -159 & 78 \\
\hline 10 & DFX-A1 & fracture & $x$ & $A, B$ & -39 & -82 & -159 & 39 & -88 & -159 & 78 \\
\hline 11 & DSX-A2 & matrix & $x$ & $A, A$ & -128 & 0 & 159 & -51 & 0 & 159 & 76 \\
\hline 12 & DSY-A2 & matrix & $y$ & $A, A$ & -77 & 38 & 159 & -77 & -38 & 159 & 76 \\
\hline 13 & DSX-G2 & matrix & $x$ & $B, B$ & 127 & 0 & -159 & 51 & 0 & -159 & 76 \\
\hline 14 & DSY-G2 & matrix & $y$ & $\mathrm{~B}, \mathrm{~B}$ & 77 & 39 & -159 & 77 & -39 & -159 & 78 \\
\hline 15 & DSZ-A0 & matrix & $z$ & $B, B$ & 89 & 139 & -107 & 89 & 139 & -32 & 75 \\
\hline 16 & DSZ-A4 & matrix & $z$ & $B, B$ & 87 & -138 & -106 & 87 & -138 & -30 & 76 \\
\hline
\end{tabular}

Digital photographs were taken of the fracture surfaces and of all of the block faces after the holes were cored. The fracture surfaces are shown in Figure 3-4. The surfaces have been wetted to improve contrast between the pink matrix and the white secondary minerals filling the vugs. The secondary minerals may erode during the flow experiments creating channels that permit increased levels of flow along portions of the fracture. After the photographs were taken, the fracture surfaces were roughened by manually sanding at medium pressure with \#60 grit silicon carbide paper and water for two hours. The blocks were then cleaned for one hour each with a Branson Sonifer model 250 ultrasonic bath. The color of the fracture surfaces was noticeably changed by the ultrasonic cleaning because many of the light-colored fines were removed from cracks and pore spaces.

Figure 3-4. Photographs of the fracture surfaces for Block A (top) and Block B (bottom) 


\subsection{Equipment for Data Collection}

\subsubsection{Heat Source}

Heat is provided by three Omega CIR series 400-watt electrical-resistance cartridge heaters, positioned in a single line along the $z$-axis of the specimen. Three cartridge heaters are used so that the output of each can be adjusted independently, if necessary, to maintain a uniform temperature distribution. The central cartridge heater is $152.4 \mathrm{~mm}$ long and the outer heaters are each $76.2 \mathrm{~mm}$ long. Their combined length of $305 \mathrm{~mm}$ is just $12.5 \mathrm{~mm}$ short of the specimen length, so that the heaters provide a good approximation to a continuous line source. The heaters, which are $6.30 \mathrm{~mm}$ in diameter, are inserted into $6.35-\mathrm{mm}$ diameter holes providing a tight fit for efficient heat transfer. A very thin coat of Omega Heat Conducting Paste will also be applied to the heater cartridges to promote efficient heat transfer into the heater bar. The lead wires for the central heater cartridge are led out of the bar through two small holes. The lead wires are enclosed in fiberglass insulation and are rated to $200^{\circ} \mathrm{C}$.

The heater bar was fabricated from a $\mathrm{Cu}-\mathrm{Ni}$ alloy $(70 \% \mathrm{Cu}, 30 \% \mathrm{Ni})$ with good corrosionresistance and thermal conductivity properties (Metals Handbook Committee, 1961, pp. 1029-1030) The dimensions of the heater bar are a few thousandths of an inch smaller than the channel to allow for the metal bar's greater thermal expansion. Thirteen cross-shaped, 1.1-mm-deep channels were milled into the upper and lower surfaces of the heater bar (Figure 3-5). The channels are aligned with their long (22- $\mathrm{mm})$ arms parallel and short (19-mm) arms perpendicular to the trace of the fracture. A 3.2-mm-wide unmilled barrier exists between each pair of cross-shaped channels to preclude flow in the $z$ direction. The long channel arms are intended to collect water along the fracture trace on the upper surface of the bar and disperse it along the fracture trace at the lower surface. The short channel arms on the upper surface divert water toward the sides of the heater bar, and those on the lower surface return it toward the center. Small holes near the ends of the short arms allow water to flow through the bar without coming into contact with the cartridge heaters. One concern is that some water may flow from channel to channel along the top surface of the heater bar. A very thin coat of Permatex UltraCopper High Temperature room-temperature vulcanizing (RTV) silicone may be applied to form a gasket between the heater bar and the tuff.

\section{Figure 3-5. SB4 heater bar}

The bar can accommodate three cartridge heaters and three thermocouple probes. A system of holes and channels allows water to flow through the bar without coming into contact with the heater cartridges.

Three 3.2-mm diameter holes allow thermocouples to be inserted into the heater bar to measure temperature near the center of each heater cartridge. The heater cartridges are powered by separate PMC power supplies, and the input currents will be adjusted, if necessary, to provide a uniform temperature distribution throughout the heater bar.

\subsubsection{Temperature Measurements}

Temperatures will be measured in the tuff specimen with 91 Omega model JQSS-116G sheathed, type J (iron-constantan) thermocouples. Three identical thermocouples will measure temperature in the heater bar, and one thermocouple will record the ambient air temperature. The thermocouples are grounded at their measuring tips and have a maximum 
service temperature of $760^{\circ} \mathrm{C}$. The standard wire error for type $\mathrm{J}$ thermocouples is $\pm 2.2^{\circ} \mathrm{C}$. The thermocouple sheaths are $1.6 \mathrm{~mm}$ in diameter and 305,457 , or $610 \mathrm{~mm}$ in length.

The thermocouples are to be calibrated in our laboratory using a Hart Scientific model 9100 dry-well and a Hart Scientific secondary reference temperature standard. The dry-well produces a uniform and stable $\left( \pm 0.3^{\circ} \mathrm{C}\right)$ temperature field at any prescribed temperature between $33^{\circ}$ and $300^{\circ} \mathrm{C}$. The secondary reference standard is a high-precision platinum resistance temperature detector (RTD) designed to measure temperature to within $\pm 0.02^{\circ} \mathrm{C}$. Both the dry-well and the secondary reference standard are supplied with NIST-traceable calibration certificates. The thermocouples will be connected to our data-acquisition system (Section 3.4.7) in the same manner as in our experiment so that temperature for each thermocouple is read on a different channel. The thermocouples will be inserted one at a time into the dry-well, and the difference between the RTD temperature and the temperature read by our data-acquisition system will be taken as the system error for that channel. We intend to check the entire data-acquisition line for each channel rather than just the thermocouples.

The calibrated thermocouples will be cemented in place with Omega CC High Temperature cement, a chemically-setting zircon-based adhesive designed for bonding thermocouples to ceramic surfaces. The cement has a maximum service temperature of $843^{\circ} \mathrm{C}$ and does not require exposure to air to set, so a strong bond can be expected at the bottoms of small diameter boreholes. The cement should both couple the thermocouples to the tuff and prevent fluid flow in the thermocouple holes, which would otherwise adversely affect the fluid-flow measurements.

\subsubsection{Displacement Measurements}

Displacement measurements will be made with 16 LVDTs. Ten LVDTs will measure displacement across the fracture, and six will measure displacement in three orthogonal directions over solid portions of the rock. The former are regularly distributed around the perimeter of the fracture with three LVDTs on each of the top and bottom faces, spaced 121 mm apart, and two LVDTs on each block end, spaced $152 \mathrm{~mm}$ apart. The data from these LVDTs will allow us to relate changes in flow to fracture closure. Four LVDTs are arranged in cross patterns at the block ends to measure displacements in the $x$ and $y$ directions, and two LVDTs are mounted along the sides to measure displacement in the $z$ direction. The data from these LVDTs will be used to calculate Young's modulus and Poisson's ratio.

The LVDTs will be mounted on 12.5-mm diameter ceramic posts cemented into 12.5-mmdeep holes cored into the tuff blocks (Figure 3-6). The holes are arranged in pairs to provide a 76-mm baseline for each LVDT. The ceramic posts are either 63.5 or $76.2 \mathrm{~mm}$ in length so that the LVDTs can stand at least $50 \mathrm{~mm}$ off the tuff surface. This offset will allow a layer of insulation to be placed between the tuff surface and the LVDTs and will also permit the LVDTs on the top and bottom faces of the blocks to sit above the water manifolds. The insulation, the 50-mm standoff and the use of ceramic rather than metal posts are intended to minimize thermal disturbances. Four 76.2-mm long ceramic posts will be used to allow LVDTs to be arranged in cross patterns at the block ends. The LVDTs will be attached to the ceramic posts with aluminum brackets.

Figure 3-6. Mounting technique for the LVDTs

Ceramic posts allow the LVDTs to sit above the insulation and water manifolds. 
The LVDTs are to be calibrated with a Mitutoyo micrometer. The micrometer was calibrated to read position to within $\pm 2.5 \mu \mathrm{m}$ by Bechtel Nevada Standards and Calibration Laboratory, Las Vegas, Nevada, during July 1998.

\subsubsection{Fluid-Flow Measurements}

The artificial fracture is a vertical plane oriented normal to the loading direction. Water will be introduced at one inch intervals through 13 linear ports along the top of the fracture and collected through 13 identical ports at the bottom. The fluid source will likely be the same pressurized reservoir used in the SB3 experiment. The reservoir allows a fluid pressure of a few psi to be created with laboratory compressed air and controlled to within \pm 0.1 psi with a regulator. Measurements will be made of the amount of fluid flowing into the specimen over time. The fracture sides will be sealed with a flexible, high-temperature RTV silicone sealant to prevent water loss through the fracture at the specimen ends.

The water collection and dispersion manifolds are identical and have been fabricated from the same $\mathrm{Cu}-\mathrm{Ni}$ alloy as the heater bar. The water manifold dimensions are $12.5 \times 38.1 \times$ $317.5 \mathrm{~mm}$. Water is collected or dispersed through 13 milled channels at 25.4-mm (center to center) intervals, aligned with the fracture plane (Figure 3-7). The water channels are $9.5 \mathrm{~mm}$ wide and $1.1 \mathrm{~mm}$ deep. Unmilled intervals $3.18 \mathrm{~mm}$ wide form barriers between adjacent channels. The ten central channels are each $22.2 \mathrm{~mm}$ long, and the edge channels are shorter to match the channel dimensions of the heater bar. A threaded pipe tap intersects each channel at its center. Barbs are screwed into each pipe tap, and a length of silastic tubing, rated to $232^{\circ} \mathrm{C}$, is clamped to each barb. A thin layer of high-temperature RTV silicone will form a watertight gasket between the water manifolds and the tuff faces. Because the tuff faces in contact with the water manifolds are not sufficiently flat for a good seal, a thin layer of Omega CC High Temperature cement will be applied to the surface and sanded smooth with emery paper to fill in the low spots.

\section{Figure 3-7. Water manifold design, with manifolds attached to the top and bottom surfaces of the specimen along the trace of the fracture}

Although most of the water is expected to flow through the artificial fracture and into the lower manifold, some water may flow into natural cracks and exit the specimen along other faces. Therefore, the nonloaded faces of the blocks will be covered with a 1.6-mm-thick sheet of G-10 mounted $3.2 \mathrm{~mm}$ off the tuff faces. Polyethylene connectors will be epoxied to sixteen 6.35-mm-diameter holes drilled through the G-10 sheets at their lowest points, and appropriate lengths of silastic tubing will be attached to allow water to drain into collection jars.

Water will be collected in 29 glass jars. The water mass in each glass jar will be weighed with a Mettler model ED601 mass balance at regular intervals to determine the flow rate through each collection port.

\subsubsection{Insulation}

The sample faces will be insulated to reduce heat flow through the ends of the specimen and through the metal loading column; to dampen the effects of room temperature fluctuations and reduce thermal disturbances to the displacement transducers; to allow the specimen to be heated more rapidly; and to lower temperature gradients within the rock.

The loaded faces will be insulated with $76 \mathrm{~mm}$ of G-10 phenolic resin board (Figure 3-8). This is a strong, dense $\left(1.85 \mathrm{~g} / \mathrm{cm}^{3}\right)$, and relatively stiff insulating material capable of with- 
standing the applied load. A flatwise compressive strength of $470 \mathrm{MPa}$ has been measured for 3.2-mm-thick G-10 sheets (Norplex, 1998) and its thermal conductivity is about $0.3 \mathrm{~W} / \mathrm{m}$ $\mathrm{K}$, one-seventh the in situ thermal conductivity of saturated Topopah Spring Tuff (DOE, 1990). Channels have been milled into the faces of the G-10 sheets that contact the rock to allow thermocouples to be fed out of the specimen. These G-10 sheets will be attached directly to the tuff faces. The other G-10 sheets will be attached to steel plates in the loading column to reduce weight on the tuff blocks.

\section{Figure 3-8. Insulation of the loaded faces, consisting of three sheets of inch-thick G-10 phenolic resin board}

The use of G-10 insulation on all of the surfaces would add considerable weight to the specimen assembly. Therefore, a very lightweight Kaowool ceramic fiber blanket will be used on the nonloaded faces. The ceramic blanket will be protected from wetting by the thin G-10 sheets used to collect water, as described above. The thermal conductivity of the Kaowool ceramic blanket is approximately $0.05 \mathrm{~W} / \mathrm{m}-\mathrm{K}$, so a thickness of only $12.5 \mathrm{~mm}$ is required to give the same degree of insulation to the loaded and nonloaded faces.

\subsubsection{Loading Apparatus and Load Measurements}

The steel loading frame has been horizontally mounted atop two 1.2-m tall plywood pillars (Figure 3-9). The tuff specimen will be positioned in the loading frame so that the artificial fracture is vertical and the load can be applied normal to the fracture. The load will be supplied by a 300-ton Simplex model RDA-300-6 hydraulic cylinder, which has been mounted in the loading frame. The full load would provide a normal stress of $12.6 \mathrm{MPa}$ on the fracture surface. Hydraulic pressure will be supplied by an Enerpac model PB2025 pump. Small adjustments to the hydraulic pressure can be made with a Haskel model M-110 pump. A Stellar Technology, Inc., model GT1600 10,000-psi pressure transducer and a Lincoln Instruments Sirius IVB five-digit digital indicator will monitor pressure in the hydraulic lines.

\section{Figure 3-9. The horizontal loading apparatus}

The applied load will be measured with three identical Sensotec model 43/6128-01 load cells positioned at the vertices of an equilateral triangle so that each load cell is in equivalent contact with the loading column. The load cells were calibrated in compression to an applied force of 200,000 pounds by Instron Corp. in Canton, Massachusetts, in July 1998. As the hydraulic ram is only capable of $152 \mathrm{~mm}$ of travel, a number of spacer plates have been attached to the inside of the loading frame.

\subsubsection{Data-Acquisition System}

The data-acquisition system is shown schematically in Figure 3-10. Up to 32 channels of data are input into each of four National Instruments (NI) SCXI 1303 isothermal terminal blocks. The SCXI 1303 terminal blocks contain a high-precision thermistor temperature sensor to provide the proper cold-junction compensation for thermocouple measurements. The SCXI 1303 terminal blocks are each connected to a NI 1100 multiplexer/signal conditioner module housed in a common NI SCXI 1000 chassis. The NI 1100 multiplexer contains two (4 Hz and $10 \mathrm{kHz}$ ) user-bypassable, low-pass filters and a software-programmable adjustable-gain amplifier. A 5-m shielded cable connects the multiplexer to a NI PCI-MIO-16XE-50, 16-bit data-acquisition board mounted in a Windows NT-based Dell Pentium II ${ }^{\mathrm{TM}}$ computer. Ninety-five channels of thermocouple data are input into three of the SCXI 1303 terminal 
blocks. The fourth block receives signals from 16 LVDTs, three load cells, the heater cartridge power supplies, and the pressure transducer.

\section{Figure 3-10. Data-acquisition schematic}

A virtual instrument program was written using NI LabView software to acquire the data and store it on a hard disk. An APC model SU1400NET uninterruptible power supply will ensure that data acquisition is not affected by short-term power outages during the experiment.

The water-flow measurements will be made manually by weighing the water collected in each glass jar at regular intervals with a mass balance as was done in the SB3 experiment.

\subsubsection{Surface Profilometry}

Fracture deformation and fluid-flow properties depend on the surface roughness of the fracture. The surface topography of a portion of the artificial fracture was recorded at LLNL with a stylus profilometer built by Keller and Bonner (1985). A $120 \times 300-\mathrm{mm}$ section of the fracture surface of Block A was profiled at a $1 \times 1-\mathrm{mm}$ resolution, and three $10 \times 10-\mathrm{mm}$ subsections were profiled at $0.05 \times 0.05-\mathrm{mm}$ resolution (Figure 3-11). The $120 \times 300-\mathrm{mm}$ section (surface profile shown in Figure 3-12) includes several thermocouple holes and also a particularly rough section near the edge of the fracture plane where secondary minerals have been partially eroded from a vug. The three small areas (Figure 3-13) have no visually obvious surface features.

Figure 3-11. Areas of the Block A fracture plane selected for surface profiling The $120 \times 300 \mathrm{~mm}$ area was profiled on a $1.0 \times 1.0 \mathrm{~mm}$ grid. The three $10 \times 10 \mathrm{~mm}$ areas were profiled on a $0.05 \times 0.05 \mathrm{~mm}$ grid.

Figure 3-12. Surface topography of a $120 \times 300 \mathrm{~mm}$ area of the fracture surface of Block A profiled at 1.0-mm resolution (DTN LL980802304243.021)

Figure 3-13. Surface topography of the (a) inner, (b) middle, and (c) outer $10 \times 10 \mathrm{~mm}$ subsections profiled at $0.05-\mathrm{mm}$ resolution (DTN LL980802304243.021)

Many of the features seen in the digital photographs of the fracture plane (Figure 3-4) can also be recognised in Figure 3-12. The large, partially eroded vug can be seen in the lower portion of surface profile as well as in the digital photograph. The vug is about $50 \mathrm{~mm}$ in diameter and as much as $2 \mathrm{~mm}$ in depth in the eroded portions. At least six smaller vugs seen in the digital photograph appear as diffuse yellow patches in the surface profile. The fracture surface is on the order of $0.1 \mathrm{~mm}$ lower in these areas. Two partially open fractures cross the image plane from left to right, and a couple of smaller fractures can be seen as well. The ten thermocouple holes, which appear as two rows of dark spots, will be filled in with high-temperature cement before the flow experiments begin. Comparatively few features are apparent in the $10 \times 10 \mathrm{~mm}$ areas profiled at higher resolution, but a few fine cracks can be seen in Areas 1 and 2 (Figure 3-12a and Figure 3-12b), and Area 3 is slightly rougher than the others. Standard deviations of the sampled surface elevations for Areas 1, 2, and 3 are 6.8, 5.4 and $7.3 \mu \mathrm{m}$, respectively. That most of the surface variation is well under $0.025 \mathrm{~mm}$ attests to the smoothness of the fracture surface through the welded tuff matrix. 
Two cross-sectional profiles are shown in Figure 3-14. The first profile (Figure 3-14a) was constructed parallel to the $z$ axis at $y=60 \mathrm{~mm}$; the second profile (Figure $3-14 \mathrm{~b}$ ) was constructed parallel to the $y$ axis at $z=150 \mathrm{~mm}$. The vertical exaggeration is 150 for the first profile and 600 for the second profile. The eroded protion of the vug dominates the surface profile in Figure 3-14a, but two fractures are also visible (at $z=115 \mathrm{~mm}$ and $z=245 \mathrm{~mm}$ ). The remainder of the surface profile, and the entire surface profile in the orthogonal direction, are very smooth in comparison with the surface profiles (Figure 2-5) for SB3, which had been subjected to bead blasting. The grinding and surface-sanding operations performed on the SB4 block have created fracture surfaces that are very smooth over the hard welded matrix and somewhat rougher over the soft vugs. If the secondary minerals in the vugs are eroded by fluid flow, the fracture-surface topography will change somewhat during the experiment. Although it will not be possible to profile the fracture surfaces during the flow tests, a second surface profile will be taken at the end of the experiment.

\section{Figure 3-14. Cross sections of SB4 fracture-surface topography, Block A}

\section{(a) cross-section $x-y$ (scale reduced)}

(b) cross section $x-z$

\subsubsection{Thermocouple Location Measurements}

Accurate locations for the bottoms of the thermocouple holes are needed to relate the temperature measurements to the heat flow regime in a meaningful way. A simple jig was designed and built to facilitate the thermocouple hole location measurements. The jig provided a level working surface, an axial bar for aligning the tuff blocks, a fixed reference point, and a movable arm with a level bar so that angle measurements could be made along smooth, regular surfaces (Figure 3-15). A tight-fitting aluminum rod was inserted into each thermocouple hole so that the hole's position and bearing could be determined by measuring with reference to the rod. Length measurements were made with a precision caliper, and angle measurements were made with a precision protractor. All measurements were made with the fracture surface of each block at rest on the jig working surface and with the jig's axial bar inserted into the block's heater-bar channel for proper alignment.

\section{Figure 3-15. Mechanical jig for measuring thermocouple hole locations}

To measure the angle between the fracture surface and the bearing of a given hole in the cross-sectional $(x-y)$ plane, the aluminum rod was inserted into the hole, then the jig arm was rotated into contact with the aluminum rod. The angle between the base of the jig and the jig arm was then measured with the precision protractor to within $0.25^{\circ}$. The angle between the top of the level bar on the jig arm and the aluminum rod gave the bearing angle in the longitudinal $(x-z)$ plane. The $z$ coordinate was also measured along the level bar at the top of the jig arm. Most length measurements could be made to within $\pm 0.05 \mathrm{~mm}$. The depth of the hole was measured with reference to the level bar attached to the jig arm as the faces of the tuff blocks are somewhat irregular. All of the angle and length measurements were performed twice to provide a check, with a different person performing the second set of measurements in most cases.

A short FORTRAN program was written to convert the measured angles and lengths into Cartesian coordinates. The locations of the bottoms of the thermocouple holes are given in Table 3-3 at the end of this chapter. The thermocouple holes that penetrate to a nominal 
radial distance of $40 \mathrm{~mm}$ are expected to be the least well-located. A $0.5^{\circ}$ error in measuring one of the bearing angles would result in a 1.1-mm location error, because these holes are approximately $125 \mathrm{~mm}$ long.

\subsection{Accomplishments to Date}

Specimen preparation is essentially complete. The tuff specimen has been cut into the proper shape, and more than 150 holes have been cored into it. The fracture surfaces have been sanded and ultrasonically cleaned to remove fines created in cutting and sanding that may otherwise clog small fractures and pores. The remaining step is to fill in a few low spots on the top and bottom surfaces with high-temperature epoxy to create smooth surfaces for mounting the water manifolds.

The heater block has been designed and fabricated, and it fits into its channel as intended. The heater cartridges fit tightly in the block, and spare cartridges have been obtained.

The loading frame and hydraulic ram have been mounted horizontally on plywood supports. Hydraulic pumps have been installed. A 127-mm-thick spacer column has been attached to the load frame to reduce the travel distance for the ram. Because a portion of Block B contains a through-going fracture, a small steel frame has been built to hold the specimen together. A support system has also been built so that the sample will remain in place if the load is removed. Four holes still need to be drilled into the arms of the loading frame so that the support system can be attached, and the Haskel pump needs to be attached to the hydraulic line.

The data-acquisition system has been assembled. Leads have been attached to all of the thermocouples and LVDTs. Neat and orderly connections have been made at a terminal board securely fastened to one of the plywood supports. The leads from the terminal board have been attached to four NI SCXI 1303 isothermal blocks and connected to the data acquisition card via four NI SCXI 1100 multiplexer modules. Data-acquisition software has been written and an uninterruptible power supply system has been acquired.

The locations of the 99 thermocouple holes have been measured.

Surface profiling has been completed. The surface profiles reveal a few cracks and a partially eroded vug. In general, the fracture surfaces are smoother than in the SB3 experiment and smoother than those expected in a nature fracture.

Pieces of G-10 insulation have been fabricated to cover the loaded faces and to provide a layer of stiff insulation between the tuff blocks and the support frame. Lightweight ceramic fiber blanket insulation has been obtained for the nonloaded faces.

The load cells have been calibrated and mounted in the load frame. Equipment for performing the thermocouple calibrations has been ordered. The micrometer for the LVDT calibrations has itself been calibrated.

The water manifolds have been designed, and the necessary materials for their construction have been gathered. 
Table 3-3. Thermocouple locations (DTN LL980802304243.021)

\begin{tabular}{|c|c|c|c|c|c|}
\hline \multirow[t]{2}{*}{ Name } & \multirow[t]{2}{*}{ Plane } & \multirow[t]{2}{*}{ Block } & \multicolumn{3}{|c|}{ Coordinates } \\
\hline & & & $x(\mathrm{~mm})$ & $y(\mathrm{~mm})$ & $z(\mathrm{~mm})$ \\
\hline TB0000 & B & A & -13 & 0 & -130 \\
\hline TB0001 & B & B & 40 & 0 & -136 \\
\hline TB0002 & B & B & 86 & -5 & -137 \\
\hline TB0451 & B & B & 28 & -31 & -133 \\
\hline TB0901 & B & A & 0 & 41 & -131 \\
\hline TB0902 & B & A & 0 & 86 & -131 \\
\hline TB0903 & B & A & 0 & 149 & -131 \\
\hline TB1351 & $\mathrm{B}$ & A & -28 & -29 & -140 \\
\hline TB1801 & B & $A$ & -42 & 0 & -142 \\
\hline TB1802 & B & A & -86 & 4 & -141 \\
\hline TB2251 & B & A & -27 & 29 & -143 \\
\hline TB2701 & $B$ & A & 0 & -40 & -130 \\
\hline TB2702 & B & A & 0 & -84 & -130 \\
\hline TB2703 & $\mathrm{B}$ & A & 0 & -149 & -130 \\
\hline TB3151 & $\mathrm{B}$ & B & 28 & 30 & -137 \\
\hline TC0000 & C & A & -13 & 0 & -60 \\
\hline TC0001 & C & B & 41 & 0 & -67 \\
\hline TC0451 & $\mathrm{C}$ & B & 27 & -30 & -64 \\
\hline TC0452 & C & $\mathrm{B}$ & 58 & -71 & -64 \\
\hline TC0453 & $\mathrm{C}$ & B & 110 & -107 & -65 \\
\hline TC0901 & C & A & 0 & 41 & -60 \\
\hline TC0902 & $C$ & A & 0 & 86 & -61 \\
\hline TC0903 & C & A & 0 & 150 & -61 \\
\hline TC1351 & C & A & -28 & -29 & -70 \\
\hline TC1801 & $C$ & A & -41 & 0 & -70 \\
\hline TC2251 & $C$ & A & -30 & 33 & -70 \\
\hline TC2252 & $C$ & A & -59 & 70 & -71 \\
\hline TC2253 & $C$ & A & -107 & 104 & -72 \\
\hline TC2701 & $C$ & A & 0 & -40 & -60 \\
\hline TC2702 & C & A & 0 & -85 & -60 \\
\hline TC2703 & $C$ & A & 0 & -149 & -60 \\
\hline TC3151 & C & B & 30 & 31 & -68 \\
\hline TD0000 & $\mathrm{D}$ & A & -13 & 0 & -11 \\
\hline TD0001 & D & B & 41 & -1 & 3 \\
\hline
\end{tabular}


3. SB4: Flow through a Vertical Fracture

\begin{tabular}{|c|c|c|c|c|c|}
\hline \multirow[t]{2}{*}{ Name } & \multirow[t]{2}{*}{ Plane } & \multirow[t]{2}{*}{ Block } & \multicolumn{3}{|c|}{ Coordinates } \\
\hline & & & $x(\mathrm{~mm})$ & $y(\mathrm{~mm})$ & $z(\mathrm{~mm})$ \\
\hline TD0002 & $\mathrm{D}$ & $\mathrm{B}$ & 88 & -6 & 4 \\
\hline TD0003 & $\mathrm{D}$ & $\mathrm{B}$ & 148 & 6 & 4 \\
\hline TD0451 & $\mathrm{D}$ & B & 26 & -29 & 6 \\
\hline TD0452 & D & B & 59 & -71 & 6 \\
\hline TD0453 & $\mathrm{D}$ & $\mathrm{B}$ & 110 & -107 & 5 \\
\hline TD0901 & D & A & 0 & 41 & -11 \\
\hline TD0902 & D & A & 0 & 86 & -11 \\
\hline TD0903 & D & $A$ & 0 & 149 & -11 \\
\hline TD1351 & $\mathrm{D}$ & $\mathrm{A}$ & -29 & -30 & 0 \\
\hline TD1352 & $\mathrm{D}$ & A & -69 & -66 & 1 \\
\hline TD1353 & D & A & -98 & -113 & 0 \\
\hline TD1801 & D & $A$ & -41 & 1 & 0 \\
\hline TD1802 & $\mathrm{D}$ & A & -87 & 5 & 0 \\
\hline TD1803 & $\mathrm{D}$ & A & -149 & -8 & 0 \\
\hline TD2251 & D & A & -28 & 32 & 0 \\
\hline TD2252 & $\mathrm{D}$ & A & -59 & 72 & 0 \\
\hline TD2253 & $\mathrm{D}$ & $A$ & -109 & 107 & -1 \\
\hline TD2701 & $\mathrm{D}$ & $A$ & 0 & -39 & -12 \\
\hline TD2702 & $\mathrm{D}$ & $A$ & 0 & -85 & -11 \\
\hline TD2703 & $\mathrm{D}$ & A & 0 & -149 & -11 \\
\hline TD3151 & D & B & 31 & 32 & 2 \\
\hline TD3152 & $\mathrm{D}$ & $\mathrm{B}$ & 65 & 62 & 3 \\
\hline TD3153 & D & B & 95 & 111 & 2 \\
\hline TE0000 & $\mathrm{E}$ & $A$ & -13 & 0 & 58 \\
\hline TE0001 & E & B & 40 & 1 & 74 \\
\hline TE0451 & E & B & 26 & -30 & 75 \\
\hline TE0901 & E & A & 0 & 42 & 59 \\
\hline TE0902 & $E$ & A & 0 & 87 & 59 \\
\hline TE0903 & E & A & 0 & 149 & 59 \\
\hline TE1351 & E & A & -28 & -28 & 71 \\
\hline TE1352 & E & A & -69 & -65 & 70 \\
\hline TE1353 & $E$ & A & -98 & -112 & 69 \\
\hline TE1801 & E & A & -47 & 0 & 68 \\
\hline TE2251 & E & A & -27 & 32 & 69 \\
\hline TE2701 & E & A & 0 & -40 & 58 \\
\hline
\end{tabular}




\begin{tabular}{|c|c|c|c|c|c|}
\hline \multirow[t]{2}{*}{ Name } & \multirow[t]{2}{*}{ Plane } & \multirow[t]{2}{*}{ Block } & \multicolumn{3}{|c|}{ Coordinates } \\
\hline & & & $x(\mathrm{~mm})$ & $y(\mathrm{~mm})$ & $z(\mathrm{~mm})$ \\
\hline TE2702 & $E$ & $A$ & 0 & -85 & 58 \\
\hline TE2703 & $\mathrm{E}$ & A & 0 & -149 & 58 \\
\hline TE3151 & $E$ & $\mathrm{~B}$ & 31 & 32 & 73 \\
\hline TE3152 & $E$ & $\mathrm{~B}$ & 66 & 61 & 73 \\
\hline TE3153 & $E$ & $\mathrm{~B}$ & 94 & 111 & 73 \\
\hline TF0000 & $\mathrm{F}$ & A & -13 & 0 & 130 \\
\hline TF0001 & $\mathrm{F}$ & $\mathrm{B}$ & 41 & -1 & 144 \\
\hline TF0002 & $\mathrm{F}$ & $\mathrm{B}$ & 87 & -7 & 144 \\
\hline TF0003 & $\mathrm{F}$ & $\mathrm{B}$ & 147 & 5 & 145 \\
\hline TF0451 & $\mathrm{F}$ & $\mathrm{B}$ & 25 & -29 & 144 \\
\hline TF0452 & $\mathrm{F}$ & B & 58 & -71 & 144 \\
\hline TF0453 & $\mathrm{F}$ & $\mathrm{B}$ & 108 & -106 & 144 \\
\hline TF0901 & $\mathrm{F}$ & A & 0 & 42 & 130 \\
\hline TF0902 & $\mathrm{F}$ & A & 0 & 87 & 130 \\
\hline TF0903 & $\mathrm{F}$ & A & 0 & 149 & 129 \\
\hline TF1351 & $\mathrm{F}$ & A & -29 & -30 & 142 \\
\hline TF1352 & $\mathrm{F}$ & A & -70 & -67 & 141 \\
\hline TF1353 & $\mathrm{F}$ & A & -96 & -113 & 141 \\
\hline TF1801 & $\mathrm{F}$ & A & -40 & 0 & 140 \\
\hline TF1802 & $\mathrm{F}$ & A & -88 & 4 & 140 \\
\hline TF1803 & $\mathrm{F}$ & A & -149 & -9 & 139 \\
\hline TF2251 & $\mathrm{F}$ & A & -28 & 33 & 139 \\
\hline TF2252 & $\mathrm{F}$ & A & -58 & 71 & 139 \\
\hline TF2253 & $\mathrm{F}$ & A & -109 & 108 & 139 \\
\hline TF2701 & $\mathrm{F}$ & A & 0 & -40 & 130 \\
\hline TF2702 & $\mathrm{F}$ & A & 0 & -85 & 130 \\
\hline TF2703 & $\mathrm{F}$ & A & 0 & -149 & 129 \\
\hline TF3151 & $\mathrm{F}$ & $\mathrm{B}$ & 30 & 32 & 143 \\
\hline TF3152 & $\mathrm{F}$ & $\mathrm{B}$ & 65 & 62 & 143 \\
\hline TF3153 & $\mathrm{F}$ & B & 97 & 114 & 143 \\
\hline
\end{tabular}




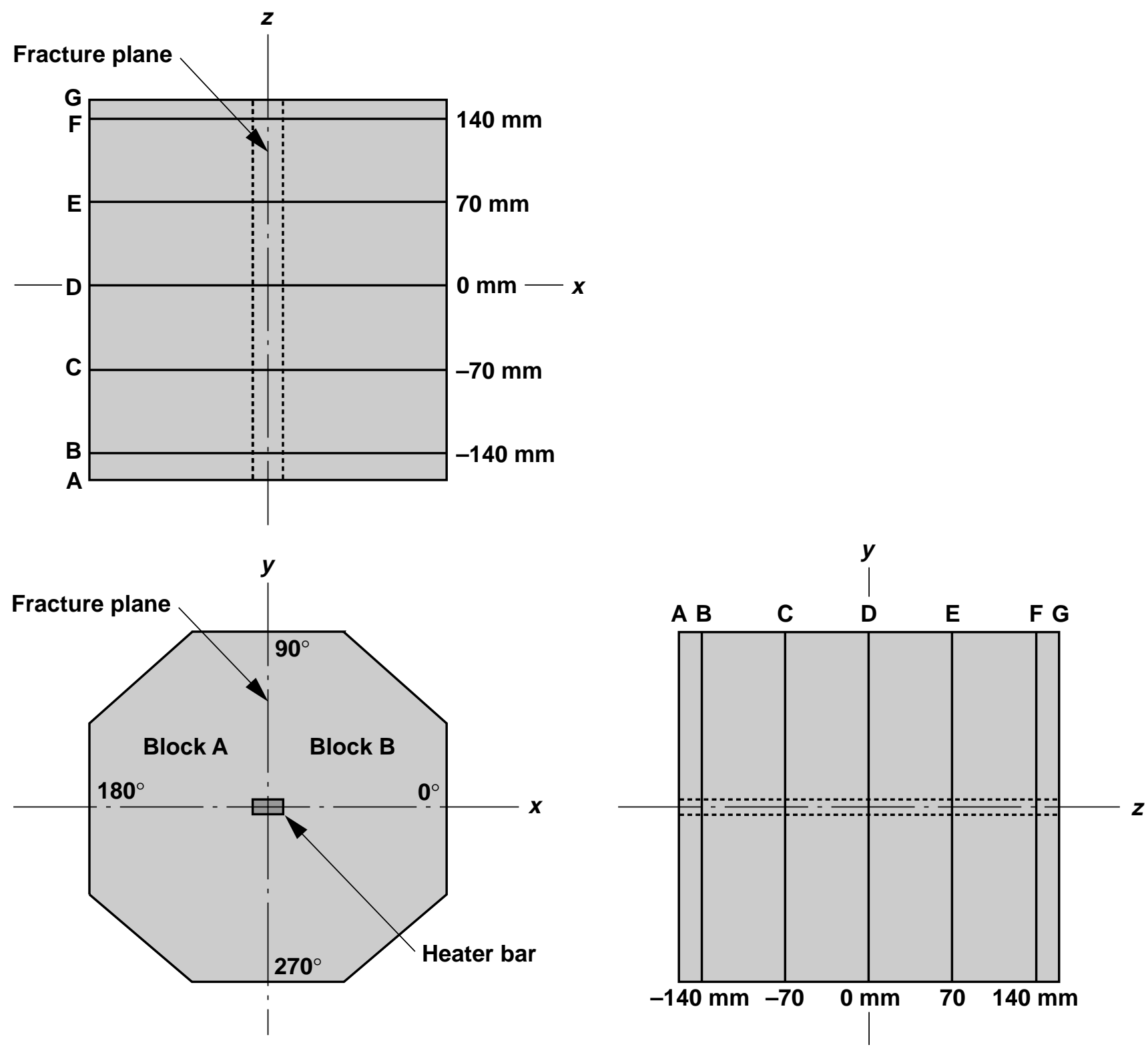

Figure 3-1. Specimen geometry, coordinate system and thermocouple array. The thermocouples are distributed over five cross-sectional planes at $z=-140,-70,0,70$, and $140 \mathrm{~mm}$, respectively. 

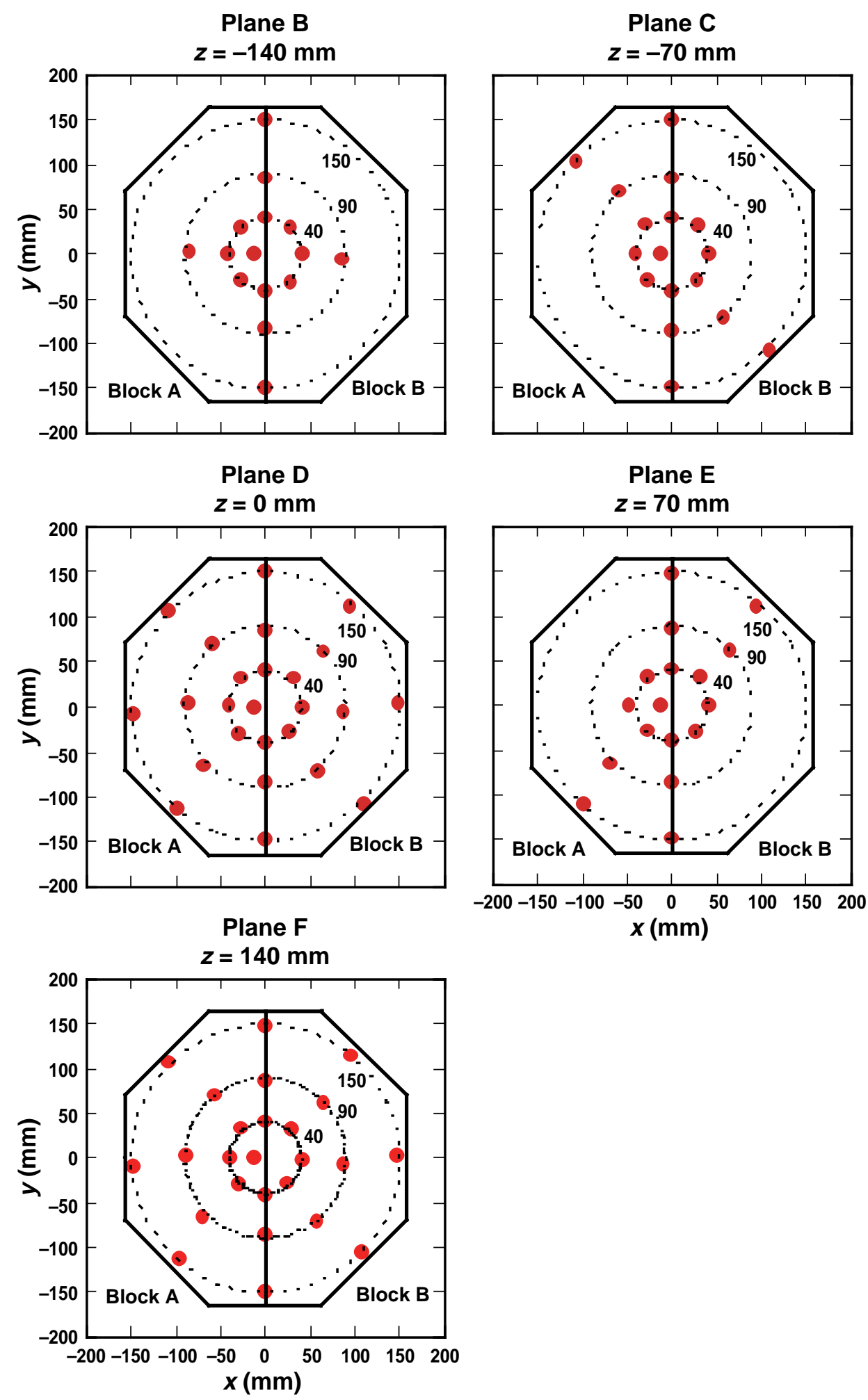

Figure 3-2. Thermocouple locations for the central $(z=0)$ cross-sectional plane 


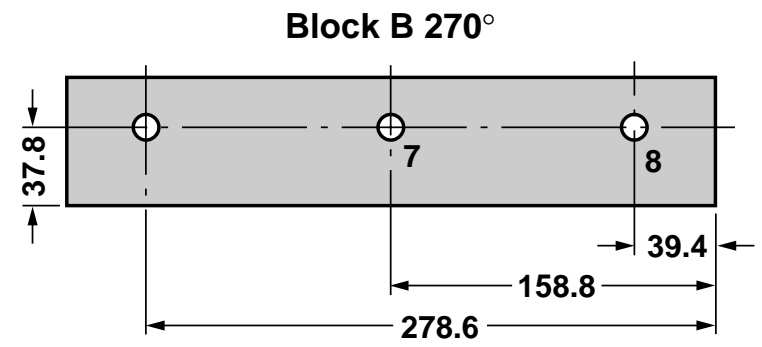

Block B $90^{\circ}$

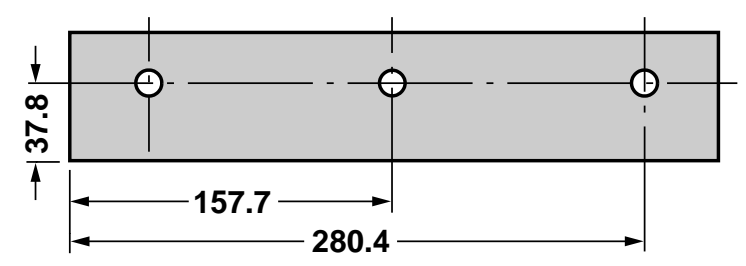

Block A $270^{\circ}$

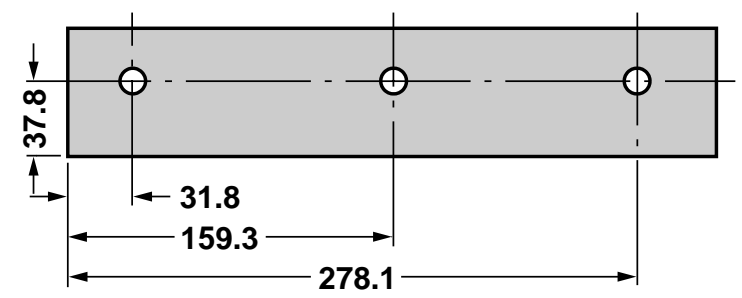

Block A $90^{\circ}$

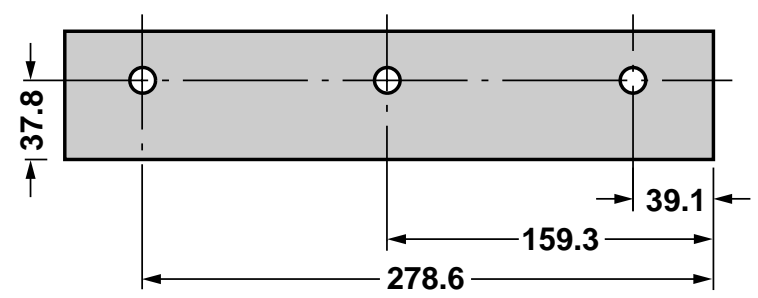

Note: all measurements in $\mathrm{mm}$

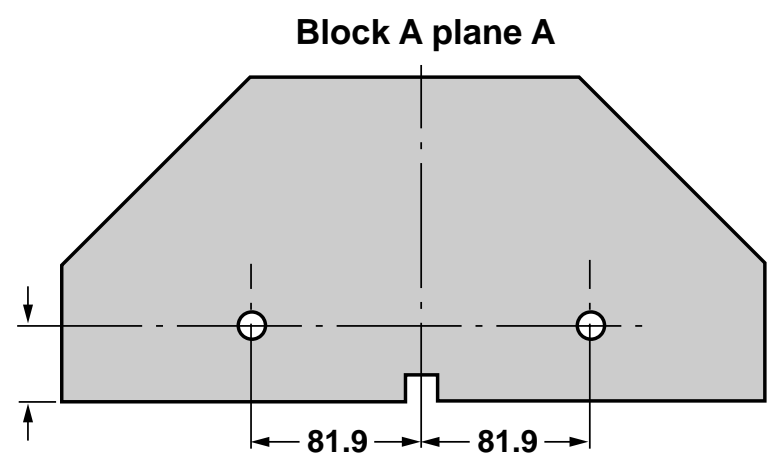

Block A plane G

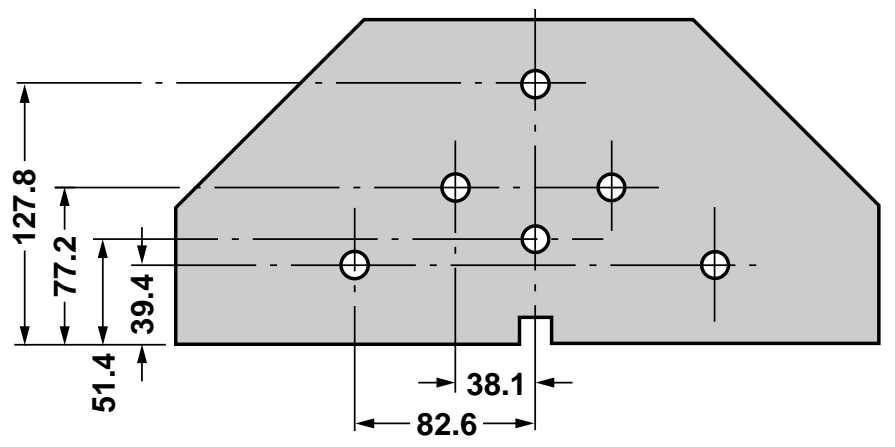

Block B plane $G$

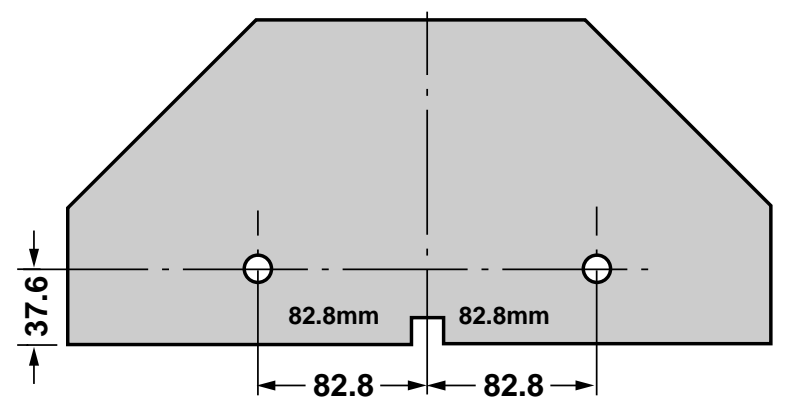

Block B plane A

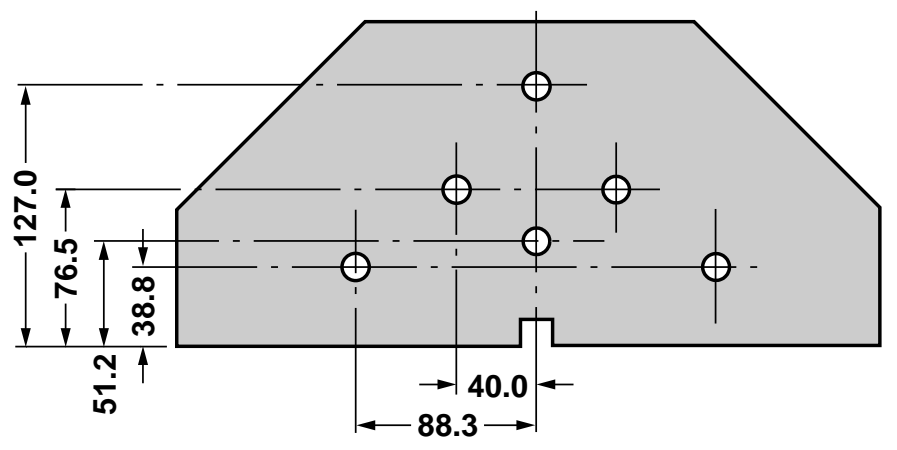

Figure 3-3. Positions of the LVDT mounting holes. Holes are positioned in pairs $76 \mathrm{~mm}$ apart so that 10 LVDTs span the fracture and 6 LVDTs span solid portions of the rock in three orthogonal directions. 


\section{(a)}

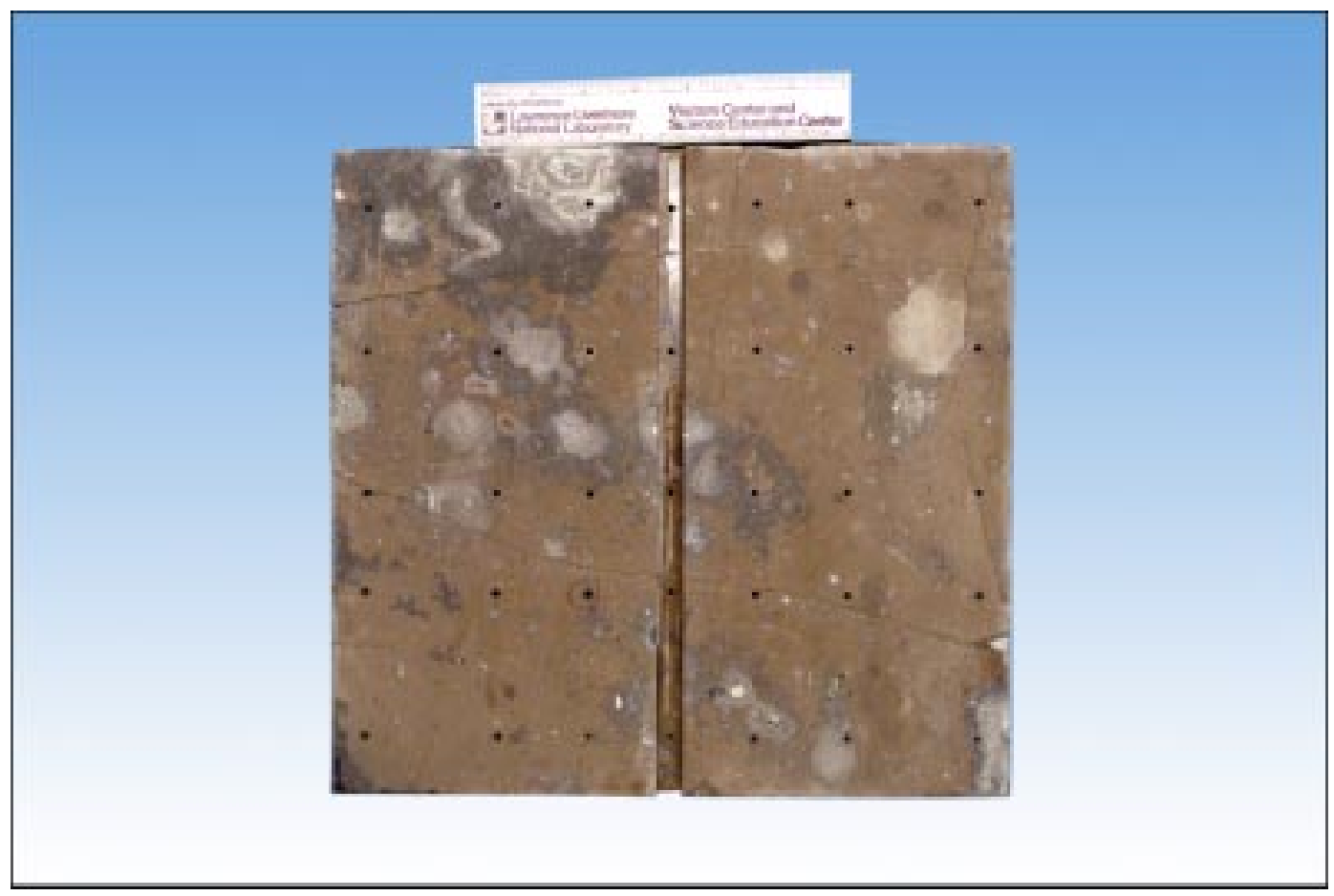

(b)

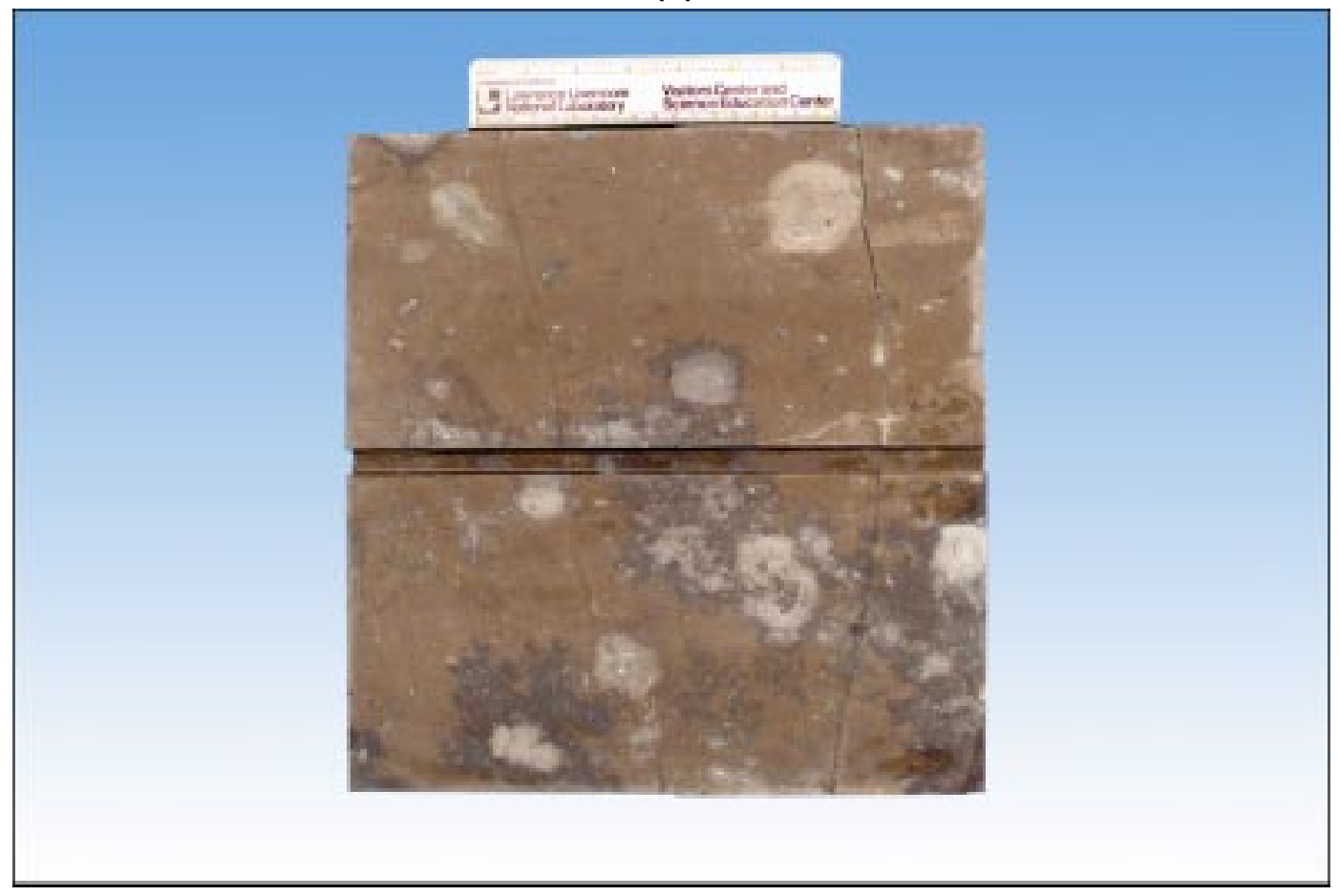

Figure 3-4. Photographs of the fracture surfaces for Block A (top) and Block B (bottom) 

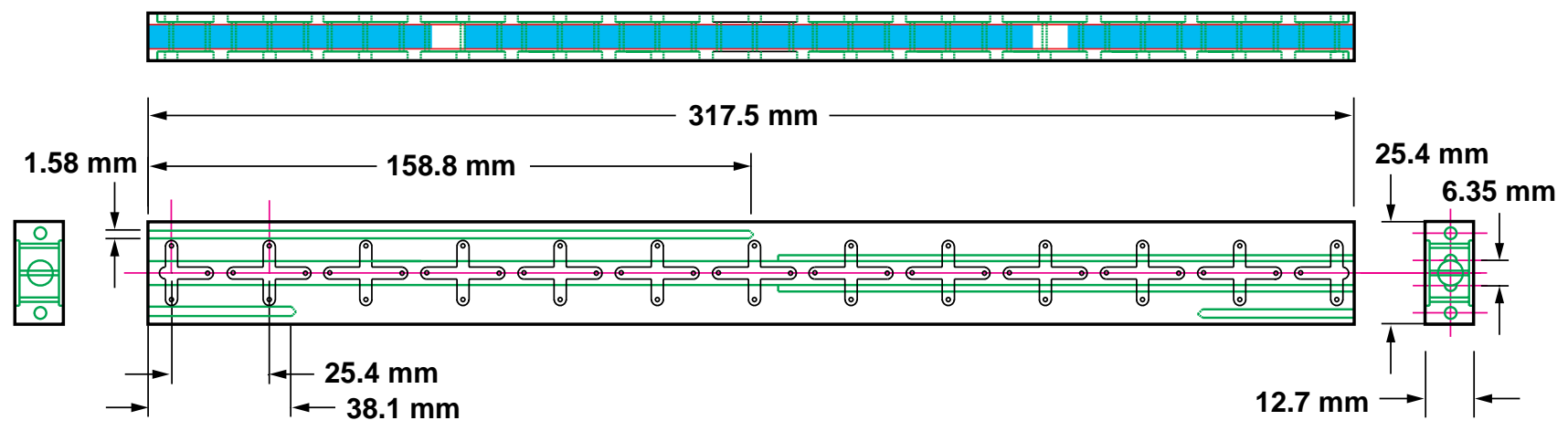

Figure 3-5. SB4 heater bar. The bar can accommodate three cartridge heaters and three thermocouple probes. A system of holes and channels allows water to flow through the bar without coming into contact with the heater cartridges.

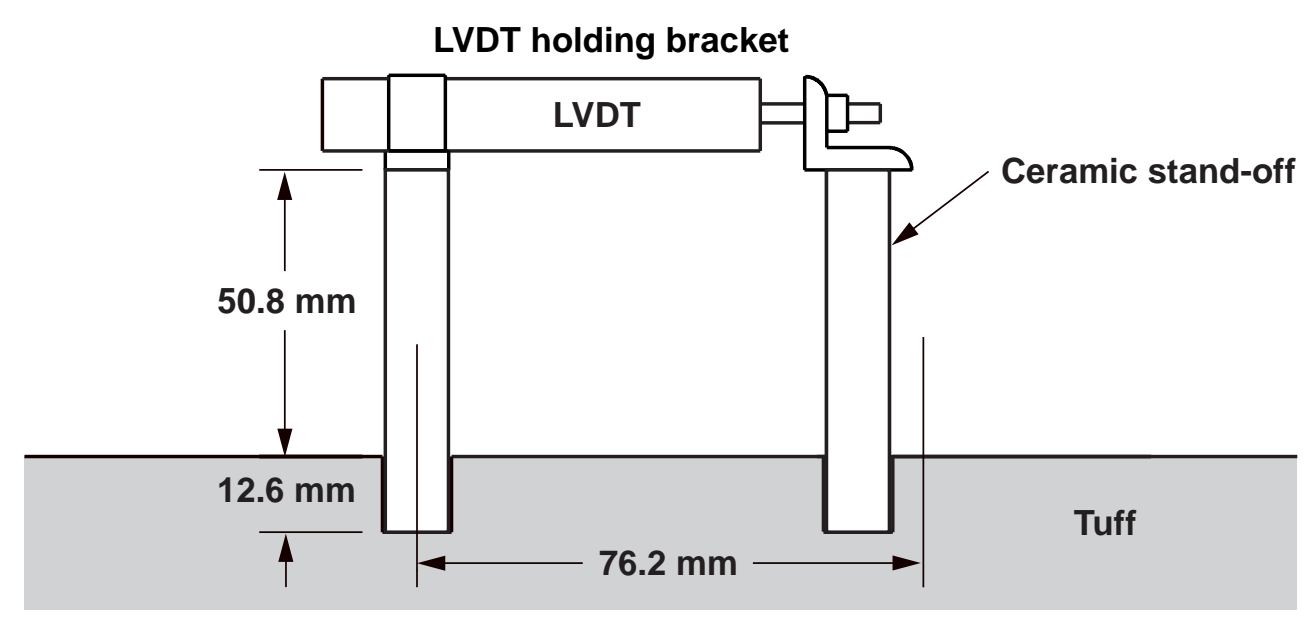

Figure 3-6. Mounting technique for the LVDTs. Ceramic posts allow the LVDTs to sit above the insulation and water manifolds.
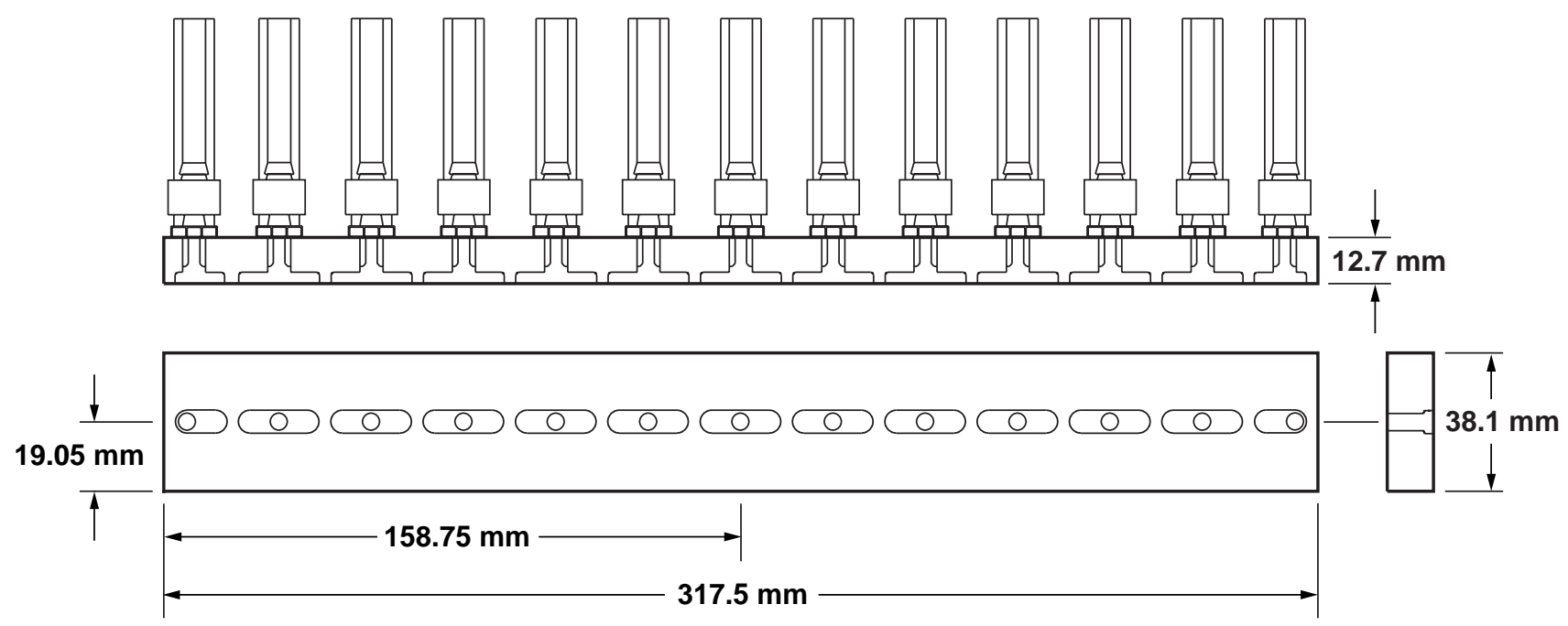

Figure 3-7. Water manifold design, with manifolds attached to the top and bottom surfaces of the specimen along the trace of the fracture 


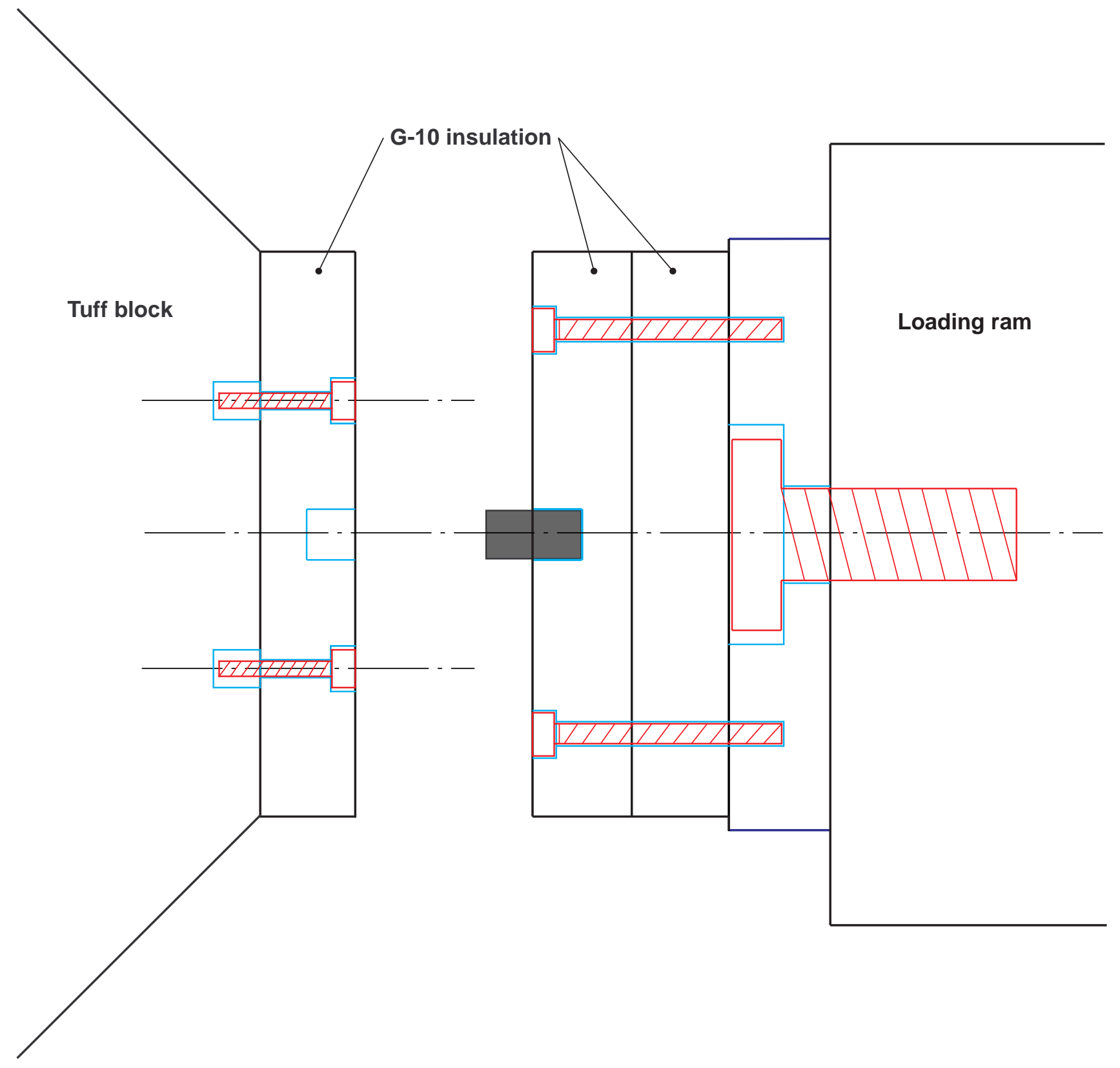

Figure 3-8. Insulation of the loaded faces, consisting of three sheets of inch-thick G-10 phenolic resin board 


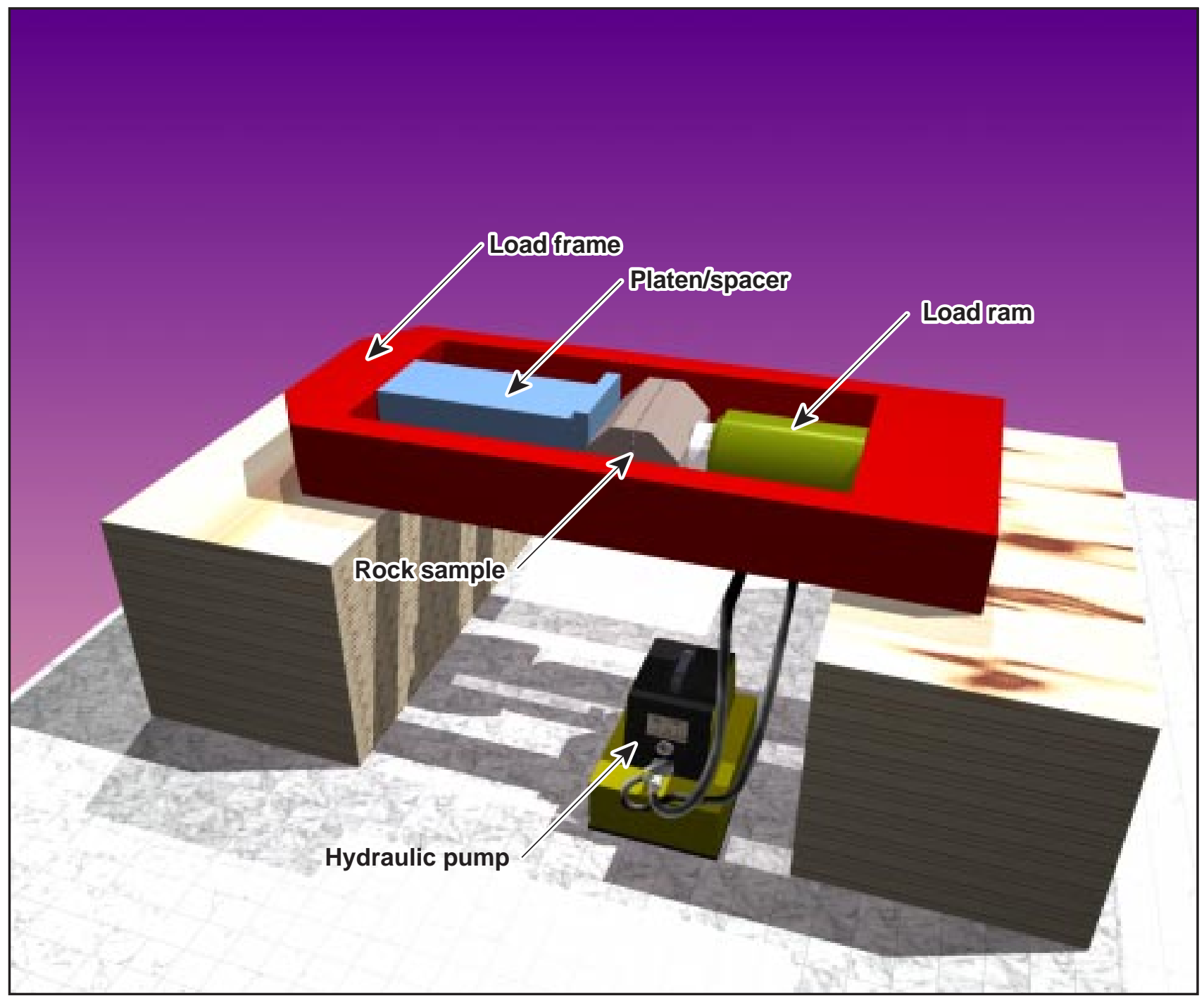

Figure 3-9. The horizontal loading apparatus 


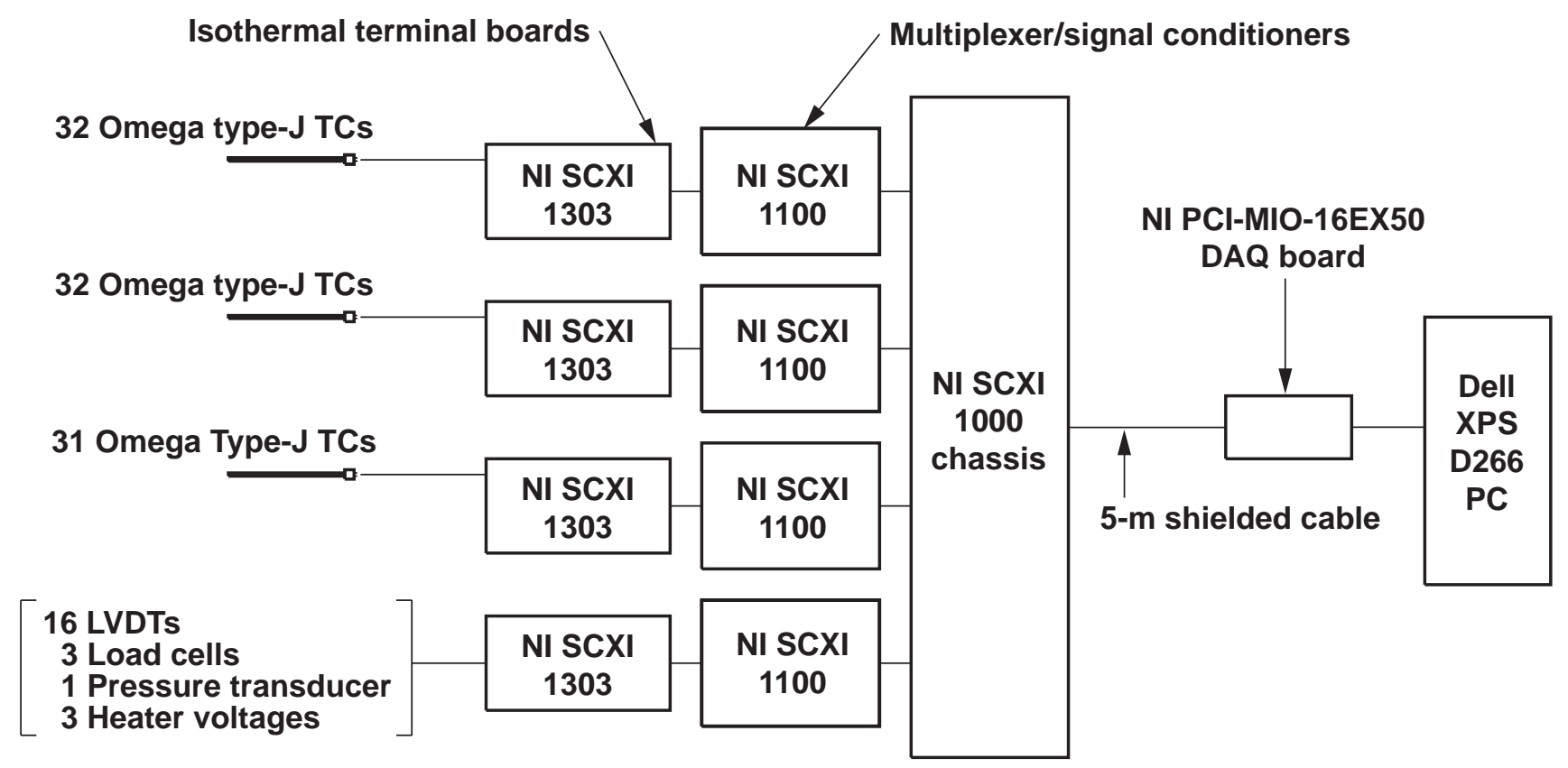

Figure 3-10. Data-acquisition schematic 


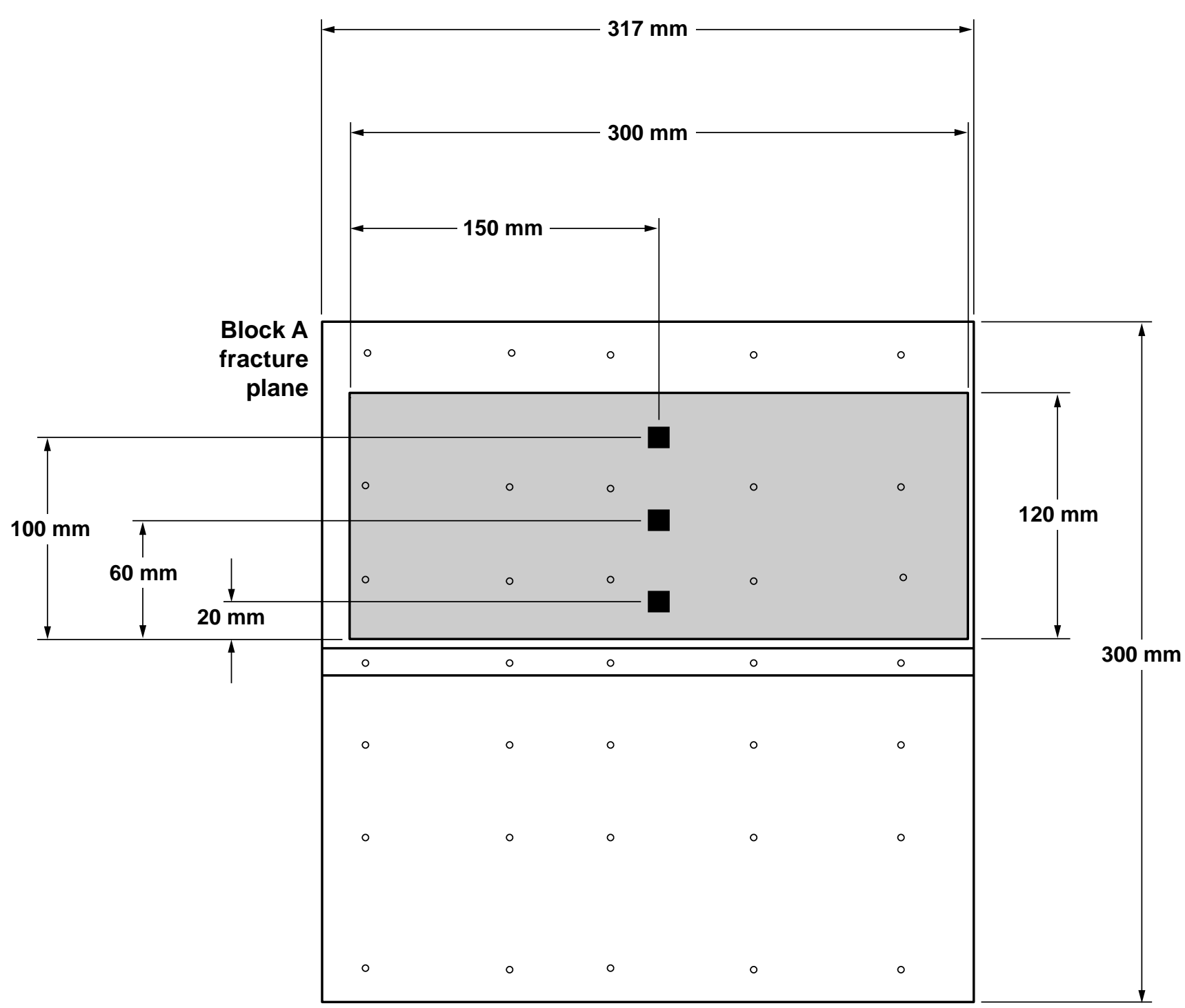

Figure 3-11. Areas of the Block A fracture plane selected for surface profiling. The $120 \times 300 \mathrm{~mm}$ area was profiled on a $1.0 \times 1.0 \mathrm{~mm}$ grid. The three $10 \times 10 \mathrm{~mm}$ areas were profiled on a $0.05 \times 0.05 \mathrm{~mm}$ grid. 


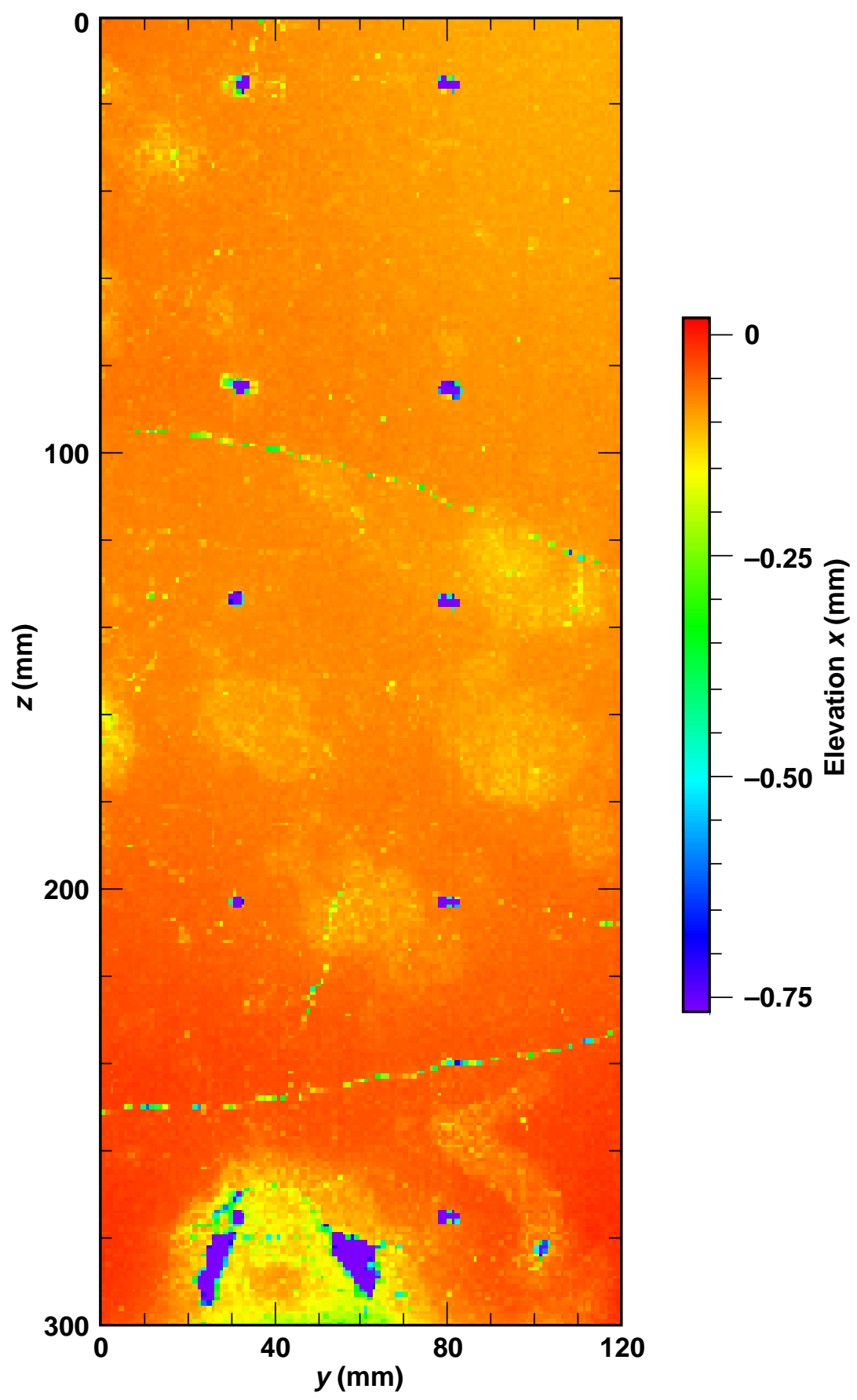

Figure 3-12. Surface topography of a $120 \times 300 \mathrm{~mm}$ area of the fracture surface of Block A profiled at 1.0-mm resolution 


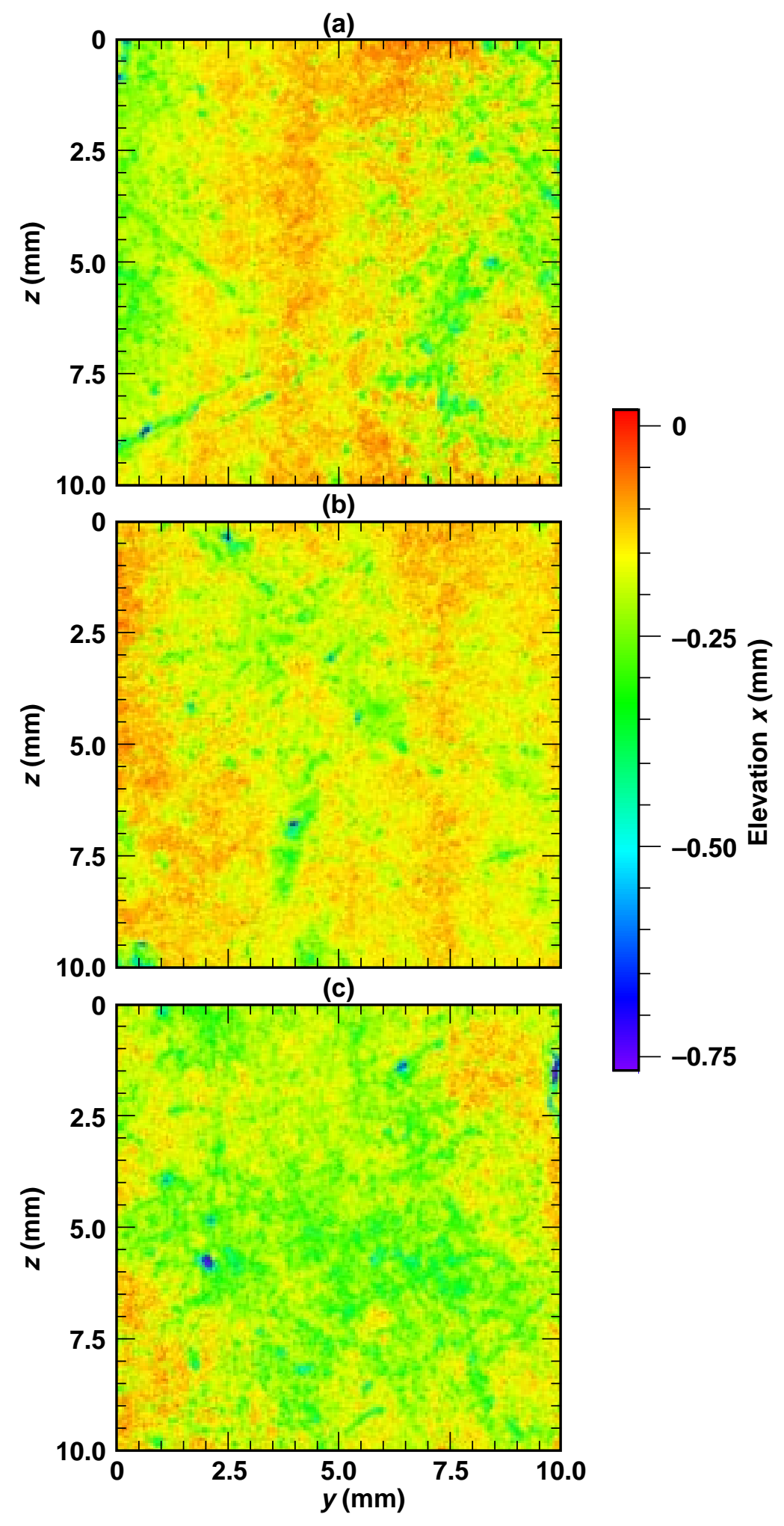

Figure 3-13. Surface topography of the (a) inner, (b) middle, and (c) outer $10 \times 10 \mathrm{~mm}$ subsections profiled at $0.05-\mathrm{mm}$ resolution 
(a)

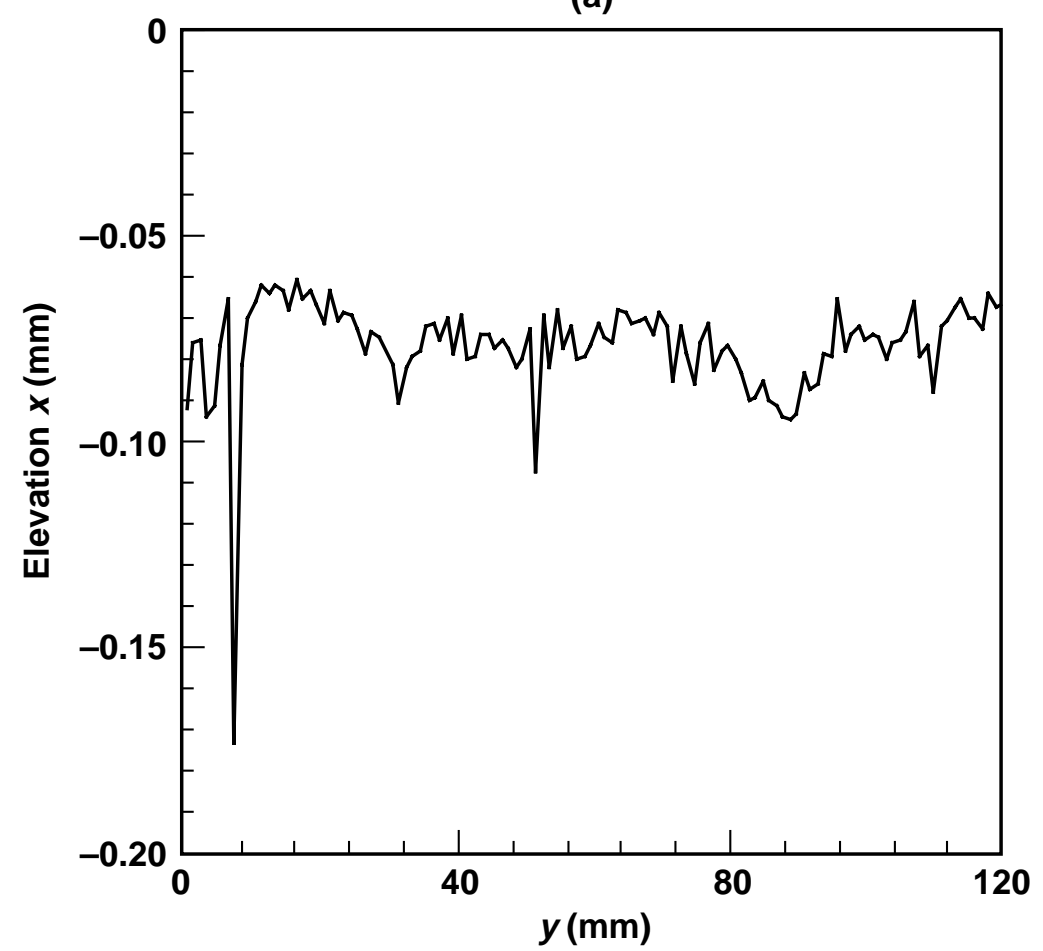

(b)

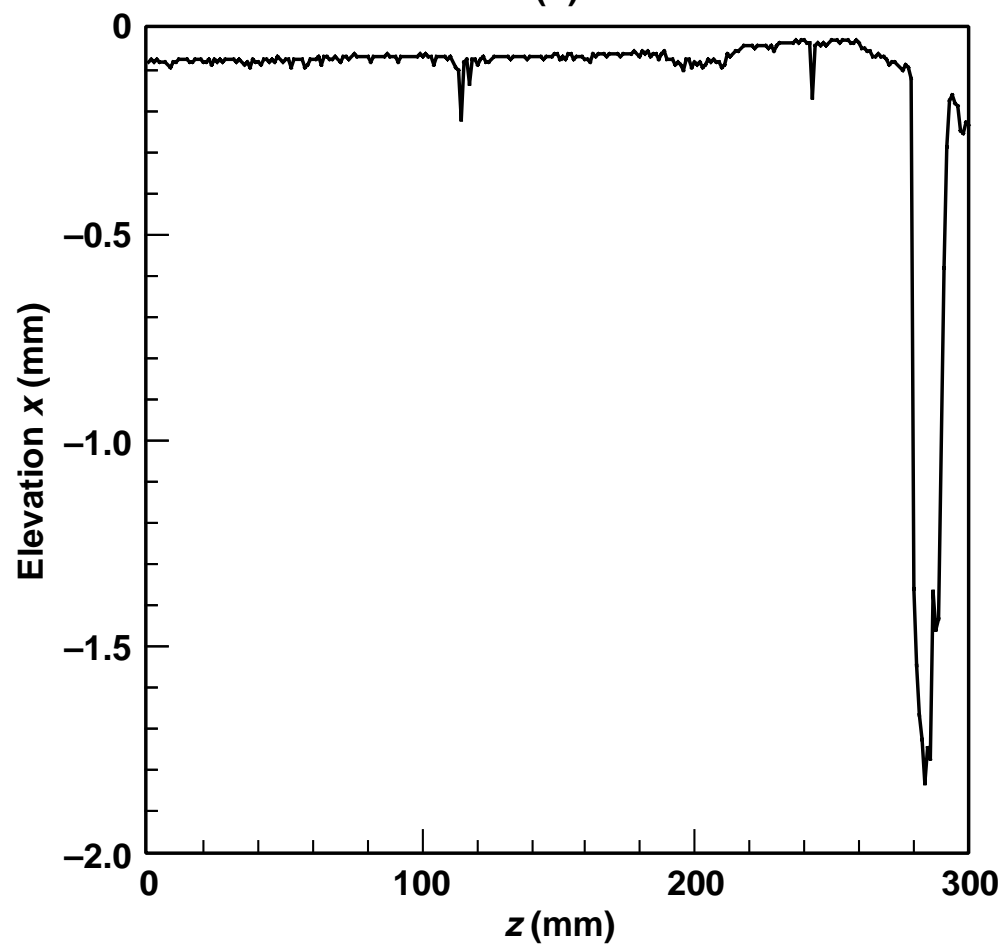

Figure 3-14. Cross sections of SB4 fracture-surface topography, Block A; (a) cross-section $x-y$ (scale reduced); (b) cross section $x-z$ 

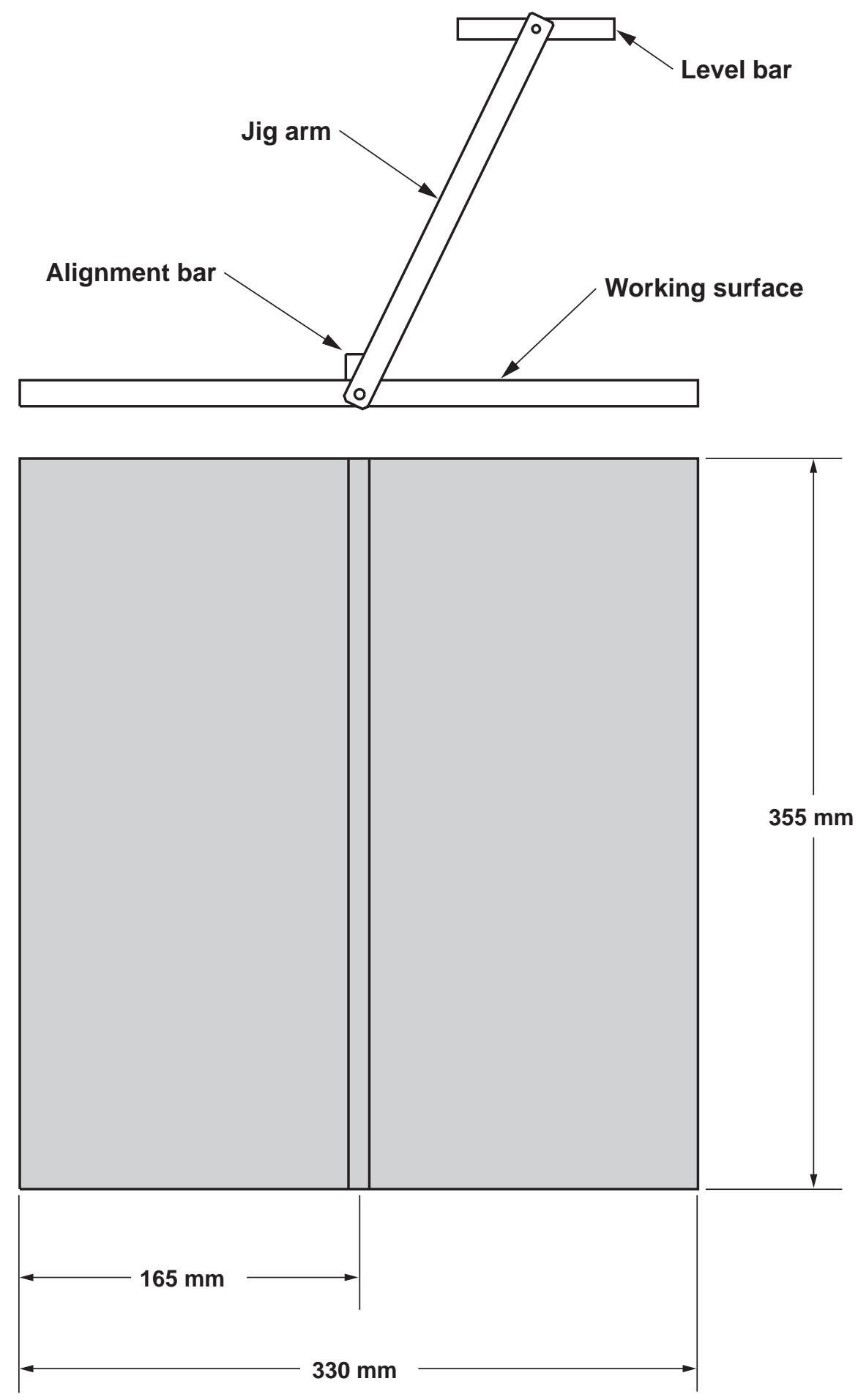

Figure 3-15. Mechanical jig for measuring thermocouple hole locations 



\section{Summary and Future Work}

We believe the results of our experiment SB3 have significant implications for modeling coupled thermal-hydrologic-chemical-mechanical (THCM) processes in the near-field environment (NFE). Any source of shear displacement of fractures, whether from mining, mechanical relaxation, or response to thermal fields, will result in uncorrelated fracture surfaces. Those surfaces that intersect a porosity distribution above the percolation limit will form high-conductance paths for fluid into and out of the NFE.

The fluid flow through such a fracture is not described correctly by a parallel-plane model. Stresses normal to the fracture surface on the order of $1 \mathrm{MPa}$ are sufficient to close the fracture mechanically, such that its stiffness is comparable to the host rock, but not hydraulically. The fluid forms an advective and conductive thermal short circuit, compared to the host rock thermal conductance. Over long times, the chemistry owing to the elevated temperature fluid flow may increase the fracture conductance by erosion and dissolution, or may decrease it as the fracture surfaces re-correlate by deposition.

The effective Young's modulus of this tuff is significantly anisotropic. The modulus normal to the major axes of the oblate spherical porosity is of the order of $20 \mathrm{GPa}$, while that parallel to the major axes is about $40 \mathrm{GPa}$.

Experiment SB4 on an intermediate-scale, heterogeneous tuff is designed to accomplish several objectives:

- Establish symmetry, initial, and boundary conditions; spatially resolved temperature contours; and known thermal sources to provide a viable validation problem for THCM models

- Measure such properties as fluid flow in a vertical fracture, thermal diffusivity, effective Young's modulus, and imbibition as a function of mean uniaxial stress to about $10 \mathrm{MPa}$ and temperatures to about $150^{\circ} \mathrm{C}$

- Measure the effect of high thermal conductivity paths ("heat pipes") on the thermal field

- Observe the thermal and hydrologic effects of a reflux zone in a gravitational field.

The SB4 experiment design and construction will be complete this quarter; we expect to then begin an experimental plan of measurements lasting through the third quarter of FY99.

The fifth, and final, experiment in this series on coupled THCM processes in intermediate-scale tuff samples, SB5, has similar objectives to SB4 but will employ a true biaxial stress field. In SB5, we will observe THCM processes as a function of stresses normal and parallel to a natural fracture surface. An important, additional, feature of SB5 is to use remote-sensing diagnostics to monitor in a controlled laboratory environment the THCM response that occurs after the repository is sealed. 



\section{References}

Barton, C.A., M.D. Zoback, and D. Moos (1995). “Fluid flow along potentially active faults in crystalline rock." Geology 23(8):683-686.

Blair, S.C., and P.A. Berge (1996). Geomechanical Properties of Topopah Spring Tuff at the 0.5-m Scale: Preliminary Results of Compression Tests at Elevated Temperature. (UCRLID-125089) Livermore, CA: Lawrence Livermore National Laboratory. [MOL.19961107.0096; 226211]

Blair, S.C., P.A. Berge, and H.F. Wang (1997). Bounding Models for Estimating Changes in Fracture Permeability due to Thermo-Mechanical Stresses in Host Rock Surrounding the Repository. I: Permeability Changes Estimated for the Heated Drift Test. Milestone report for the CRWMS Management and Operating Contractor, U.S. Department of Energy. (SPLF2M4) Livermore, CA: Lawrence Livermore National Laboratory. [MOL.19980107.0411]

Blair, S.C., and M.S. Costantino (1997). Preliminary Results of a Coupled Fracture-Flow Test at the 0.5-m Scale. Milestone report for the CRWMS Management and Operating Contractor, U.S. Department of Energy. (UCRL-ID-129731) Livermore, CA: Lawrence Livermore National Laboratory. (SPLFA2M4) [MOL.19970507.0181]

Blair, S.C., and W. Lin (1997). Thermal-Mechanical Behavior of a Heated $3 m$ Block of Fractured Tuff. June 1997. (UCRL-JC-128350) Livermore, California: Lawrence Livermore National Laboratory.

Blair, S.C., and M.S. Costantino (1998). “Anisotropic Behavior in 0.5-m Scale Blocks of Topopah Spring Tuff." Proceedings of the Eighth International Conference on HighLevel Radioactive Waste Management. p. 60. La Grange Park, IL: American Nuclear Society. (UCRL-JC-128800)

Carslaw, H.S., and J.C. Jaeger (1986). Conduction of Heat in Solids. (2nd edition) Oxford, UK: Clarendon Press. [NNA.19900522.0259 (1988)]

DOE (1990). Yucca Mountain Project Reference Information Base, Version 4. (YMP/CC-0002) Las Vegas, NV: Yucca Mountain Site Characterization Project Office, U.S. Department of Energy. [221856; NNA.19890330.0077]

Flint, A.L., L.E. Flint, and K.A. Richards (1994). “Evaluation of measurement scale using imbibition experiments in volcanic tuffs." Soil Sci. Soc. Am. J. 58(1):94-102. [225906]

Hardin, E.L., S.C. Blair, T.A. Buscheck, D.A. Chesnut, L.D. DeLoach, W.E. Glassley, J.W. Johnson, R.B. Knapp, K. Lee, A. Meike, K. Myers, J.J. Nitao, C.E. Palmer, L.L. Rogers, N.D. Rosenberg, B.E. Viani, H.F. Wang, C. Wittwer, and T.J. Wolery (1998). Near-Field/Altered-Zone Models Report. Milestone report for the CRWMS Management and Operating Contractor, U.S. Department of Energy. (UCRLID-129179) Livermore, CA: Lawrence Livermore National Laboratory. (SP3100M3)

Keller, K., and B.P. Bonner (1985). "Automatic, digital system for profiling rough surfaces." Rev. Sci. Instrum. 56:330-331. [NNA.19900918.0020] 
Kneafsey, T.J., and K. Pruess (1997). Preferential Flow Paths and Heat Pipes: Results from Laboratory Experiments on Heat-Driven Flow in Natural and Artificial Rock Fractures. Milestone report for the CRWMS Management and Operating Contractor, U.S. Department of Energy. (SPL6A5M4) Berkeley, CA: Lawrence Berkeley National Laboratory. [MOL.19971204.0415]

Lin, W., D.G. Wilder, J.A. Blink, S.C. Blair, T.A. Buscheck, W.E. Glassley, K. Lee, M.W. Owens, and J.J. Roberts (1995). "A heated large block test for high level nuclear waste management." In proceedings from Second International Conference on Mechanics of Jointed and Faulted Rock: MJFR-2. Vienna, Austria: April 10-14, 1995. (Also UCRL-JC-116418, Lawrence Livermore National Laboratory, Livermore, CA) [MOL.19960208.0282]

Metals Handbook Committee (1961). Metals Handbook. (8th edition) Materials Park, OH: American Society for Metals (now ASM International).

Norplex (1998). Comparative Mechanical Properties. (web page: http://www.norplex.com/TD_Lib/compare2.htm) Industrial Laminates/Norplex, Inc.

Raven, K.G., and J.E. Gale (1985). "Water flow in a natural rock fracture as a function of stress and sample size." International Journal of Rock Mechanics and Mining Science $\mathcal{E}$ Geomechanics Abstracts 22(4):251-261.

Richards, L.A. (1931). "Capillary conduction of liquids through porous mediums." Physics 1:318-333. [NNA.19890522.0282]

Taylor, E.C. (1997). Technical Progress in the Yucca Mountain Project. February 1997. (internal report to $\mathrm{M} \& \mathrm{O}$ contractor organizations)

Tsang, Y.W. (1984). “The effect of tortuosity on fluid flow through a single fracture." Water Resources Res. 20:1209-1215. [NNA.19900420.0082]

Warrick, A.W., and P. Broadbridge (1992). "Sorptivity and macroscopic capillary length relationships.” Water Resources Res. 28(2):427-431.

Zimmerman, R.W., G.S. Bodvarsson, A.L. Flint, and L.E. Flint (1993). Proceedings of the Fourth International Conference on High-Level Radioactive Waste Management. pp. 10521058. La Grange Park, IL: American Nuclear Society.

Zimmerman, R.W., G.S. Bodvarsson, and E.M. Kwicklis (1990). “Absorption of water into porous blocks of various sizes and shapes." Water Resources Res. 26(11):2797-2806. [NNA.19910909.0098] 